This document was prepared in conjunction with work accomplished under Contract No. DE-AC09-96SR18500 with the U. S. Department of Energy.

\title{
DISCLAIMER
}

This report was prepared as an account of work sponsored by an agency of the United States Government. Neither the United States Government nor any agency thereof, nor any of their employees, nor any of their contractors, subcontractors or their employees, makes any warranty, express or implied, or assumes any legal liability or responsibility for the accuracy, completeness, or any third party's use or the results of such use of any information, apparatus, product, or process disclosed, or represents that its use would not infringe privately owned rights. Reference herein to any specific commercial product, process, or service by trade name, trademark, manufacturer, or otherwise, does not necessarily constitute or imply its endorsement, recommendation, or favoring by the United States Government or any agency thereof or its contractors or subcontractors. The views and opinions of authors expressed herein do not necessarily state or reflect those of the United States Government or any agency thereof. 


\section{RHEOLOGICAL CHARACTERIZATION OF UNUSUAL DWPF SLURRY SAMPLES (U)}

D. C. Koopman

September 2005

Immobilization Technology Section Savannah River National Laboratory Aiken, SC 29808

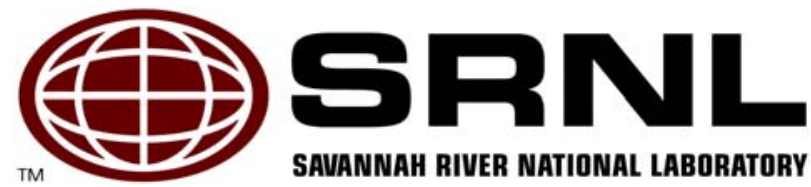




\title{
DISCLAIMER
}

This report was prepared by Westinghouse Savannah River Company (WSRC) for the United States Department of Energy under Contract No. DE-AC09-96SR18500 and is an account of work performed under that contract. Neither the United States Department of Energy, nor WSRC, nor any of their employees makes any warranty, expressed or implied, or assumes any legal liability or responsibility for the accuracy, completeness, or usefulness, of any information, apparatus, or product or process disclosed herein or represents that its use will not infringe privately owned rights. Reference herein to any specific commercial product, process, or service by trademark, name, manufacturer or otherwise does not necessarily constitute or imply endorsement, recommendation, or favoring of same by WSRC or by the United States Government or any agency thereof. The views and opinions of the authors expressed herein do not necessarily state or reflect those of the United States Government or any agency thereof.

\author{
Printed in the United States of America \\ Prepared For \\ U.S. Department of Energy
}


Key Words: DWPF, rheology, sludge, SRAT, SME, rheometer, slurry

Retention: Permanent

\section{RHEOLOGICAL CHARACTERIZATION OF UNUSUAL DWPF SLURRY SAMPLES (U)}

D. C. Koopman

September 2005

Immobilization Technology Section Savannah River National Laboratory Aiken, SC 29808

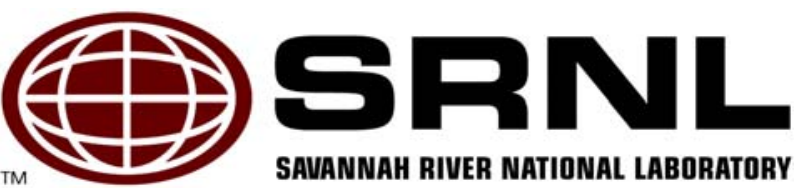




\section{REVIEWS AND APPROVALS}

\section{AUTHOR:}

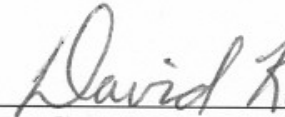

D. C. Koopman, Immobilization Technology Section

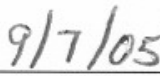

\section{TECHNICAL REVIEWER:}

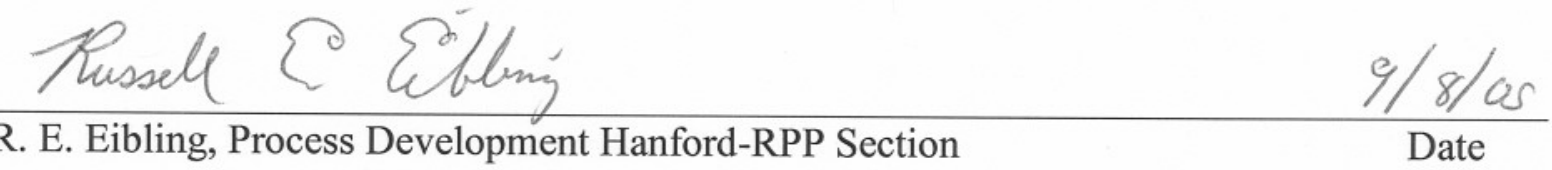

\section{APPROVERS:}

\section{S Inlana fon}

E. W. Holtzscheiter, Manager, Immobilization Technology Section

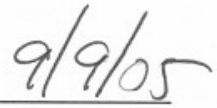

Date
\& 8 orana
S. L. Marra, Manager, Glass Formulation \& Process Development
$9 / 9 / 25$
Date 


\section{EXECUTIVE SUMMARY}

A study was undertaken to identify and clarify examples of unusual rheological behavior in Defense Waste Processing Facility (DWPF) simulant slurry samples. Identification was accomplished by reviewing sludge, Sludge Receipt and Adjustment Tank (SRAT) product, and Slurry Mix Evaporator (SME) product simulant rheological results from the prior year. Clarification of unusual rheological behavior was achieved by developing and implementing new measurement techniques. Development of these new methods is covered in a separate report, WSRC-TR-2004-00334.

This report includes a review of recent literature on unusual rheological behavior, followed by a summary of the rheological measurement results obtained on a set of unusual simulant samples. Shifts in rheological behavior of slurries as the wt. \% total solids changed have been observed in numerous systems. The main finding of the experimental work was that the various unusual DWPF simulant slurry samples exhibit some degree of time dependent behavior. When a given shear rate is applied to a sample, the apparent viscosity of the slurry changes with time rather than remaining constant. These unusual simulant samples are more rheologically complex than Newtonian liquids or more simple slurries, neither of which shows significant time dependence.

The study concludes that the unusual rheological behavior that has been observed is being caused by time dependent rheological properties in the slurries being measured. Most of the changes are due to the effect of time under shear, but SB3 SME products were also changing properties while stored in sample bottles. The most likely source of this shear-related time dependence for sludge is in the simulant preparation. More than a single source of time dependence was inferred for the simulant SME product slurries based on the range of phenomena observed. Rheological property changes were observed on the time-scale of a single measurement (minutes) as well as on a time scale of hours to weeks.

The unusual shape of the slurry flow curves was not an artifact of the rheometric measurement. Adjusting the user-specified parameters in the rheometer measurement jobs can alter the shape of the flow curve of these time dependent samples, but this was not causing the unusual behavior. Variations in the measurement parameters caused the time dependence of a given slurry to manifest at different rates.

The premise of the controlled shear rate flow curve measurement is that the dynamic response of the sample to a change in shear rate is nearly instantaneous. When this is the case, the data can be fitted to a time independent rheological equation, such as the Bingham plastic model. In those cases where this does not happen, interpretation of the data is difficult. Fitting time dependent data to time independent rheological equations, such as the Bingham plastic model, is also not appropriate. 


\section{TABLE OF CONTENTS}

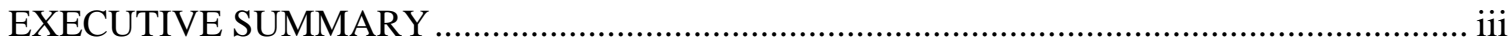

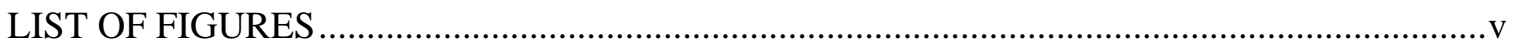

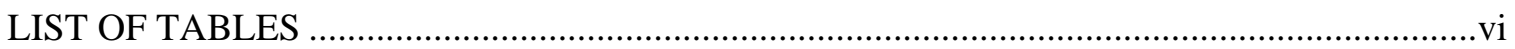

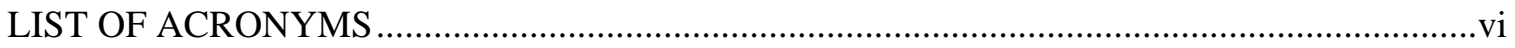

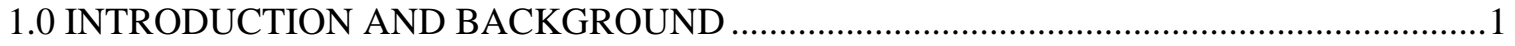

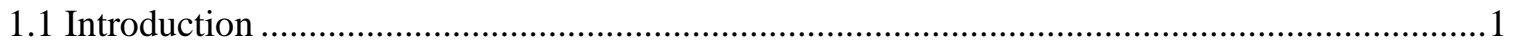

1.2 Review of Simulant Rheology for DWPF Sludge Batches ..................................................

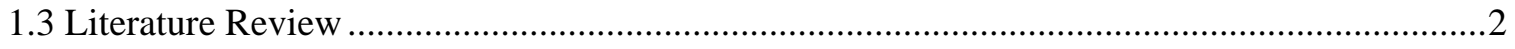

1.3.1 The Controlled Shear Rate Ramp with Hump .............................................................

1.3.2 Controlled Shear Rate Loop with Down Curve Well Above Up Curve ..........................7

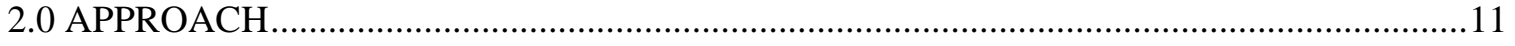

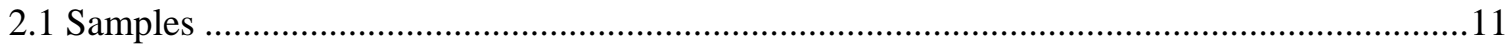

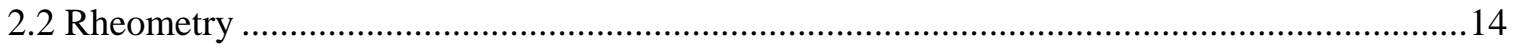

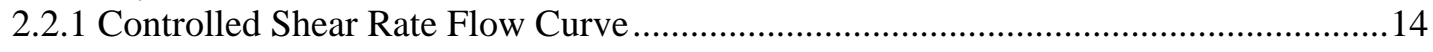

2.2.2 Controlled Shear Rate Time Curve................................................................................

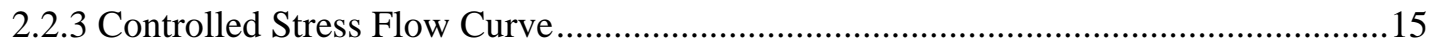

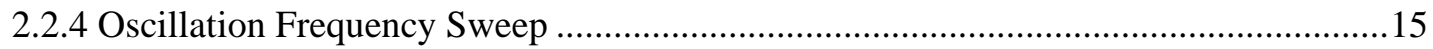

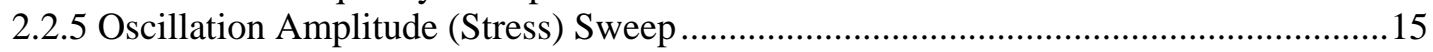

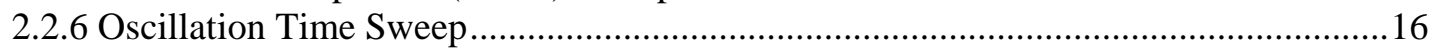

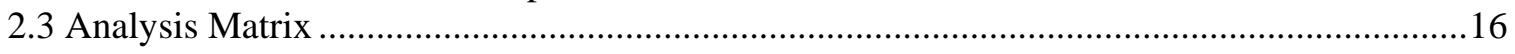

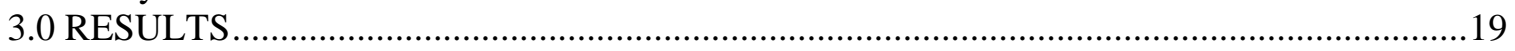

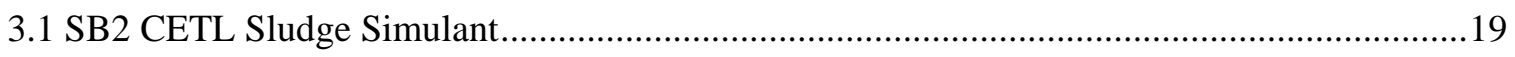

3.1.1 Controlled Shear Rate Measurements................................................................. 19

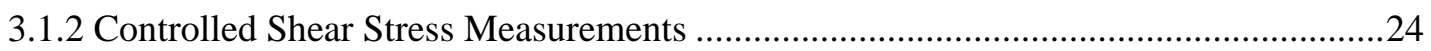

3.1.3 Constant Shear Rate Time Curve Measurement ........................................................26

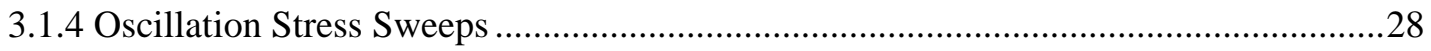

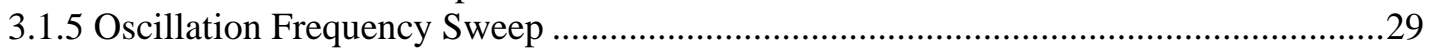

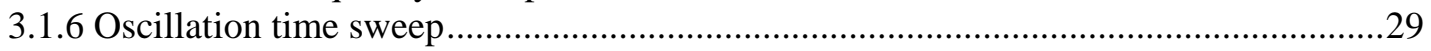

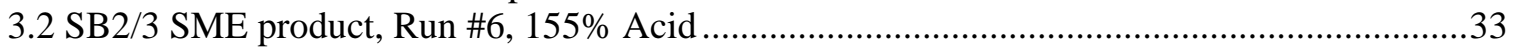

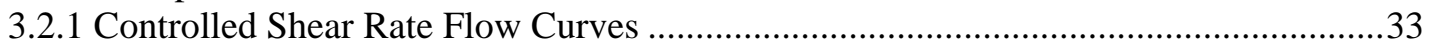

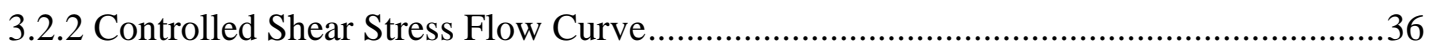

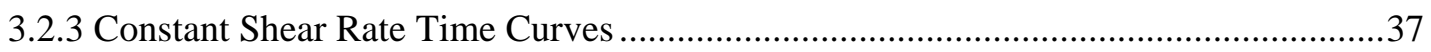

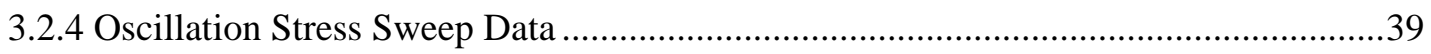

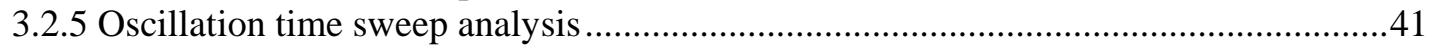

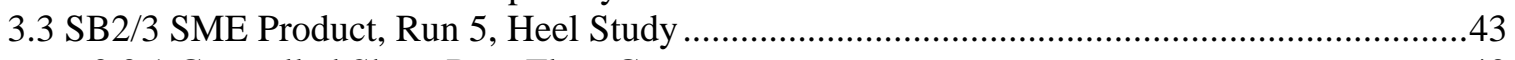

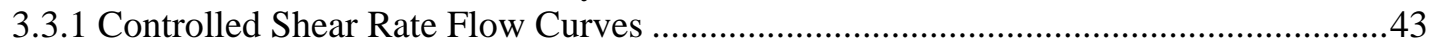

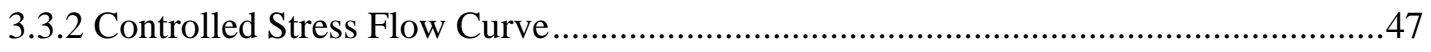

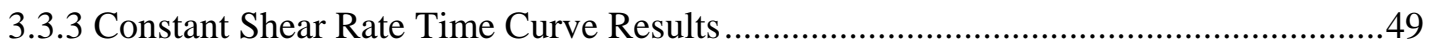

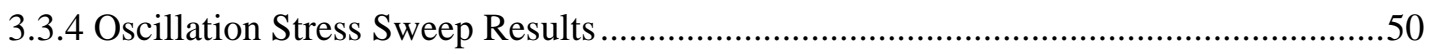

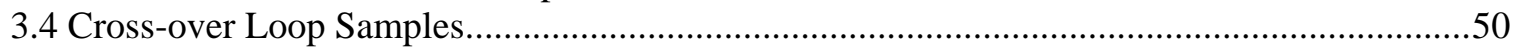

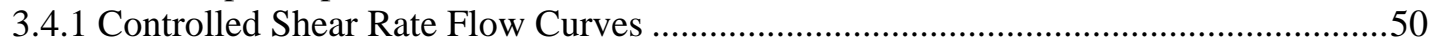

3.4.2 Controlled Stress Flow Curve Results .........................................................................51

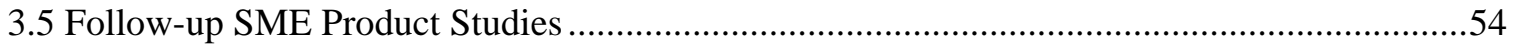

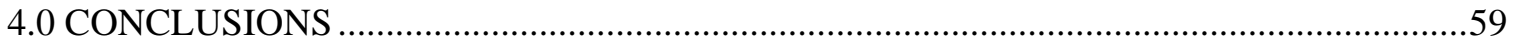

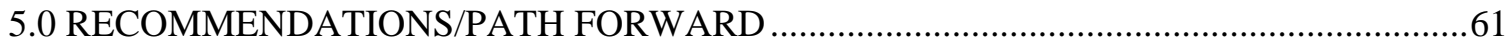

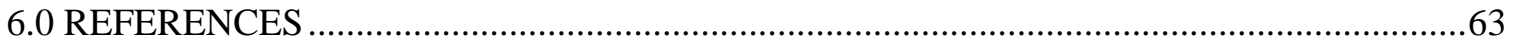




\section{LIST OF FIGURES}

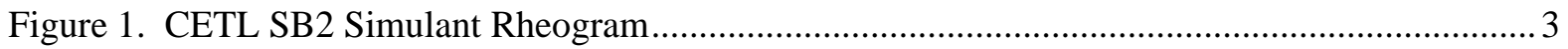

Figure 2. Shear Stress Versus Shear Rate with Phase Separation .................................................. 4

Figure 3. Schematic of Phase Separation in Concentric Cylinder Rheometry ...................................... 4

Figure 4. Time dependent Inelastic Behavior of Colloidal Systems (from Hunter) .............................. 5

Figure 5. Shear Stress/Time Behavior with Structural Breakdown...................................................... 6

Figure 6. Unusual placement of down ramp relative to up ramp flow curve. .................................. 7

Figure 7. Alternative View of the Data Contained in the Previous Figure........................................ 8

Figure 8. Slurry Viscosity vs. Shear Rate (from Alderman and Heywood) ........................................9

Figure 9. Impact of Consecutive Measurements on SB2 CETL Sludge Hump ...............................20

Figure 10. SB2 Sludge Simulant (CETL) by Z38/PZ38: Effect of Profiling .................................... 21

Figure 11. Impact of a Pre-shear on SB2 CETL Sludge Hump........................................................ 22

Figure 12. Impact of Shear-mixing CETL SB2 Sludge Simulant .................................................... 23

Figure 13. Variations in the hump from different measurements.................................................. 24

Figure 14. Controlled Stress Compared to Controlled Rate (Hump) ….............................................. 25

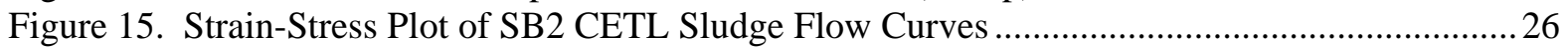

Figure 16. Comparison of the Time Dependence of Four Sludge Simulants ..................................... 27

Figure 17. SB2 CETL Sludge by Oscillation and Controlled Stress Tests ........................................28

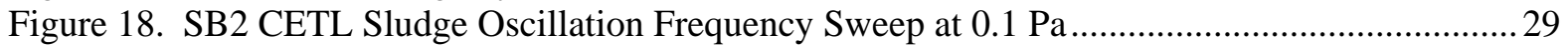

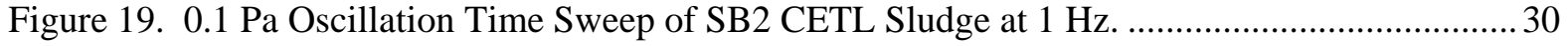

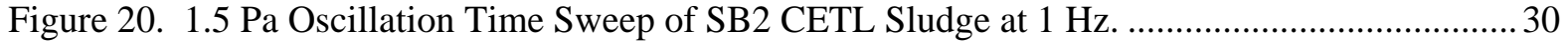

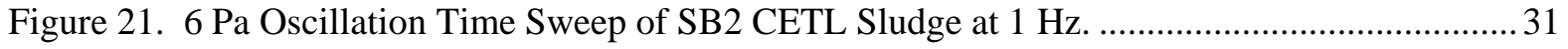

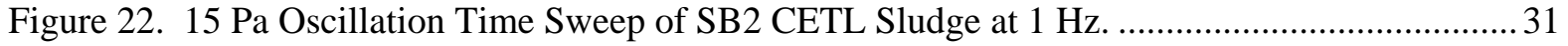

Figure 23. SB2/3 SME Product: Effect of Repeated Ramps ............................................................ 33

Figure 24. Historical SB2/3 SME Product Flow Curve Data ........................................................... 34

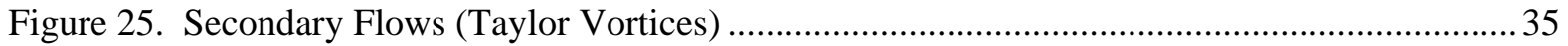

Figure 26. Pre-shear Impact on Run 6 SB2/3 SME Product ............................................................ 36

Figure 27. Controlled Stress Flow Curves for SB2/3 Run 6 SME Product......................................... 37

Figure 28. Comparison of the Time Dependence of Five SME Products ............................................ 38

Figure 29. Comparison of Constant Shear Rate Data and Flow Curve Data ......................................39

Figure 30. Effect of Frequency of Oscillation Stress Sweep Data ....................................................40

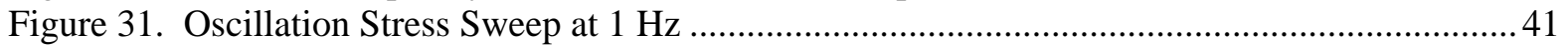

Figure 32. SB2/3 SME Product Oscillation Time Sweep at $3 \mathrm{~Pa}$ and $1 \mathrm{~Hz}$...................................... 42

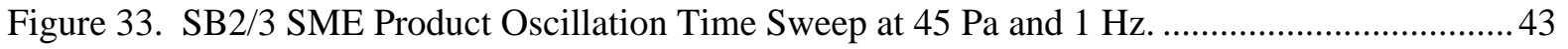

Figure 34. SB2/3 SME Product from Run 5, Heel Study: Effect of Gap ........................................... 44

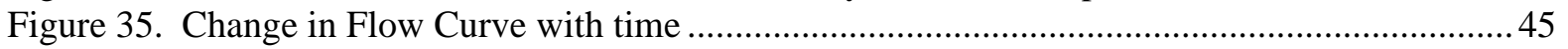

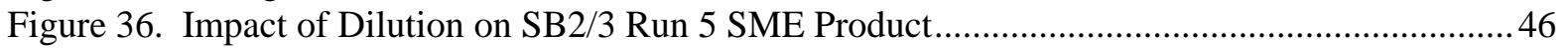

Figure 37. Impact of Taylor Vortices on Thin SME Down Curve................................................. 47

Figure 38. Non-typical strain-stress plot of Dilution 2 SME product. .................................................. 48

Figure 39. Comparison of Flow Curve to Constant Shear Rate data for Dilution 3........................... 49

Figure 40. Oscillation Stress Sweep of Dilution 2 of SME Product from Run 5 ............................... 50

Figure 41. SB2 SME Product (USC) with Cross-overs.................................................................... 51

Figure 42. SB2/3 SRAT Product: Controlled Stress vs. Controlled Shear......................................... 52

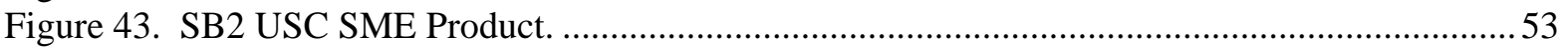

Figure 44. Controlled Rate Flow Curve for SB2/3 SME Product, Run 1 .......................................... 54

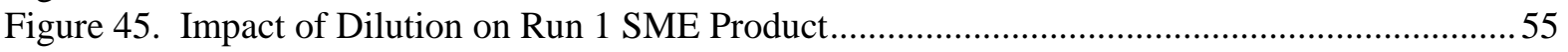

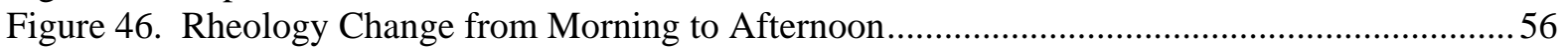

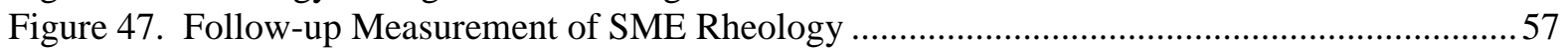




\section{LIST OF TABLES}

Table 1. Physical Properties of Rheology Slurry Samples

Table 2. Summary of Tests Performed by Sample and Test Type.

Table 3. Stress Range for SB2 CETL Sludge Controlled Stress Flow Curve

Table 4. Average Apparent Viscosity at 200/s Shear Rate of Four Sludge Simulants....................... 27

Table 5. Time Dependent Nature of SB2 CETL Sludge.

Table 6. Average Apparent Viscosities of SME Products

Table 7. Time Dependent Nature of SB2/3 SME Product, Run 6

Table 8. Dilutions of SB2/3 Run 5 SME Product

\section{LIST OF ACRONYMS}

ACTL Aiken County Technical Laboratory

CETL Clemson Environmental Technology Laboratory

DWPF Defense Waste Processing Facility

RS150 ThermoHaake RheoStress 150 rheometer

RS600 ThermoHaake RheoStress 600 rheometer

RV20 Haake RotoVisco 20 rheometer

RV30 Haake RotoVisco 30 rheometer

SB2 Sludge Batch 2

SB2/3 Sludge Batch 3 combined with SB2 in Tank 51

SB3 Sludge Batch prepared in Tank 40

SME Slurry Mix Evaporator tank in DWPF

SRAT Sludge Receipt and Adjustment Tank in DWPF

SRNL Savannah River National Laboratory 


\subsection{INTRODUCTION AND BACKGROUND}

\subsection{Introduction}

This report, along with WSRC-TR-2004-00334, summarizes the findings of a program that simultaneously developed new rheological measurement methods for DWPF slurries and characterized a set of ordinary and unusual simulant slurry samples. Additional background information can be found in the other report. New measurement methods were developed and documented in the other report. These new methods were applied to the unusual samples discussed in this report.

Recent variations in the rheology of SB2 simulants have impacted the interpretation of results obtained in a number of studies. This overall program was initiated with the following goals:

- Document the variations seen in the simulant slurries, both by a review of recent data, and by a search for similar samples for further study.

- Attempt to explain the variations in rheological behavior, or, failing that, reduce the number of possible causes. In particular, to empirically check for rheometer-related variations.

- Exploit the additional capabilities of the two cold rheometers, by developing new measurement methods to study the simulant properties in new ways.

- Formalize the rheological measurement process for DWPF-related samples into a series of protocols.

This report addresses the first two goals above. The experimental portion of this program was concentrated in the period of March to April 2004. Literature was reviewed in parallel with the experimental work. Some data analysis was performed in parallel with the experimental work, and further analysis occurred following completion of the experimental work. The new measurement methods were evolving during the experimental phase. Some of the later measurements are superior to earlier measurements due to method refinements.

\subsection{Review of Simulant Rheology for DWPF Sludge Batches}

Historical radioactive and simulant rheology data have been recently reviewed with respect to the slurries processed through DWPF, WSRC-TR-2004-00044. That report details the available data for sludges, SRAT products, and SME products for which there is both radioactive and simulant rheology data. It was noted that various recent simulant slurries have not been performing as expected. The available data were reviewed in order to select several slurries that behaved as expected plus several slurries that did not behave as expected. This was undertaken as part of the first goal in section 1.1. The limited quantity of radioactive SRAT product and SME product data may have prejudiced some of the interpretations and/or expectations for simulant rheological data.

Simulants from Optima were used through the end of studies related to SB1B. No significant issues were reported with respect to rheological measurements on these slurries. Tank 8 and Tank 40 simulants were prepared at the University of South Carolina (USC) in Columbia in preparation for SB2 testing. Additional simulant for SB2 was prepared at the Clemson Environmental Technology Laboratory (CETL). Simulants for SB3 and for preparing various future sludge batches were also 
prepared at CETL. No issues have been observed with CETL-based SB3 sludge simulant rheology to date.

The CETL SB2 simulant recipe was matched to the nominal blend of USC Tank 8 and Tank 40 simulants used in the initial SB2 studies. Rheological properties of the SB2 CETL simulant were found to be unusual. A thickening may have occurred once a shear was applied to the sample inside the rheometer. The phenomenon would be short-lived. An alternative is that the slurry was thick initially, and that no thickening occurred. As the shear rate was increased further, the sample thinned. The sample did not thicken in a similar manner when the shear rate was gradually returned to zero, i.e. the phenomenon was not reversible. This phenomenon was referred to as "the hump", because of its appearance on a flow curve graph (shear stress versus shear rate).

Other issues were observed with the rheology of CETL-sludge based SB2 SME products. These indicated that potentially significant time dependent phenomena were occurring on the time scale of the rheological measurements (about ten minutes). Many samples exhibited significant thickening during the measurement.

\subsection{Literature Review}

There have been several recent issues that have complicated the interpretation of simulant rheology data. Published rheology work was reviewed to see if these issues were unique to SRNL or had been encountered by other researchers. This was part of the first two goals of section 1.1. This information was needed to better document the variations seen in simulant rheology and to attempt to explain what might be causing the variations.

\subsubsection{The Controlled Shear Rate Ramp with Hump}

One leading candidate for further study was CETL SB2 simulant. There was a large quantity available, and the flow curves contained an unusual hump, see Figure 1. 
Figure 1. CETL SB2 Simulant Rheogram

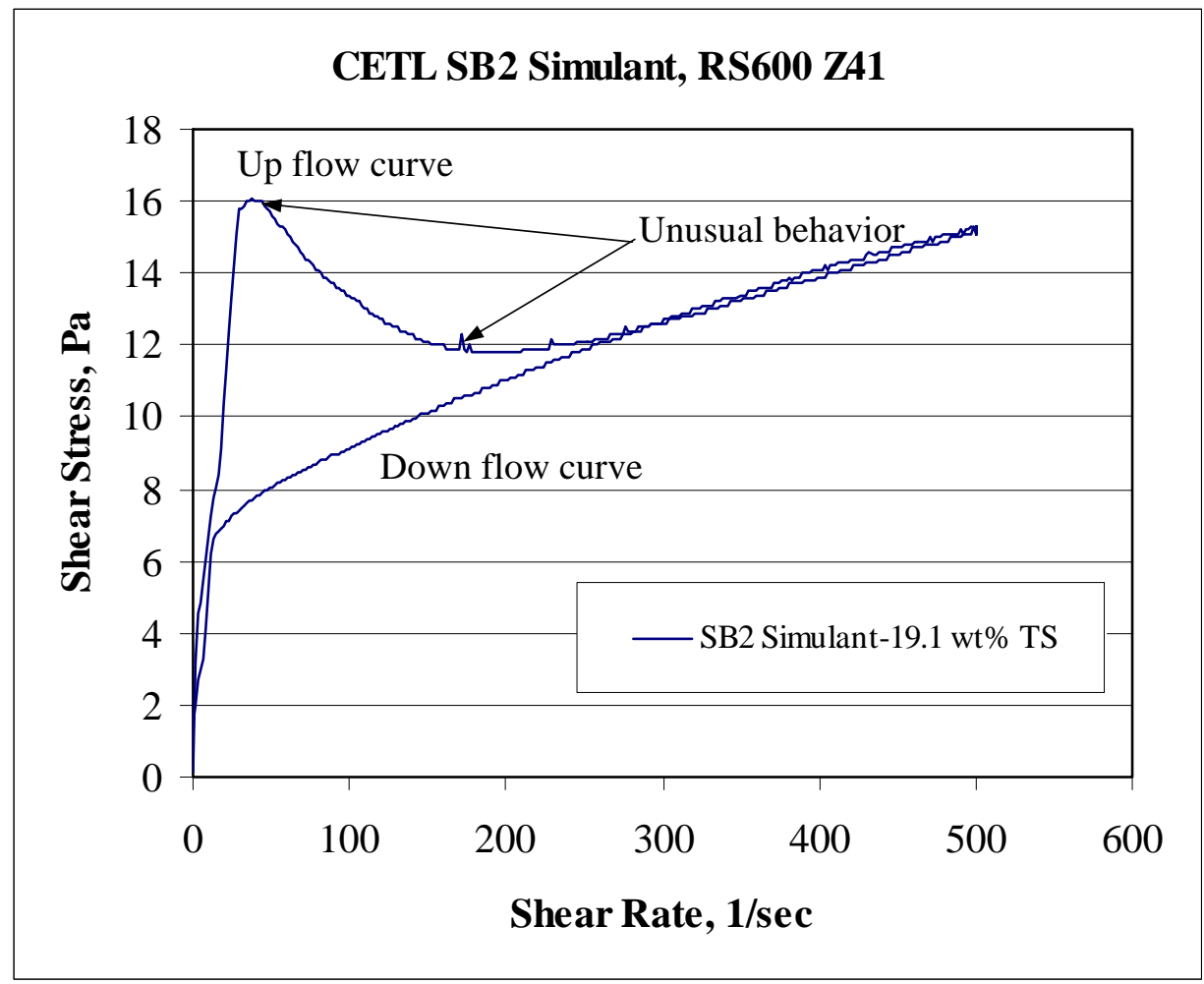

No simple fluid exhibits a falling shear stress with increasing shear rate (region between arrows). A complex fluid with considerable internal structure (e.g. a slurry with complex interparticle forces that are hard to disrupt) could transition from a more to a less viscous fluid as the structure was disrupted.

Schramm (1994) documents one hump system for a toothpaste sample. The data resemble the up flow curve in Figure 1 from 0-150/s (the hump). The down curve never passes through the hump, but stays below it. Figure 111 from Schramm is reproduced in Figure 2. 
WSRC-TR-2004-00519

Revision 0

Figure 2. Shear Stress Versus Shear Rate with Phase Separation

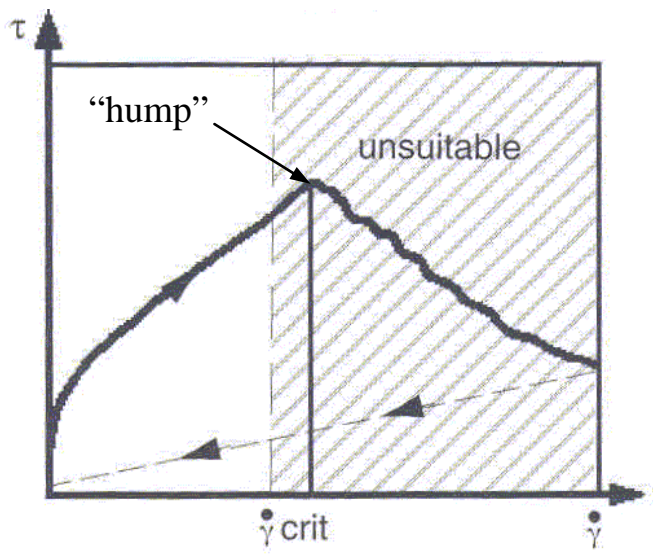

Fig. 111 Increasing shear rates beyond critical levels provides faulty viscosity data on dispersions which can show phase separatior

Schramm's analysis was that a thin liquid layer formed on the surface of the rotating cylindrical bob (phase separation of the aqueous phase from the bulk toothpaste gel). This is illustrated in Fig. 112 in Schramm, reproduced as Figure 3, on the right-hand side of the center line.

Figure 3. Schematic of Phase Separation in Concentric Cylinder Rheometry

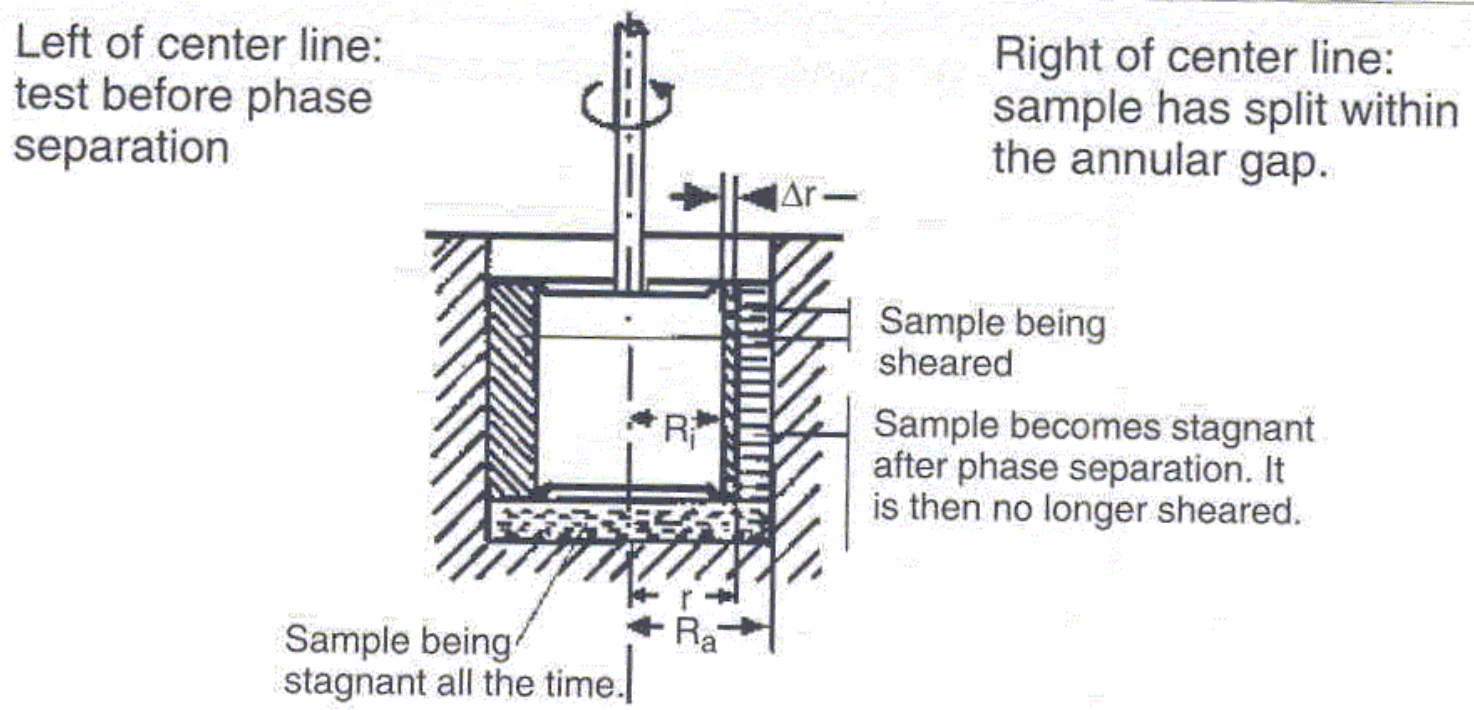

Fig. 112 Phase separation in dispersions leads to a non-uniform deformation of the sample across the shearing gap.

Also, if the Schramm sample was re-ramped up in shear rate, then the hump would not be seen (since the sample was still phase separated). Schramm's situation led to the conclusion that the only valid part of the flow curve was the up ramp from 0/s shear rate to the top of the hump (the rheology of the toothpaste, not the toothpaste plus aqueous layer). The rest of the data was meaningless. 
Another possibility was offered by Hunter (1989). This was in a discussion of "time dependent inelastic behavior" of colloidal systems. Hunter gave an idealized flow curve (b) in figure 18.8.1, reproduced as Figure 4.

\section{Figure 4. Time dependent Inelastic Behavior of Colloidal Systems (from Hunter)}

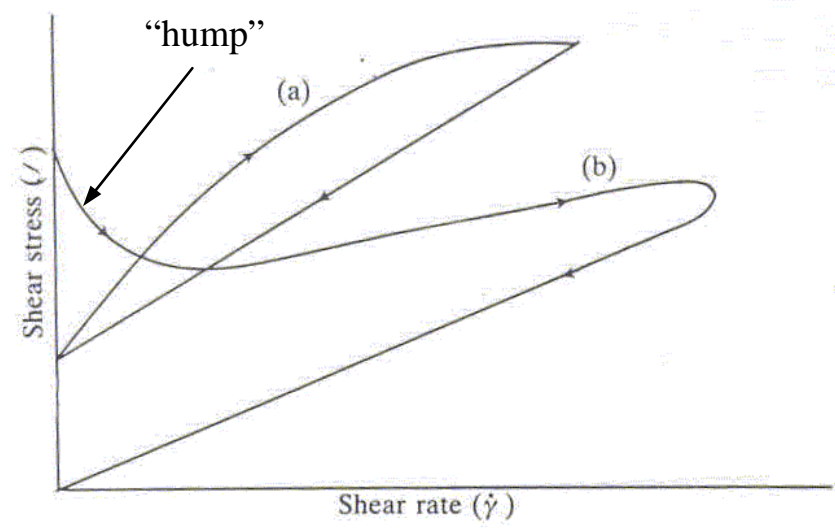

FIG. 18.8.1. Possible hysteresis behaviour for the case where (a) yield stress is fixed and (b) yield stress is reduced by shearing.

The gradual hump seen in SRNL data was abstracted to a sharp jump to a maximum yield stress at zero shear rate, followed by the down-side of the hump as shear rate increases, then followed by a later rise in shear stress during the ramp up, curve (b). The down ramp was below the up ramp. The ultimate reduction of the yield stress to zero indicated in the figure was not required. (The hysteresis curve, (a), is not relevant to the slurry issues being investigated.)

Time dependent behavior is presumed to be minimal when generating an up ramp-hold-down ramp flow curve (the normal SRNL measurement). Hunter recommended using a set of constant shear rate measurements. In these, the measured shear stress is allowed to come to a steady state value after some reasonable period of time. This concept is shown in his Fig. 18.8.2 reproduced below, Figure 5. The proposed test produces a series of humps, one for each increase in shear rate. Hunter would ignore the tops of the humps (opposite of what Schramm argued for tooth paste). This is a different phenomenon, however, so it must be differentiated from phase separation by more than just the occurrence of a hump. 
WSRC-TR-2004-00519

Revision 0

Figure 5. Shear Stress/Time Behavior with Structural Breakdown

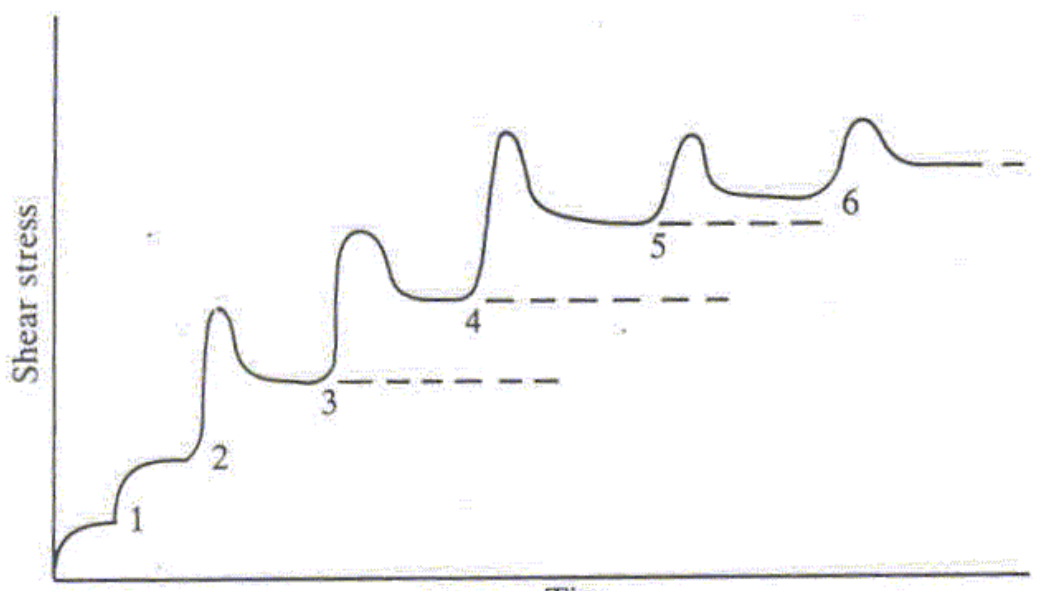

Time

FIG. 18.8.2. Shear stress/time behaviour for a material subjected to increasing strain rates at points $1,2,3, \ldots$. The stress required for that strain rate rises sharply at first and then falls exponentially to a steady state value as the 'structure' of the fluid breaks down to some extent. This method is one of a number introduced by Oesterle.

If samples do not come to steady state shear stresses after some time, then many of the DWPF slurry samples potentially have adequate time to sediment, phase separate, or whatever. The presumption of this model would be that the shear regime imposes stresses on the flow units (particles or flocs). The stresses cause the flow units to undergo structural breakdown, leading to lower viscosity with time at a given shear rate. Higher, more vigorous shear rates break down flow units that survived exposure to lower shear rates. Hunter's opinion was that reorientations or minor rearrangements of the particles were less likely to produce measurable time dependent behavior, since they would be expected to occur on too short of a time scale. (Hunter's work is textbook material drawn from a considerable body of data.)

A third potential source of the hump was found that was somewhat more complicated than that proposed by Hunter. Several articles have appeared in the literature concerning a phenomenon known as shear-induced aggregation. References include Gustafsson et al. (2001), Nystrom et al. (2001), Kawaguchi et al. (197), and Chang et al. (1994). This phenomenon has been seen in inorganic slurries. As shear is applied to the slurry, particles begin to aggregate. The stress required to shear the slurry increases as the particles aggregate. As shear rate increases, a point is reached where aggregation stops. This is followed by progressive destruction of the aggregates. This gives rise to a hump in the shear stress-shear rate plot as shear rate is ramped up. The shear rate at the point of maximum aggregation is variable. Oscillatory rheological testing indicated that the elastic modulus, G', went from less than the loss modulus, G”, to greater than it, to less than it again as time under shear increased. The elastic and loss moduli are defined and explained in WSRC-TR-200400334.

A rheometric resolution of measurement data issues will not be found if the shear stress fails to stabilize in a reasonable length of time. The issue will be with the simulant, not with the instrument. If the simulant slurry is that slow to come to rheological steady-state, then it is probably not a good rheological simulant for DWPF slurries. Similar unusual behavior has not been seen on the radioactive sample side to date, though SME product slurry data is quite scarce. 


\subsubsection{Controlled Shear Rate Loop with Down Curve Well Above Up Curve}

The slurry in Figure 6 is a SME product produced from CETL SB2 sludge simulant. Closer inspection reveals a small hump in the up curve similar to that seen with the sludge. The shear rate ramp down flow curve was well above the up curve (up to nearly six times higher in some places) over most of the shear rate range. This is clearly not the situation just described in section 1.3.1, where the shear stress goes down after the hump and stays down (Schramm toothpaste).

Figure 6. Unusual placement of down ramp relative to up ramp flow curve.

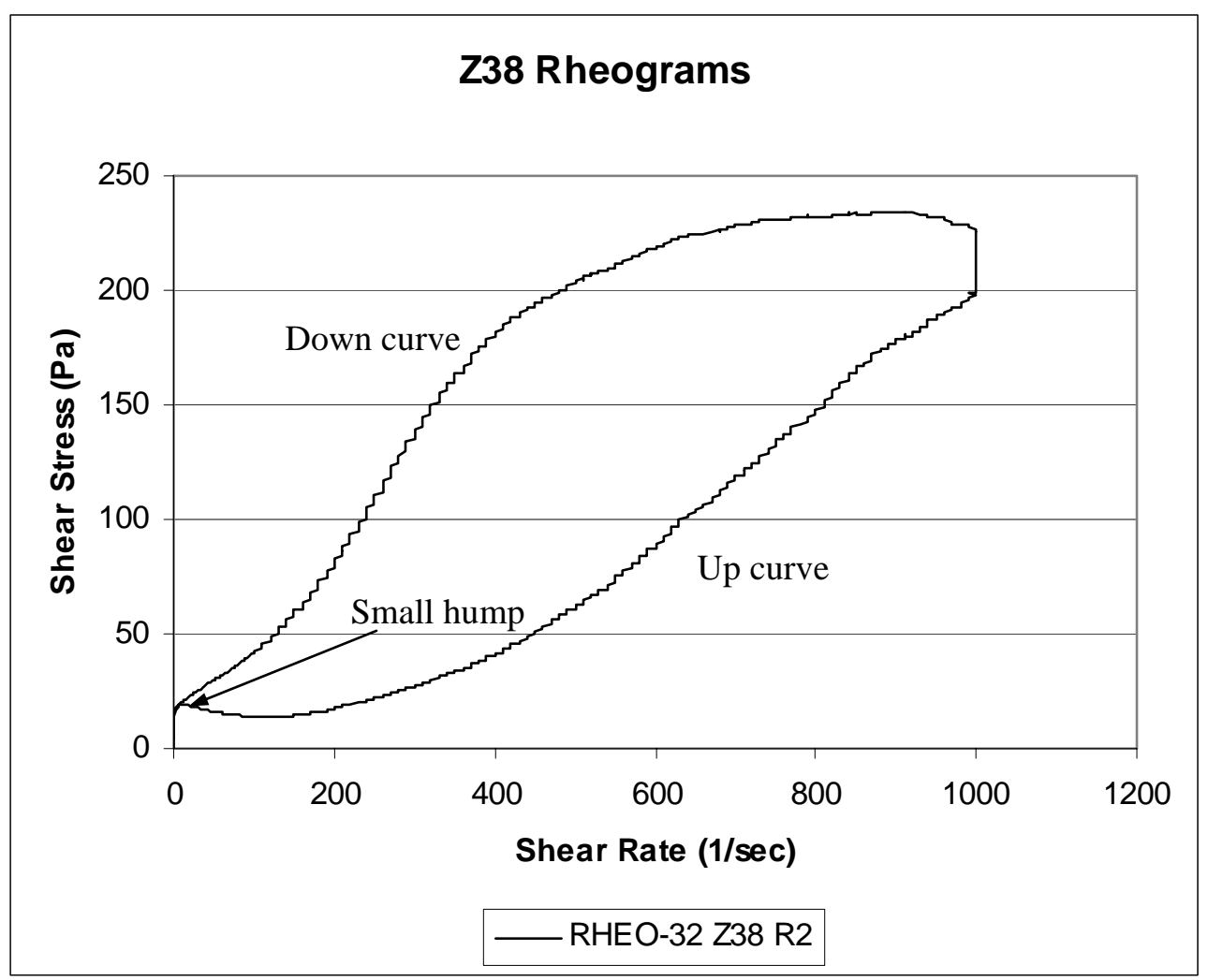

The size of the hump at about 25/s shear rate does not appear to be that large. Note however that the range of values on the y-axis is more than ten times larger than that on Figure 1 (SB2 CETL sludge hump). This rheogram does not have the linear region from low shear rates on up. Nor is it clear how to fit such data to a Bingham plastic model. This is a good time to review the apparent viscosity graph (shear stress $\div$ shear rate vs. shear rate). The corresponding plot is given below, Figure 7 . 
Figure 7. Alternative View of the Data Contained in the Previous Figure

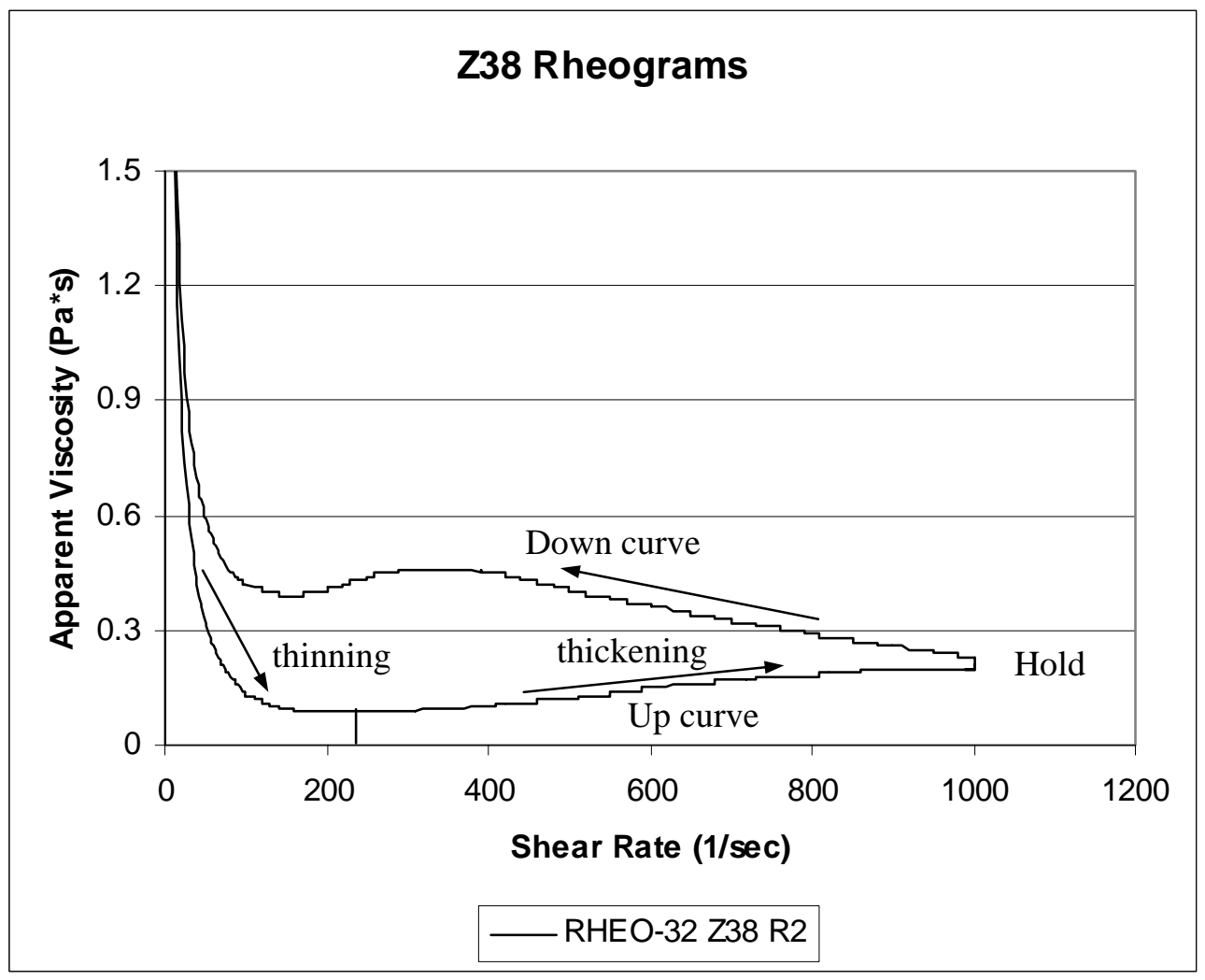

Here it is obvious that the fluid thinned with increasing shear rate (and/or time under shear) until about 200/s (on the up curve). It then thickened the remainder of the up curve, and through the hold period. The period in the down curve from 1000/s to about 300/s more closely resembles the expected behavior of a shear thinning DWPF slurry. The issue being that it is not closely aligned with the up ramp data. This suggests changes in properties with time. The slurry then thinned between 300/s and 175/s, which is unexpected, before thickening again as the rotating cylinder decelerated to a stop. (The expected shape of this curve is continuous thinning from left to right on both the up curve and the down curve.)

The slurry viscosity figure in Alderman and Heywood (2004) indicates that the behavior seen in the up flow curve is not unusual in a universal sense. Similar behavior has been observed with thick slurries in other environments. The essential features of this figure are reproduced in Figure 8 . The $\log$ shear rate axis range is $10^{-6} / \mathrm{s}$ to $10^{+6} / \mathrm{s}$. Historical DWPF sample data is typically free of instrument effects from 10/s out to $1000 / \mathrm{s}$ (the region from $0 / \mathrm{s}$ to $10 / \mathrm{s}$ is subject to inertial issues). The above SB2 SME product simulant sample might be interpreted as comparable to the third or fourth curve up from the bottom in Figure 8. 
Figure 8. Slurry Viscosity vs. Shear Rate (from Alderman and Heywood)

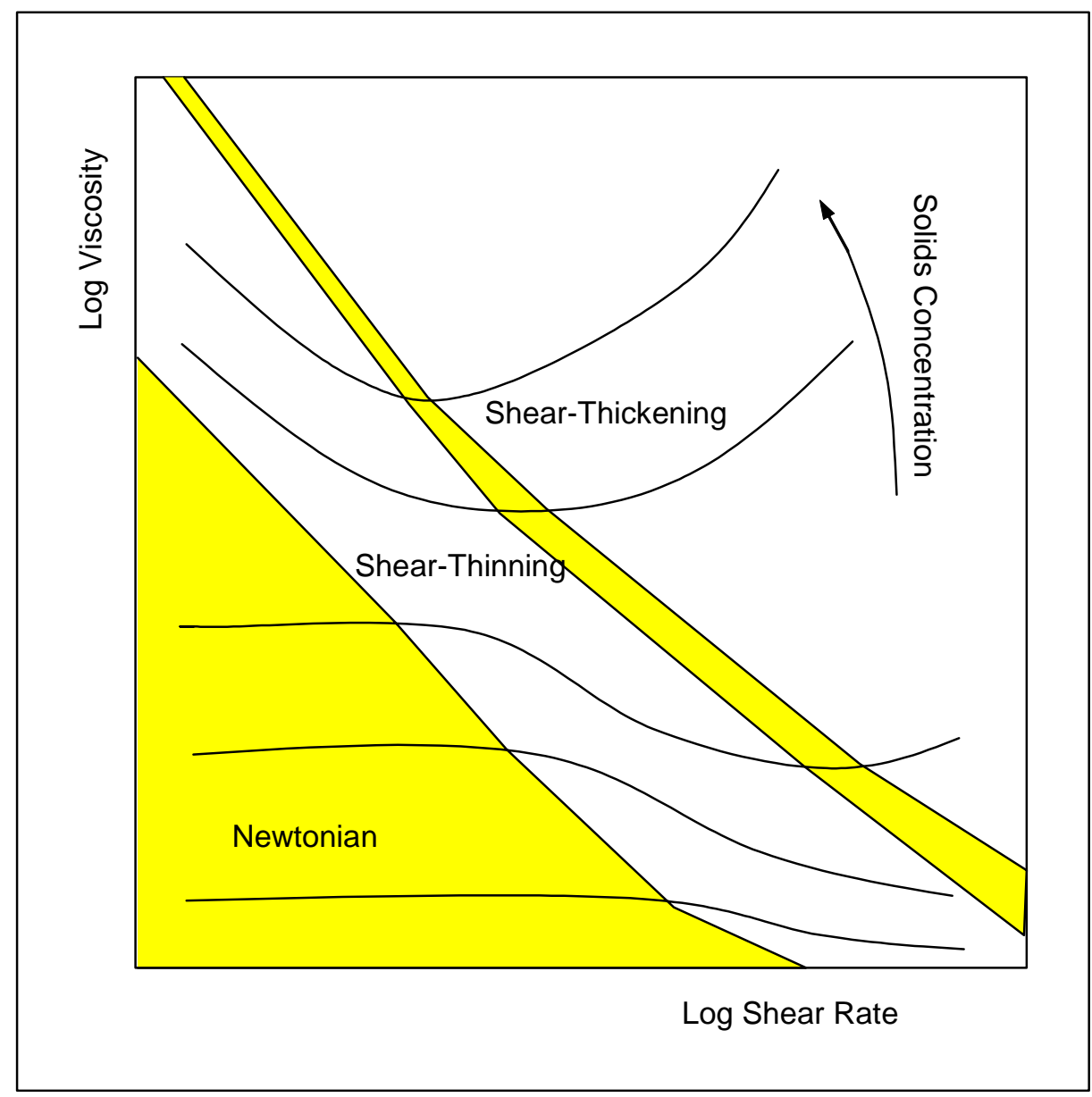

The key feature of Figure 8 is that increasing solids concentrations leads to systems that are shearthinning at low shear rates, but shear-thickening at high shear rates. It also indicates that as solids concentration increases, the possibility of spanning a shear rate range that shows both shear-thinning and shear-thickening behavior increases. Data such as this could explain the shape of either the SB2 SME product up or down flow curves. These data, however, do not explain the difference between the up and down flow curves.

The most likely explanation for the relative differences between the up ramp and down ramp flow curve data is that the sample is exhibiting limited rheopectic behavior. Rheopexy is the tendency to develop an increased viscosity during time under shear. It is the opposite of thixotropy, which is the tendency to develop a lower viscosity with time under shear. (Note: Some authors in the literature have used the terms shear-thickening and shear-thinning for rheopexy and thixotropy. Usage of terms such as shear-thinning and shear-thickening, however, is usually limited to synonyms of pseudo-plastic and dilatant behavior, as in Figure 8. These terms focus on the effect of varying shear rate on the viscosity when no time dependence is present. Time independent DWPF slurries that have been studied were pseudo-plastic, i.e. the apparent viscosity decreased smoothly with increasing shear rate.)

Time dependent rheological data make even the relative ranking of samples difficult. Familiar quantities such as the yield stress and consistency from the Bingham plastic model are not uniquely 
determined, but depend on the measurement parameters of the rheometer. Most time dependent samples have an "equilibrium flow curve". This is a relationship between shear stress and shear rate that develops within the sample after a relatively long time under shear. A long time could be as short as 5-10 minutes, or it could be longer than an hour. One way to obtain the equilibrium flow curve is to ramp the shear rate up and down over and over again until the data from successive ramps stop changing. 


\subsection{APPROACH}

The program summarized in this report and WSRC-TR-2004-00334 was primarily rheological in nature. The second, third, and fourth goals in section 1.1 could not be accomplished without new rheological measurements. A series of measurements was made on a set of DWPF simulant samples. The sample set included simulated sludges, simulated SRAT products, and simulated SME products. The set included some examples of typical slurries and some examples of unusual slurries. The also set included some examples of rheologically thick slurries and some examples of thin slurries. This was done to provide broad coverage of the potential DWPF operating regime. The samples are described in this section, 2.1.

One focus of the work was the development of new rheological measurement methods. These are described in detail in WSRC-TR-2004-00334. This section includes a brief summary outlining the rheological measurement methods used in this program, 2.2.

\subsection{Samples}

The primary samples in this study included three sludges, two SRAT products, and two SME products. These seven samples were subjected to more tests than the eight supporting samples. The samples are summarized in the following paragraphs. Table 1 gives the sample name and summarizes measured non-rheological properties. Additional visual observations related to these samples can be found in WSRC-TR-2004-00334. Two more SME products were examined several months after completion of the main experimental phase of the program to follow-up on an issue related to aging of SME products. These are discussed in section 3.5.

Primary Simulant Samples

1. SB2/3 CETL SME Product, 155\% Acid, Run 6, 1/16/04 (composite of 2 (or more) 22-L SME products for Slurry-fed Melt Rate Furnace).

2. SB3 CETL SME Product (from SB3A-19, one of the two final flow sheet study runs in support of the SB3 Shielded Cells SRAT/SME simulation).

3. SB2 USC sludge simulant (a blend of Tank 8 and Tank 40 USC sludge simulants).

4. SB2 CETL sludge simulant, RM-03-131, 8/8/03 (similar in composition to SB2 USC sludge, but made directly).

5. Tank 8 USC sludge simulant, Old Drum 8-1 (a single recipe).

6. SB2 Sludge SRAT Product MB3-9/9/03, Mike Stone (CETL-based, from Mike Stone's processing issues work).

7. SB2/3 CETL SRAT Product (from ARP study, baseline case SRAT cycle).

The focus was on the unusual primary samples. These included SB2 CETL sludge simulant and the two SME products. The SB2/3 SRAT product also exhibited some unusual behavior. 
Supporting Simulant Samples

1. N35 viscosity standard.

2. “Batch 1, Test 6” Optima sludge simulant (probably equivalent to SB1A).

3. Tank 8/40 (SB2) USC SME Product (from GFPS runs with Frit 200).

4. SB3 CETL sludge simulant.

5. SB2 CETL sludge simulant - shear mixed.

6. SB2 CETL SRAT Product - decanted.

7. SB2/3 CETL SME Product, Run 5, 155\% Acid (heel study) and its dilutions.

8. SB2/3 CETL SME products from acid stoichiometry program (140\%, 155\%, 170\%, and $185 \%$ of stoichiometry).

The available physical properties for the above samples are given below, Table 1 . The list in Table 1 is somewhat longer than that above, since individual variations of some samples are listed separately. Many of these samples did not exhibit unusual behavior. They were chosen for that reason, so that the response of the new rheological test methods could be observed for both typical and unusual samples. 
Table 1. Physical Properties of Rheology Slurry Samples

\begin{tabular}{|c|c|c|c|c|c|c|}
\hline & 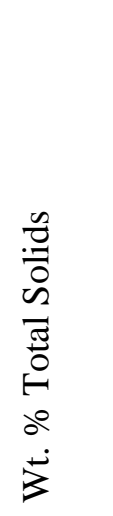 & 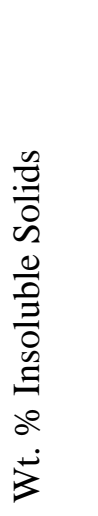 & 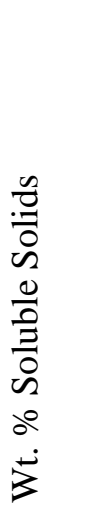 & 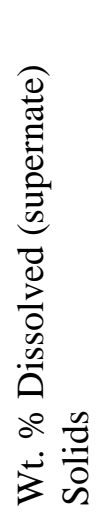 & 焉 & 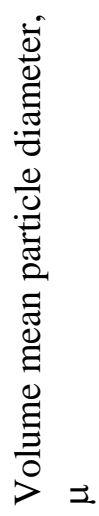 \\
\hline Tank 8 USC Sludge & 17.7 & 15.2 & 2.50 & 2.95 & 10.35 & n. a. \\
\hline Tank 8/40 (SB2) USC Sludge & 16.5 & 13.3 & 3.18 & 3.67 & 11.46 & 4.8 \\
\hline SB2 CETL Sludge & 19.4 & 17.4 & 1.99 & 2.41 & 13.06 & 17.24 \\
\hline Batch 1, Test 6 (SB1A) Sludge & 20.9 & 16.5 & 4.42 & 5.29 & 13.11 & $\sim 4$ \\
\hline SB2 CETL SRAT Product, 9/9/03 & 12.6 & 8.03 & 4.55 & 4.94 & 7.91 & n. a. \\
\hline SB2/3 CETL SRAT Product & 25.4 & 12.8 & 12.6 & 14.5 & 7.43 & n. a. \\
\hline Tank 8/40 (SB2) USC SME Product & 49.3 & 43.3 & 6.02 & 10.6 & 7.98 & n. a. \\
\hline SB2/3 CETL SME Product, Run 6 & $\sim 54.4$ & n. a. & n. a. & n. a. & n. a. & n. a. \\
\hline SB3 CETL SME Product (SB3A-19) & 54 & 37 & 17. & 25 & 7.67 & n. a. \\
\hline SB2 CETL Sludge, shear-mixed & 19.4 & 17.4 & 1.99 & 2.41 & 13.06 & 12.17 \\
\hline SB2/3 SME, Run 5, neat & 50.2 & 37.1 & 13.1 & 20.8 & 6.66 & n. a. \\
\hline SB2/3 SME, Run 5, dilution 1 & 37.9 & n. a. & n. a. & n. a. & n. a. & n. a. \\
\hline SB2/3 SME, Run 5, dilution 2 & 29.5 & n. a. & n. a. & n. a. & n. a. & n. a. \\
\hline SB2/3 SME, Run 5, dilution 3 & 41.5 & n. a. & n. a. & n. a. & n. a. & n. a. \\
\hline SB2 CETL SRAT - decanted & 17.5 & 12.3 & 5.17 & 5.89 & 7.70 & n. a. \\
\hline SB2/3, SME Product, $140 \%$ acid & 55.5 & $\sim 45$ & $\sim 10$ & n. a. & 7.08 & n. a. \\
\hline SB2/3, SME Product, 155\% acid & 52.34 & $\sim 41$ & $\sim 11$ & n. a. & 7.10 & n. a. \\
\hline SB2/3, SME Product, $170 \%$ acid & 53.59 & $\sim 42$ & $\sim 11$ & n. a. & 5.89 & n. a. \\
\hline SB2/3, SME Product, 185\% acid & 53.27 & $\sim 42$ & $\sim 11$ & n. a. & 4.70 & n. a. \\
\hline SB3 CETL Sludge & 17.7 & 17.4 & 0.42 & 0.35 & 11.03 & 9.71 \\
\hline
\end{tabular}

The abbreviation "n.a.” in Table 1 stands for not analyzed. 


\subsection{Rheometry}

Rheology is the science of the deformation and flow of matter. Rheometry is the measurement of the deformation and flow of matter. Rheological testing was almost entirely completed using the Haake RS150 rheometer at ACTL. A few samples were run on the Haake RS600 rheometer. These instruments use an identical set of axisymmetric cylindrical bobs and beakers. The six measurement methods that gave the most useful data are briefly summarized below. Analysis methods for the new measurements are discussed in WSRC-TR-2004-00334.

\subsubsection{Controlled Shear Rate Flow Curve}

In this measurement, the cylindrical bob is accelerated through a predetermined range of rotational speeds (ramped up), held at the upper speed, and then decelerated back to a stationary position (ramped down). Times for each step are user-controlled inputs to the job program, as are the shear rate ranges. Both the full set of shear stress-shear rate data, as well as the sets of data from individual shear rate ramp segments, are referred to as flow curves. The test is a standard one for checking for thixotropy (time dependence) in samples simultaneously with obtaining shear stress-shear rate flow curve data. This makes it a versatile test. While it is useful in identifying the presence of time dependent rheological behavior in a sample, it is not always the best choice for quantifying time dependent behavior.

Ramping of the cylindrical bob speed was done as a linear function of the time, i.e. constant acceleration. If the shear rate was to be ramped from $0 / \mathrm{s}$ to $600 / \mathrm{s}$ over five minutes, then the shear rate was 120/s after one minute, 240/s after two minutes, etc. Initial rheology measurements used five minutes for both the up flow curve ramp time and for the down flow curve ramp durations. Different ramp end points and times were selected for follow-up measurements based on the choice of the cylindrical bob and the nature of the sample. Temperature was maintained at $25^{\circ} \mathrm{C}$. A rheometer measures the torque and angular speed of the rotating bob. Torque is converted to shear stress using a mathematical model. The angular speed is converted to shear rate using a mathematical model that assumes the fluid is Newtonian in behavior.

\subsubsection{Controlled Shear Rate Time Curve}

This measurement is similar in structure to the controlled shear rate flow curve, but the emphasis is on obtaining data in the constant shear rate hold period rather than during the up and down shear rate ramps. The ramps can be very short in duration, while the hold is much longer than in the controlled shear rate flow curve. Hold times were typically ten to fifteen minutes, while up and down ramp times were typically 5-20 seconds. Temperature was controlled at $25^{\circ} \mathrm{C}$. Samples were taken to constant shear rates in the range of 100/s to 200/s. SME products were typically taken to 100/s, while sludges and SRAT products were taken to 200/s. The lower shear rate for SME products was related to issues associated with the larger annular gap used when frit is present in the slurry.

The constant shear rate time curve measurement provides a direct test of time dependent behavior. Lack of time dependence in the sample produces a constant shear stress response at a given shear rate for the duration of the hold period. (A possible exception occurs in the first minute of the hold where inertial effects of the instrument may not have been damped out by the viscosity of the sample. As viscosity decreases, the time to dampen the inertial effects increases. This is taken into consideration when reviewing the data.) 


\subsubsection{Controlled Stress Flow Curve}

The controlled shear rate flow curve measurement, 2.2.1, varies shear rate and measures shear stress. The controlled stress variation of the concept varies the shear stress and measures the shear rate. The variation is in the form of a shear stress ramp as a function of time. This is a powerful test for samples suspected of having a yield stress. During the controlled shear rate flow curve up ramp segment, the rheometer drives the stress to whatever level is necessary to deliver a non-zero shear rate. Consequently, these stresses are above the true yield stress of the sample, since any lower stress would not give a non-trivial shear rate (motion). Conversely, in the controlled stress ramp, a stress below the true yield stress gives rise to a zero or trivial shear rate. The sample, however, begins to deform (strain) as the stress applied increases. All testing was done at $25^{\circ} \mathrm{C}$.

Most of the data unique to this measurement are obtained during the up ramp portion. The data can be analyzed for the true yield stress and for the Bingham plastic yield stress and consistency. The true yield stress corresponds to a gel-like to fluid-like transition, while the Bingham plastic yield stress is an empirical extrapolation of high shear rate data back to zero shear rate. The two yield stresses are typically quite different. Only the two cold rheometers (RS150, RS600) presently have this measurement mode capability.

\subsubsection{Oscillation Frequency Sweep}

The user must specify an oscillation frequency range, e.g. $0.1-10 \mathrm{~Hz}$, and a shear stress to perform this test. Temperature was $25^{\circ} \mathrm{C}$. The shear stress specified becomes the amplitude of a sine wave function input through the cylindrical bob to the sample. The angular displacement of the bob wall is regulated by the slurry properties. If the sample is rigid, then it oscillates in phase with the applied stress. If the sample is entirely fluid-like, then is oscillates with a $90^{\circ}$ phase lag to the applied stress.

The test is usually applied at a shear stress level below the true yield stress of the sample (not to be confused with the Bingham plastic model yield stress, which is generally much larger). The purpose of the test is to confirm that the sample behaves in a generally solid-like manner over a range of frequencies. This confirmation is needed for the oscillation stress sweep and oscillation time sweep tests, where the oscillation frequency must be specified as an input. The two cold rheometers (RS150, RS600) possess the oscillation mode capabilities for this and the two tests below. The two rheometers in radioactive service have no oscillation mode.

\subsubsection{Oscillation Amplitude (Stress) Sweep}

This test is similar to the oscillation frequency sweep in concept. The difference is that the frequency is held constant and the stress is varied, instead of vice versa. Most testing in this program was done at a frequency of $1 \mathrm{~Hz}$. Higher frequencies gave noisier data, while lower frequencies prolonged the duration of the measurement unduly. Temperature was $25^{\circ} \mathrm{C}$. A logarithmic distribution was used for the shear stress. A test typically covered 3-4 orders of magnitude in shear stress.

The rheological response to various oscillating shear stresses is obtained by this test. The controlled shear stress flow curve obtains the rheological response to a pseudo-steady state flow field. The two sets of data can be fairly similar. Certain physical phenomena, however, can be different. One of these is particle alignment. Particles tend to align their long axis parallel to the fluid streamlines in steady flow in order to reduce drag. The reversal of flow direction in the periodic flow pattern of the oscillation tests can inhibit this reorientation of particles. 


\subsubsection{Oscillation Time Sweep}

This test is the oscillatory analog to the controlled shear rate time curve. A shear stress (not a shear rate) is specified along with a frequency. The sample is then subjected to this oscillating stress for a pre-determined time. This was generally 10-15 minutes. Frequency was typically $1 \mathrm{~Hz}$. Temperature was $25^{\circ} \mathrm{C}$.

The samples studied in considerable detail were subjected to at least three different oscillation time sweeps, i.e. a time sweep series. Typically, one test targeted a shear stress that was indicated to be in the region below the true yield stress, i.e. the solid-like region. A second test targeted a shear stress that was indicated to be in the region above the Bingham plastic yield stress, i.e. in the definitely fluid-like and yielded region. Additional tests targeted shear stresses in the intermediate region between the true and Bingham plastic yield stress values. This oscillation time sweep series permits characterizing the time dependence of the sample in three different flow regions. Data obtained indicate the extent of thixotropy or rheopexy at each stress level. This cannot be accomplished with the controlled shear rate time curve, since it is unable to make measurements below the Bingham plastic yield stress with any reliability.

\subsection{Analysis Matrix}

The following table, Table 2, summarizes the number of each of the tests outlined in section 2.2 that were performed on each sample. 
Table 2. Summary of Tests Performed by Sample and Test Type

\begin{tabular}{|c|c|c|c|c|c|c|}
\hline & 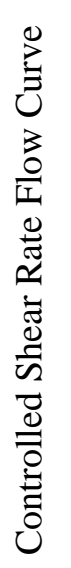 & 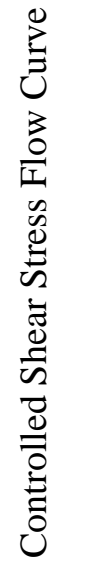 & 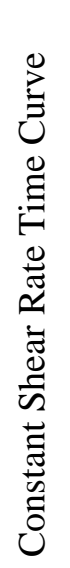 & 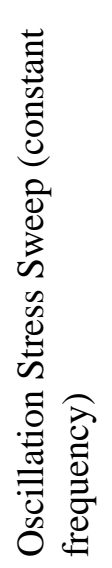 & 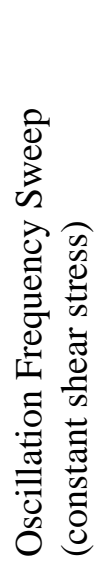 & 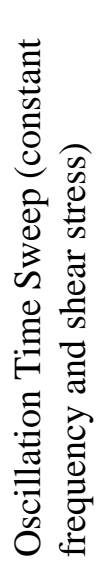 \\
\hline N35 Viscosity Standard & 5 & 3 & 1 & 4 & 4 & 0 \\
\hline Tank 8 USC Sludge & 1 & 3 & 1 & 3 & 1 & 3 \\
\hline Tank 8/40 (SB2) USC Sludge & 1 & 5 & 2 & 2 & 1 & 4 \\
\hline SB2 CETL Sludge & 9 & 3 & 3 & 2 & 6 & 4 \\
\hline Batch 1, Test 6 (SB1A) Sludge & 0 & 1 & 1 & 0 & 0 & 0 \\
\hline SB2 CETL SRAT Product & 2 & 2 & 1 & 1 & 1 & 0 \\
\hline SB2/3 CETL SRAT Product & 8 & 2 & 1 & 1 & 1 & 0 \\
\hline Tank 8/40 (SB2) USC SME Product & 2 & 1 & 1 & 1 & 0 & 0 \\
\hline SB2/3 CETL SME Product & 3 & 4 & 2 & 6 & 5 & 4 \\
\hline SB3 CETL SME Product (SB3A-19) & 5 & 4 & 3 & 3 & 1 & 3 \\
\hline SB2 CETL Sludge, shear-mixed & 1 & 0 & 0 & 0 & 0 & 0 \\
\hline SB2/3 SME, neat + dilutions (4) & 8 & 1 & 2 & 1 & 0 & 0 \\
\hline SB2 CETL SRAT - decanted & 1 & 1 & 2 & 1 & 0 & 0 \\
\hline SB2/3, 4 Acid-level SME Products & 0 & 1-2ea & 0 & 1 ea & 0 & 0 \\
\hline SB3 CETL Sludge & 1 & 0 & 0 & 0 & 0 & 0 \\
\hline
\end{tabular}


WSRC-TR-2004-00519

Revision 0

This page intentionally left blank. 


\subsection{RESULTS}

Significant experimental measurement results will be covered in this section. These were extracted from a larger body of data. The full data set can be found in WSRC-NB-2004-00009. The discussion that follows is sorted by sample. The only sludge simulant discussed in detail is SB2 CETL sludge. This slurry had an unusual hump in the up ramp of the controlled shear rate flow curve measurement. No SRAT products were found that had unusual rheological behavior. Several SME products were found that had varying degreed of rheopectic behavior based on initial rheological measurements. Data for several of these are given below.

\subsection{SB2 CETL Sludge Simulant}

SB2 CETL sludge simulant has given problematic up ramp flow curves since it was received. The main feature is a broad shear stress hump in the first few minutes of the up ramp flow curve segment of the controlled rate flow curve, Figure 1. Measurements were typically made using the Z41 bob. The impact of the spacing between the bob and the bottom of the cup was checked. It was not a factor for the Z41 bob, so the raw data are not shown. Specific measurement results are discussed below.

\subsubsection{Controlled Shear Rate Measurements}

Figure 9 shows the effect of following one Z41 flow curve measurement with another. The first measurement was to 600/s using $300 \mathrm{~s}$ for the up and down ramps and $60 \mathrm{~s}$ for the hold. The second measurement was to 300/s using $150 \mathrm{~s}$ (same ramp rate) for the up and down ramps and $2 \mathrm{~s}$ for the hold. 
Figure 9. Impact of Consecutive Measurements on SB2 CETL Sludge Hump

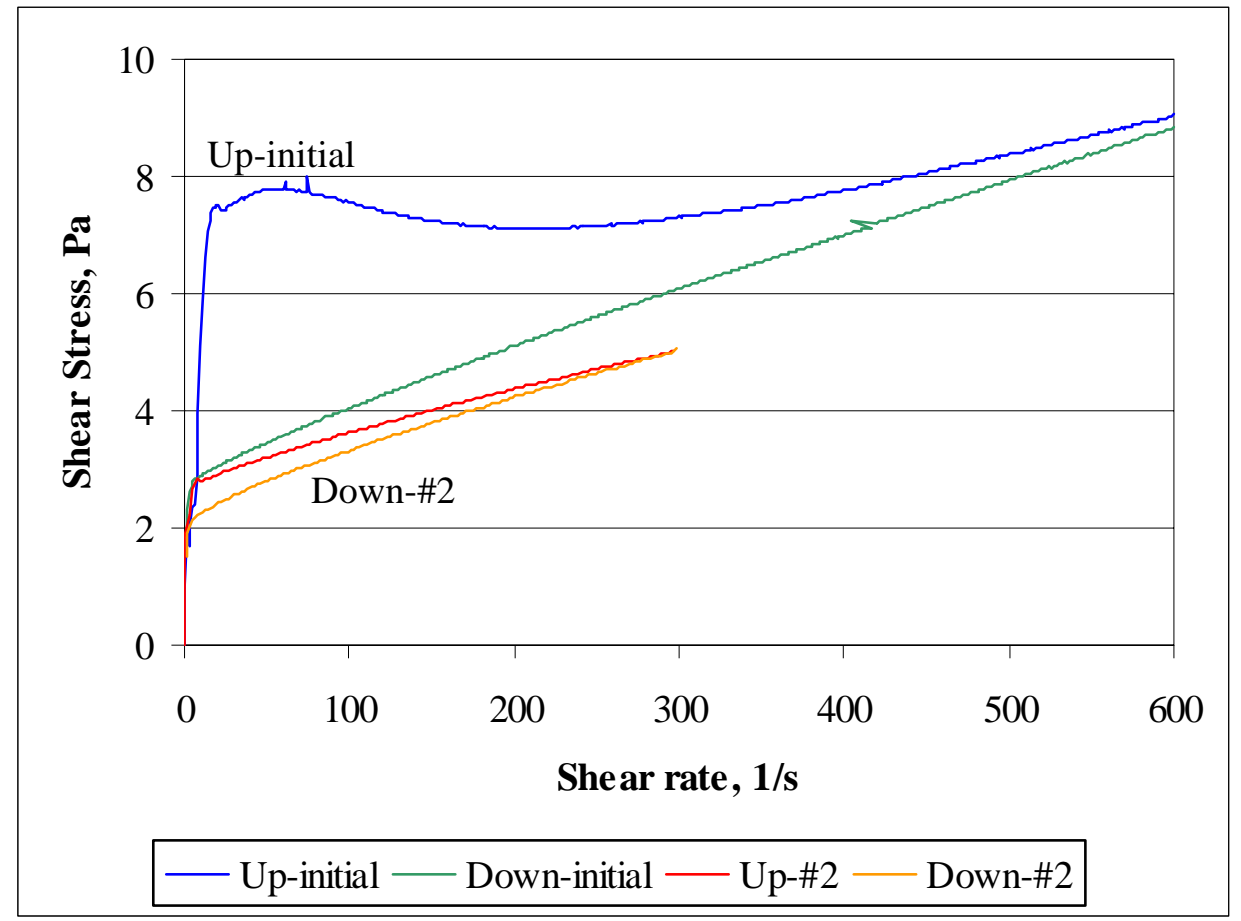

The major observation is that there is no hump on the up ramp segment of the follow-up flow curve. This result has since been observed with two of the samples in the SB2 depleted uranium program, WSRC-TR-2004-00206. The second significant observation was that the second ramp set was fairly close to the initial down ramp, indicating that the sample was trending toward the equilibrium flow curve.

SB2 CETL sludge simulant was then subjected to a pair of controlled shear rate flow curve tests using smooth and profiled cups and bobs, Figure 10. These were both of the Z38 type, i.e. had a larger annular gap width than the Z41 bob. The instruments are not presently equipped with a profiled cup and bob with the Z41 gap (this may not be possible due to geometric concerns). One purpose for using the profiled cup and bob is to check for slip. Slip occurs when a thin layer of supernate is eluted from the slurry to form a layer on the rotating bob surface. Most of the rotational velocity gradient is lost across this layer. The slurry from the supernate layer to the cup wall does not appear to be moving as though it were attached to the bob wall, which is why this is called slip. The slurry seems to have slipped (detached) relative to the moving bob wall. This is analogous to the toothpaste sample discussed in section 1.3.1. 
Figure 10. SB2 Sludge Simulant (CETL) by Z38/PZ38: Effect of Profiling

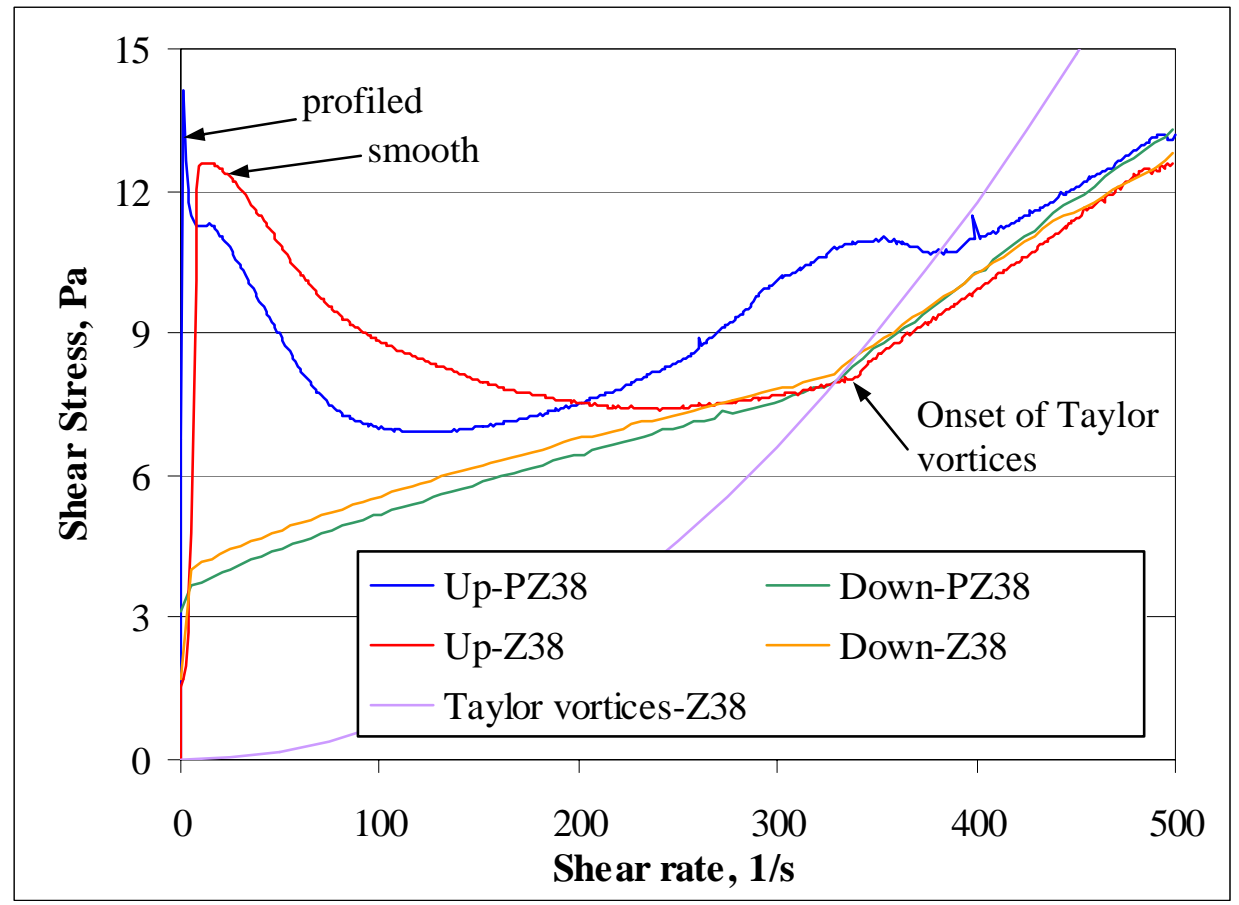

Changing from the smooth Z41 to the smooth Z38 bob did not mitigate the hump. Use of the profiled cup and bob seemed to put the up ramp flow curve to the top of the hump almost immediately compared with the Z38 smooth bob and cup (and also to the Z41 smooth bob and cup). Both of these measurements were pushed to 500/s shear rate (five minute ramp) to compare the onset of Taylor vortices with the profiled geometry relative to the smooth geometry. Down curve results were similar with a transition at about 330/s shear rate back to laminar flow for the remainder of the down ramp. The Z38 up flow curve also seemed to transition into Taylor vortices at about 330/s. The PZ38 up flow curve, however, may have transitioned into some intermediate flow pattern at about 250/s shear rate. Note how the down ramp for Z38 comes out of the Taylor vortices region at nearly the same point that the up ramp entered the Taylor vortices region. More discussion on Taylor vortices will be given below with a focus on SME product rheology.

The profiled geometry data in Figure 10 seem to rule out the phase segregation option discussed in section 1.3.1 as a possible explanation for the hump. A thin film of supernate forming on the bob wall would have to be larger than the groove depth, i.e. macroscopic, not microscopic in scale. This was neither observed nor considered likely. The profiled bob data look more like Figure 4 than the smooth bob data.

While the elimination of the hump in a repeated up ramp of shear rate could have supported the hypothesis that phase segregation had occurred at the cylinder wall, the subsequent data with the profiled geometry have effectively eliminated that option. Furthermore, the data do not seem to be consistent with shear-induced aggregation, which seems to be a reversible process, i.e. the shear rate can be ramped back and forth across a certain range, and the hump will be there every time. The data to this point are still consistent with curve (b) in Figure 4. The profiled geometry data, Figure 10, are actually a better match to the shape of curve (b) than the smooth geometry data. The likeliest explanation for the hump based on the options found in the literature appears to be time dependent inelastic behavior. 
Another factor studied during this program was the impact of time at shear on the shape of the flow curve. The CETL SB2 sludge simulant (hump) was pre-sheared at 400/s for 60 seconds prior to making the Z41 up ramp measurement. This was based on the hump lasting only about 75 seconds at lower shear rates and the premise that both time and shear rate contribute to moving beyond the hump. The result is shown in Figure 11.

Figure 11. Impact of a Pre-shear on SB2 CETL Sludge Hump

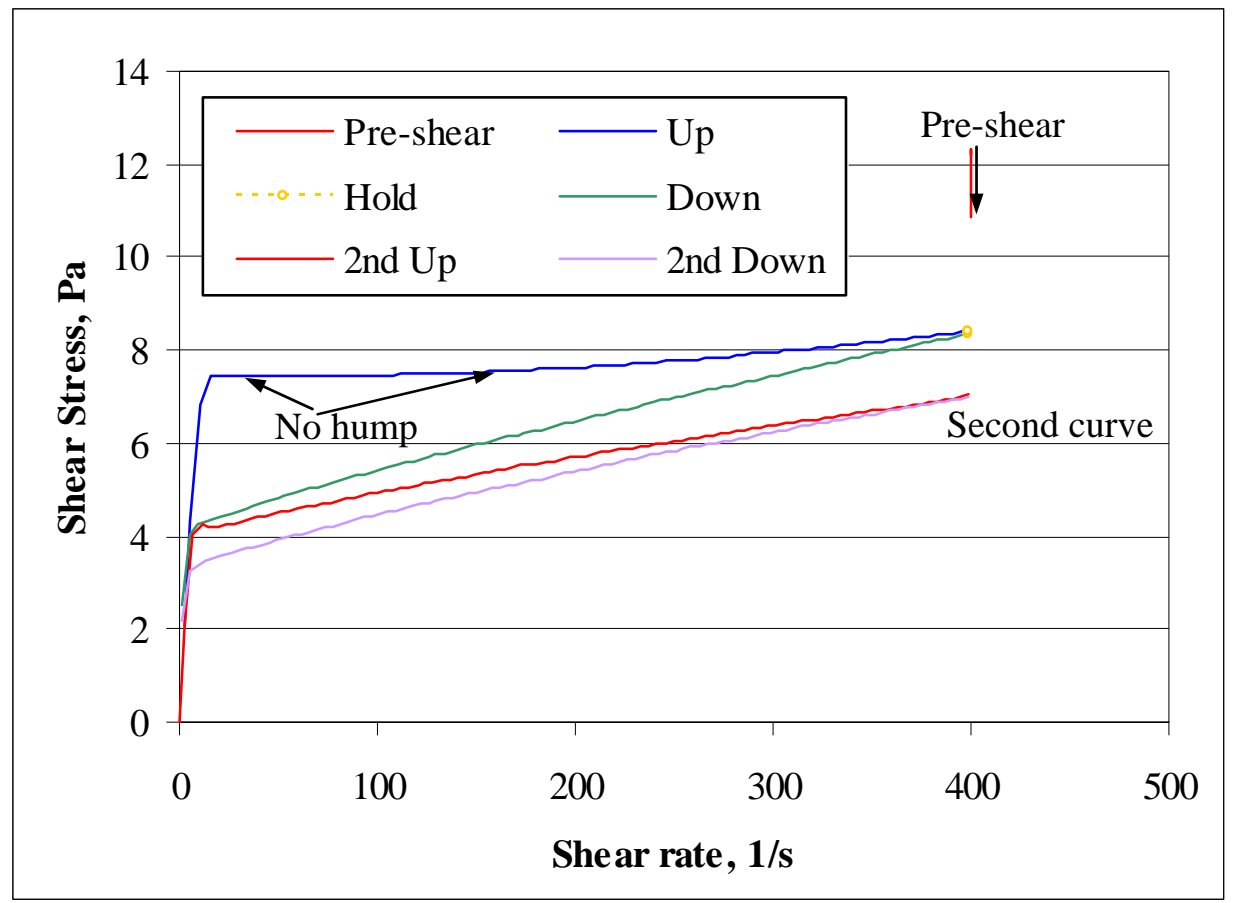

The shear stress fell during the pre-shear (arrow), indicating that the sample had time dependence in the form of thixotropy. The effect of pre-shearing the sample was to reduce the height of the hump on the conventional flow curve up ramp that followed. The rest of the measurement was "fast", $100 \mathrm{~s}$ for the up ramp, $2 \mathrm{~s}$ for the hold, and $100 \mathrm{~s}$ for the down ramp. The 75 second pre-shear was insufficient to put the sample at the equilibrium flow curve location. The sample was then ramped up a second time over $100 \mathrm{~s}$, and then ramped down again over $100 \mathrm{~s}$. Variations between successive ramp segments seemed to be diminishing as also seen in Figure 9.

A large aliquot of SB2 CETL sludge simulant was taken and put into a shear-mixer for about 30 minutes. Microtrac particle size analysis indicated about a $35 \%$ reduction in the volume mean particle diameter following shear mixing. The sample was then given a controlled rate flow curve measurement. The baseline and shear-mixed samples were measured with the Z41 bob, using five minute ramps and a one minute hold. 
Figure 12. Impact of Shear-mixing CETL SB2 Sludge Simulant

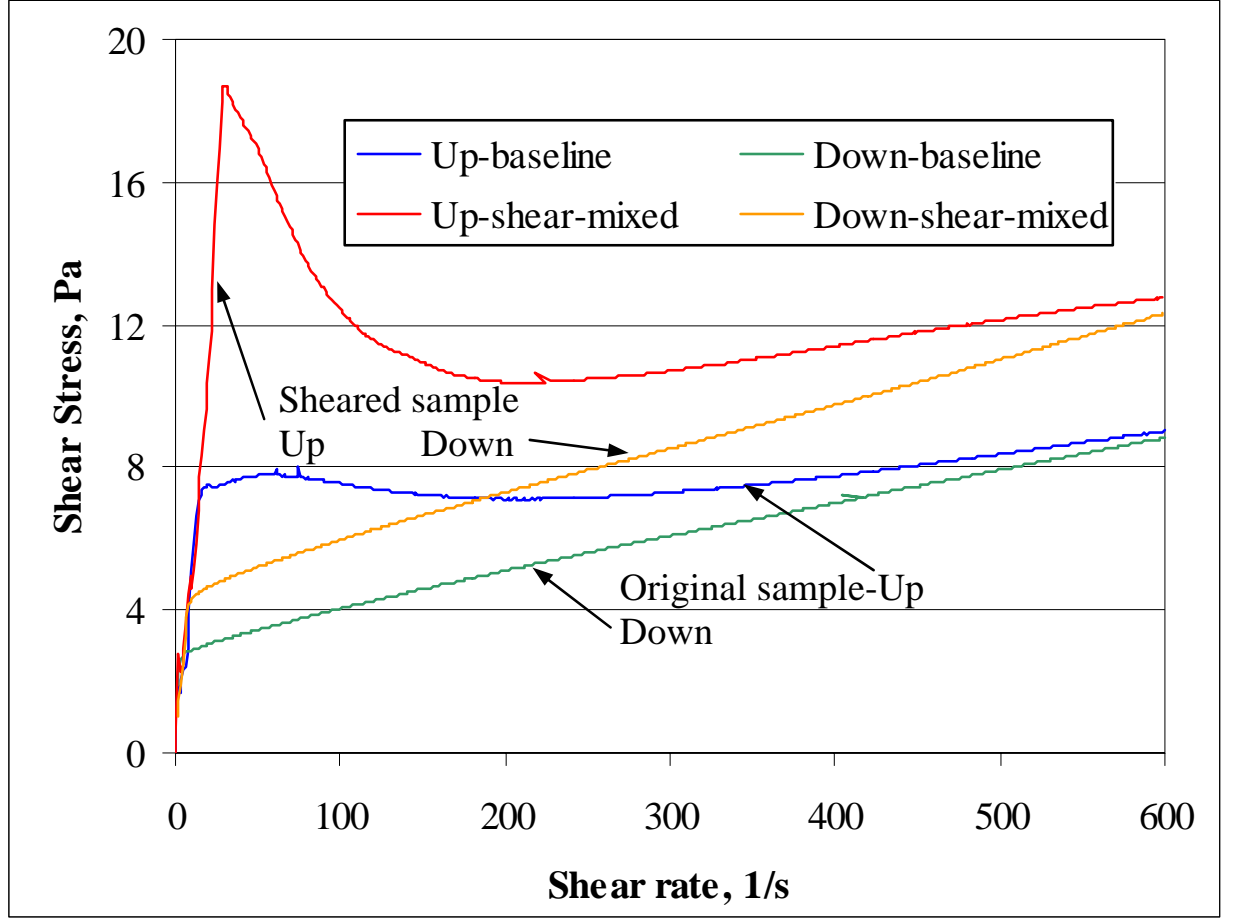

The impact of external shear-mixing was to permanently and significantly increase the apparent viscosity of the sample. This is consistent with literature statements concerning particle size impact on rheology. Shear mixing was not effective in eliminating the hump in the up flow curve. The sample still showed a tendency to be thixotropic (thinning with time).

There were some reproducibility issues with the hump. Measurements made at different times are illustrated in Figure 13. 
Figure 13. Variations in the hump from different measurements

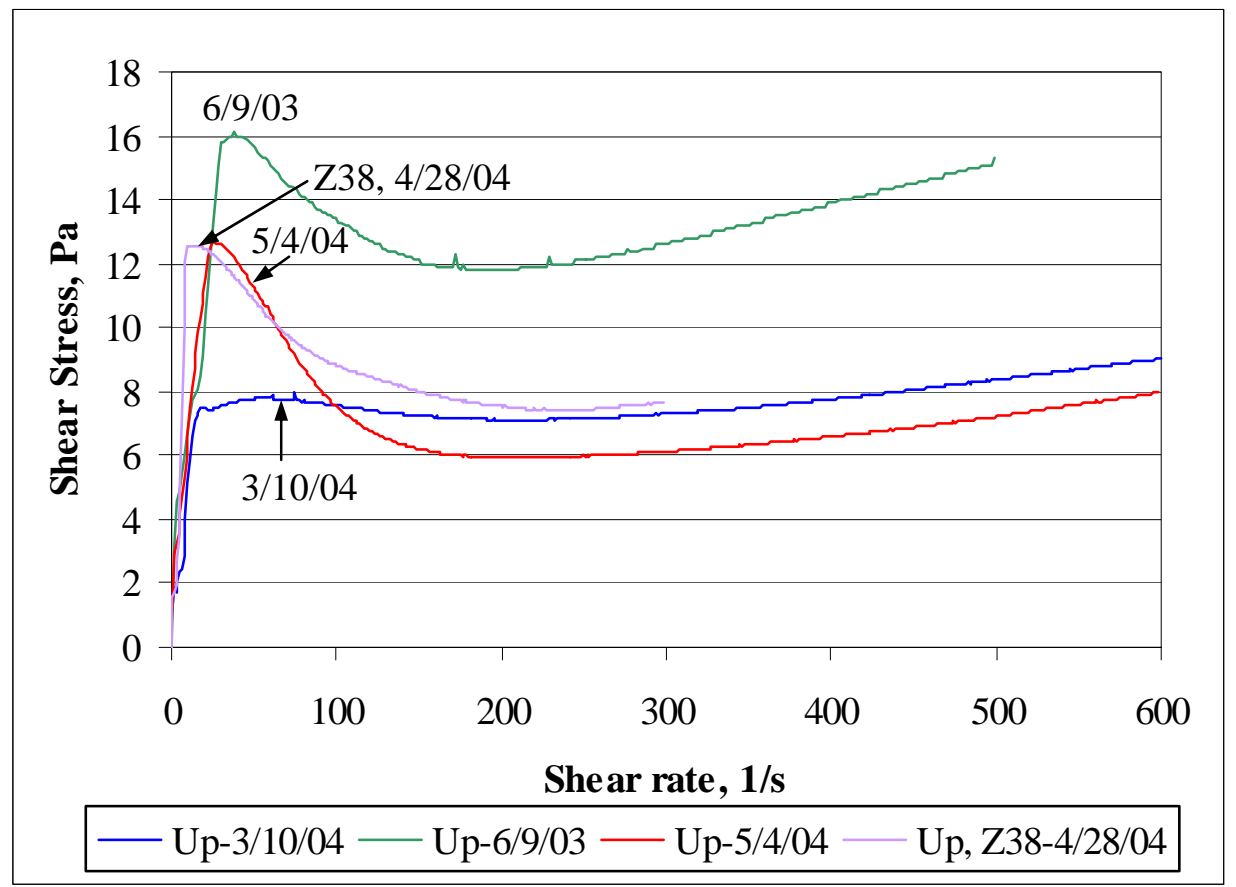

All but one flow curve was obtained using the Z41 bob. This was obtained by the Z38 bob, as indicated in the figure. The 6/9/03 sample had a generally thicker flow curve than the 2004 curves. The 3/10/04 flow curve had a generally lower hump for some reason. The variations indicate that equilibrium flow curve properties are not being measured. The shear stress at the top of the hump is presumably being controlled by rheometer performance, sample handling, etc. rather than by the true nature of the slurry. This is an indication that the hump stress data are not a reliable indication of the fluid properties.

\subsubsection{Controlled Shear Stress Measurements}

SB2 CETL sludge was tested using several of the new methods developed. The first of these was the controlled shear stress flow curve, Figure 14. 
Figure 14. Controlled Stress Compared to Controlled Rate (Hump)

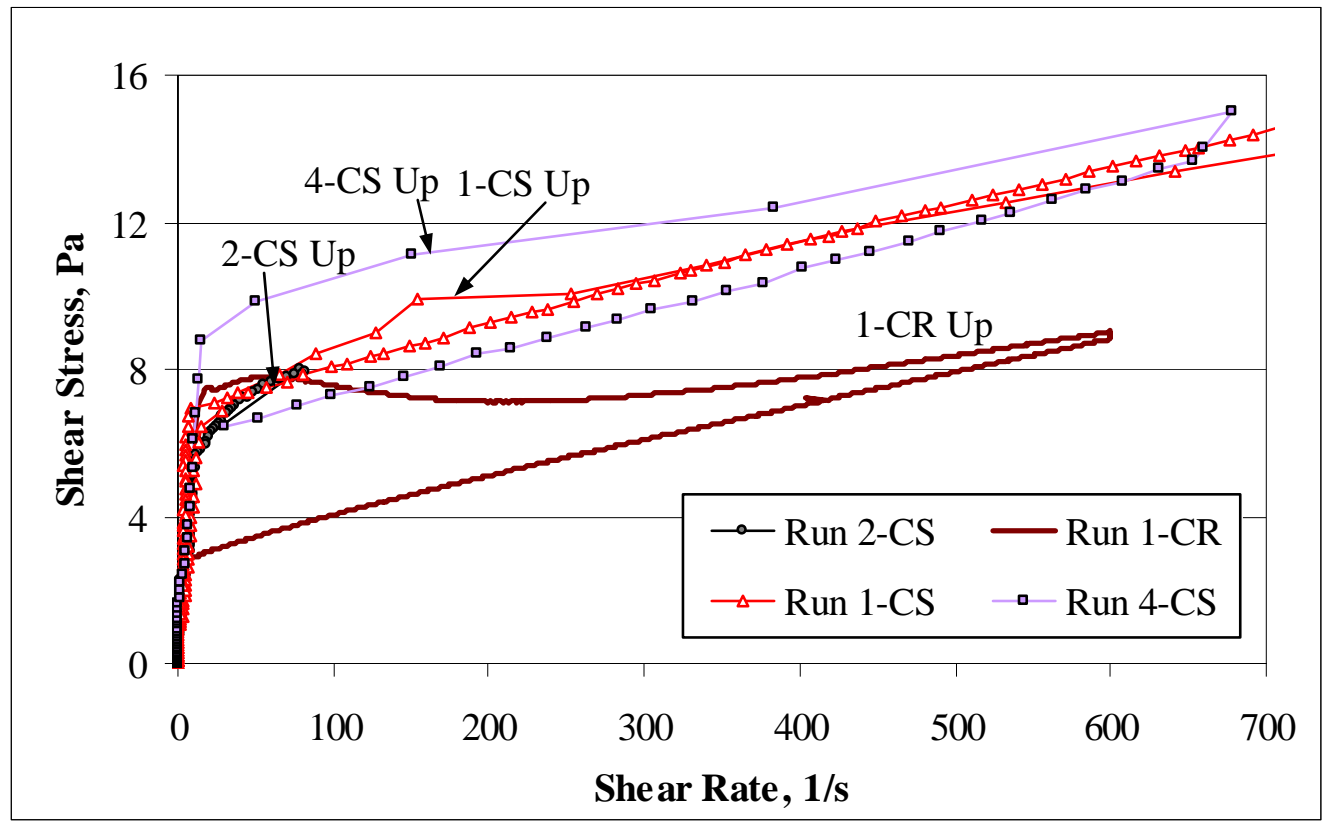

Variations within the set of three controlled stress ramps may be due to the variations in the maximum stress specified for the ramp, Table 3. These measurements included both an up and a down ramp, but no hold period. Down ramps were $100 \mathrm{~s}$ for runs 1 and 2, and $30 \mathrm{~s}$ for run 4 . These were much shorter than used in the controlled rate flow curve.

Table 3. Stress Range for SB2 CETL Sludge Controlled Stress Flow Curve

\begin{tabular}{|l|c|c|c|c|}
\hline & Time at Gap & Initial Stress, Pa & Final Stress, Pa & Time to 10/s \\
\hline Run 1 & Brief & 0.03 & 30 & $218 \mathrm{~s}$ \\
\hline Run 2 & Brief & 0.05 & 8 & $268 \mathrm{~s}$ \\
\hline Run 4 & 10 minutes & 0.01 & 15 & $263 \mathrm{~s}$ \\
\hline
\end{tabular}

None of the three controlled stress ramp flow curves duplicated the hump in the controlled rate flow curve nor should they have. The controlled rate flow curve with hump includes a period of falling shear stress with increasing shear rate. The controlled stress ramp has a continuously increasing shear stress by definition. More separation between the up and down ramps would probably have been observed if the measurements had included a hold period and if the times allotted for the down ramp segments had been closer to 300 seconds.

Various supporting measurements using controlled shear rates, however, indicated that the shear stress at the top of the hump was very sensitive to the measurement conditions. The main contribution that the controlled stress measurement brings to this sample is that significant time dependent properties are still indicated. The strain data for the above controlled stress flow curves are given in Figure 15. 
Figure 15. Strain-Stress Plot of SB2 CETL Sludge Flow Curves

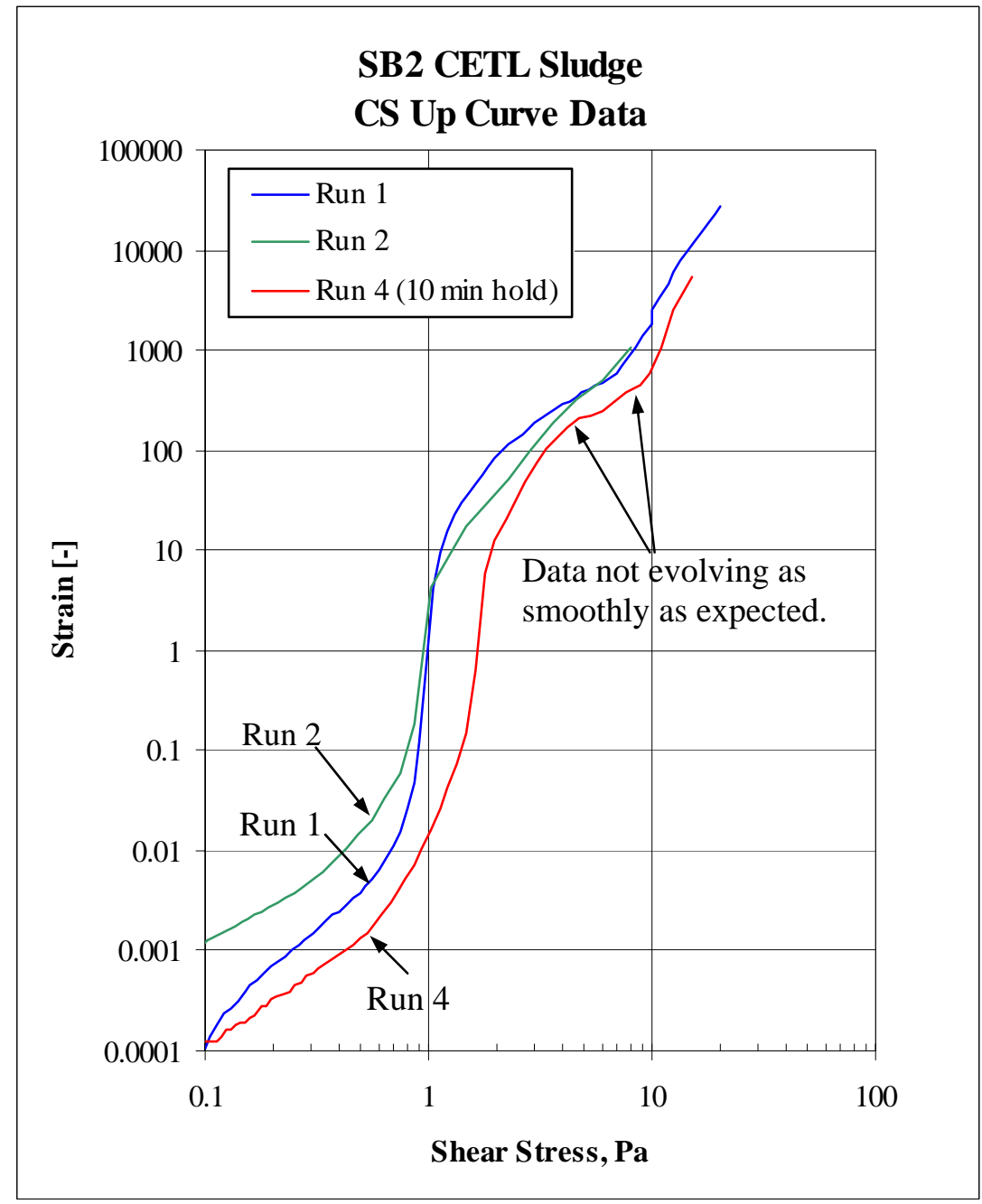

The data in the range of 4-10 Pa (hump in the controlled rate data) are more meandering than was typically observed, especially in the Run 4 measurement.

\subsubsection{Constant Shear Rate Time Curve Measurement}

The SB2 CETL sludge simulant, along with three other sludge simulants, was subjected to a constant shear rate time curve measurement. The "relative viscosity" in Figure 16 is the ratio of the apparent viscosity of the sample to the average of the apparent viscosities over the duration of the constant shear rate period. (The apparent viscosity is defined as the shear stress divided by the shear rate.) These data were all taken using the Z41 bob. Hold times were short, since the sample would be fully yielded during the constant shear rate period. All four samples were sheared at a shear rate of 200/s for 15 minutes. There were brief up ramps (5 s) and down ramps (30 s) prior to and following the 15 minute periods at constant shear. That transitional shear rate data were left off of the plot. 
Figure 16. Comparison of the Time Dependence of Four Sludge Simulants

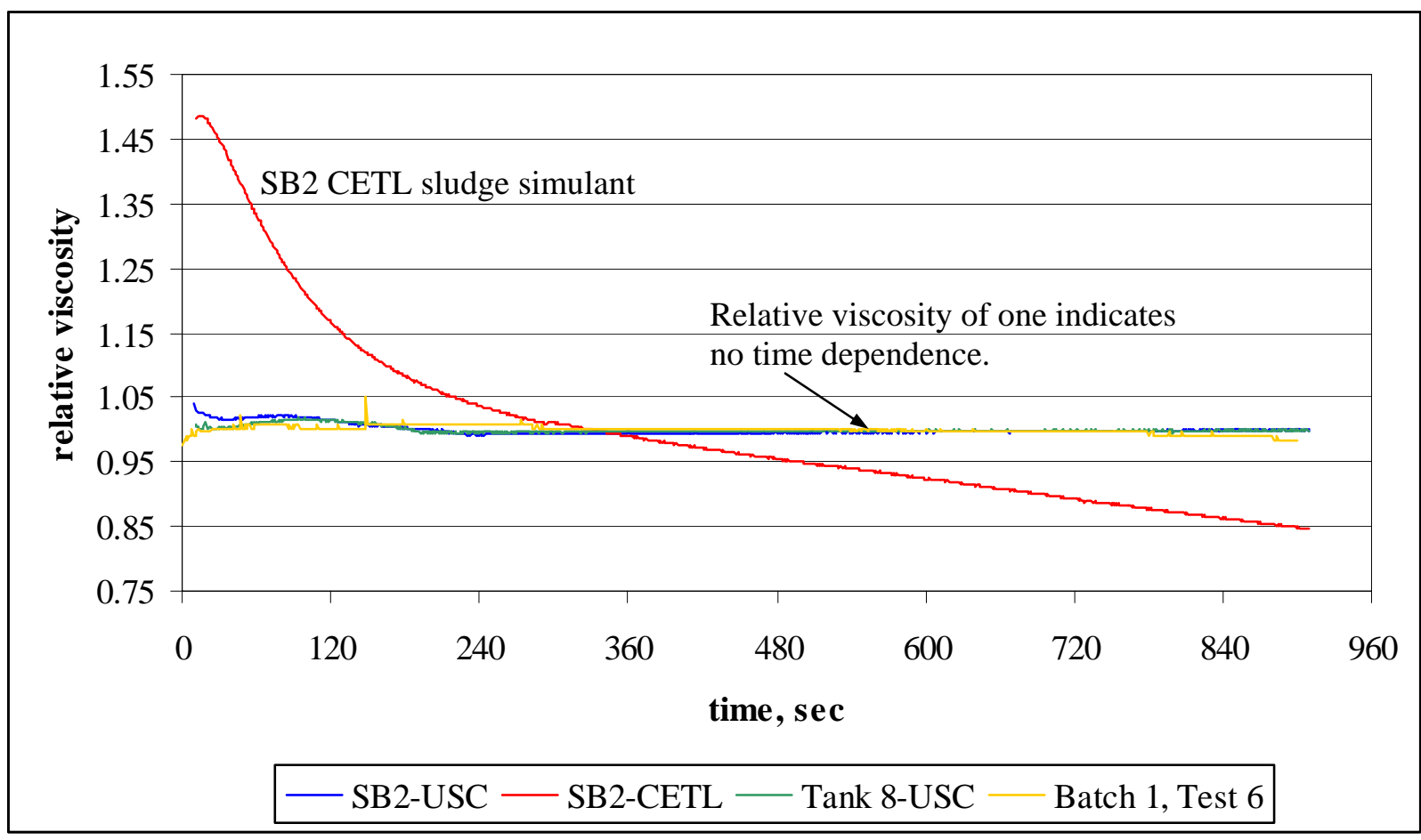

The dominant feature of Figure 16 is the relatively strong time dependence of the SB2 CETL sludge simulant data. The apparent viscosity fell by about $42 \%$ over fifteen minutes. The other three simulants appear completely time independent in comparison to SB2 from CETL. There are some effects, however, at short times that were somewhat different for each sample. The average apparent viscosities, $\tau / \dot{\gamma}$, of these four samples at $\dot{\gamma}=200 /$ s are given in Table 4 .

Table 4. Average Apparent Viscosity at 200/s Shear Rate of Four Sludge Simulants

\begin{tabular}{|l|c|}
\hline Sample & Average Apparent Viscosity \\
\hline SB2-CETL & $33.25 \mathrm{cP}$ \\
\hline SB2-USC & $25.85 \mathrm{cP}$ \\
\hline Tank 8-USC & $19.15 \mathrm{cP}$ \\
\hline Batch 1, Test 6 (Optima) & $158.6 \mathrm{cP}$ \\
\hline
\end{tabular}

The primary conclusion from the constant shear rate rheology data is that the CETL SB2 simulant has significant time dependence in its rheological properties compared with other sludge simulants. Past data do not indicate that real radioactive waste sludge has this time dependence.

CETL SB2 simulant, however, has an unusual history. The first attempt to make SB3 simulant at CETL did not produce the expected composition of $\mathrm{Mn}, \mathrm{Ni}, \mathrm{Fe}$, and $\mathrm{Ca}$ at the end of the first phase. A decision was made to convert this into SB2 simulant instead of abandoning it. Additional nickel nitrate was added and then precipitated onto the Mn-Ni-Fe matrix and any calcium carbonate present. This was an atypical step. The simulant preparation continued from that point in the normal manner. The final product was more dilute than desired. It was later decanted to lower the water content, and some sodium nitrite and nitrate were added in to offset the amounts of those two species lost in decanting. This step did not produce the anticipated results, however. Because there were no large 
demands for this simulant, the remaining soluble species lost during decanting were not replaced. There may be some aspect of this unique history that altered the rheological properties.

\subsubsection{Oscillation Stress Sweeps}

Oscillation stress sweep measurements were made on SB2 CETL simulant at $1 \mathrm{~Hz}$. There were no obvious issues with SB2 CETL sludge when run by this test, Figure 17. The controlled stress (CS) flow curve data from Run 4 in Figure 15 is included for comparison.

Figure 17. SB2 CETL Sludge by Oscillation and Controlled Stress Tests

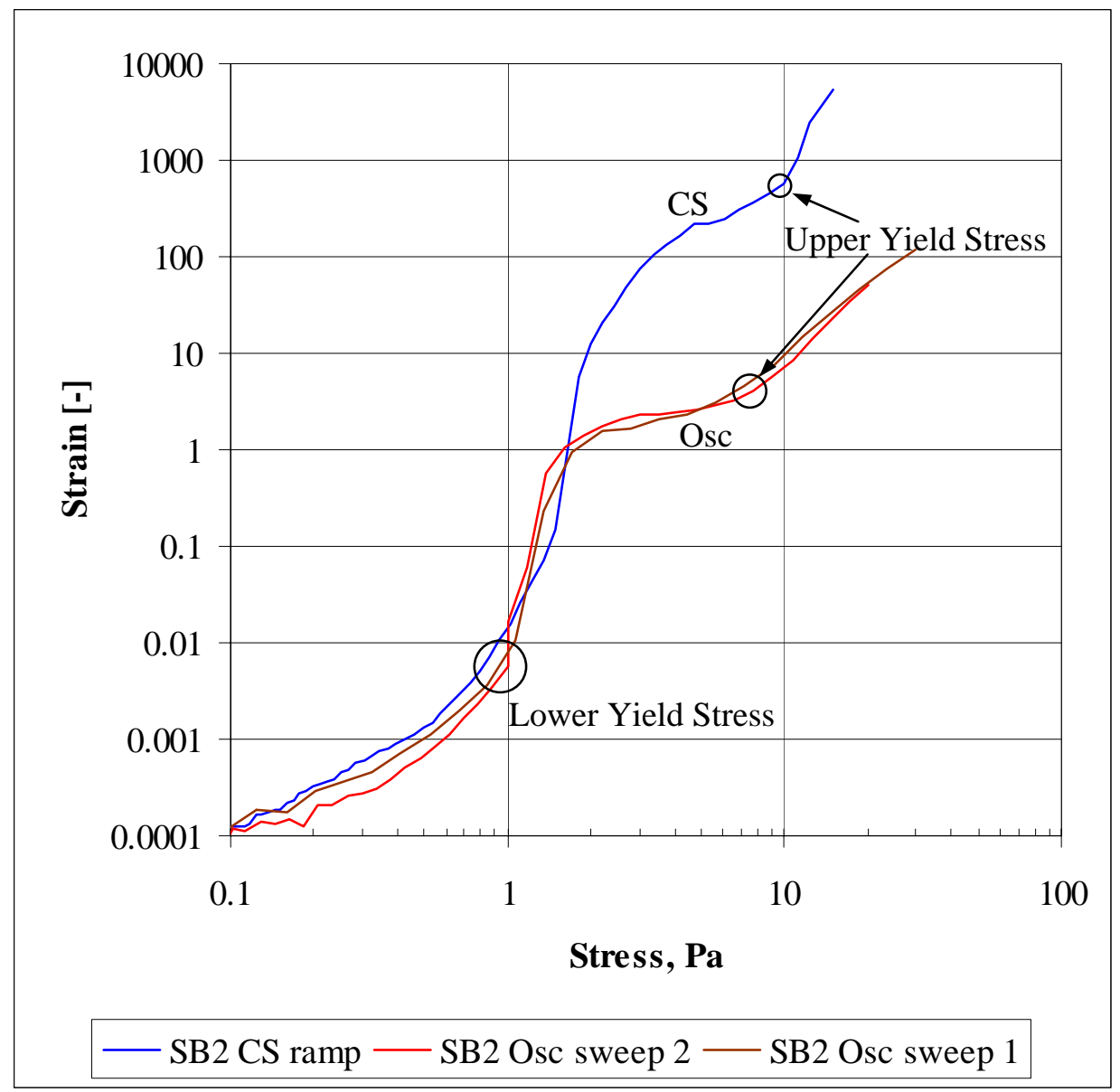

Reproducibility of the results for the two oscillation stress sweeps was good. The controlled stress ramp data was coincidentally similar in strain as well as stress up to almost $2 \mathrm{~Pa}$. This is neither expected nor required. Strain in the controlled stress ramp increases for two reasons, first because the increased stress distorts the sample more at any instant, and second because all previous stress has rotated the bob away from the initial position. The oscillation stress sweep always resets to the starting position before applying the next level of stress oscillation. A strain of 100 is a large oscillation. For perspective, the bob is rotating more than a full revolution in each direction each second. The relationship between the upper yield stress by controlled shear stress flow curves and the oscillation stress sweep was similar to that seen with normal samples (oscillation sweep value typically lower). 


\subsubsection{Oscillation Frequency Sweep}

SB2 CETL sludge (hump) was given the oscillation frequency test at a stress of $0.1 \mathrm{~Pa}$. The true yield stress was in the vicinity of $1 \mathrm{~Pa}$, Figure 17, so the test was below the true yield stress. It showed G' $>$ G” as expected for a sample in a solid-like state.

Figure 18. SB2 CETL Sludge Oscillation Frequency Sweep at $0.1 \mathrm{~Pa}$

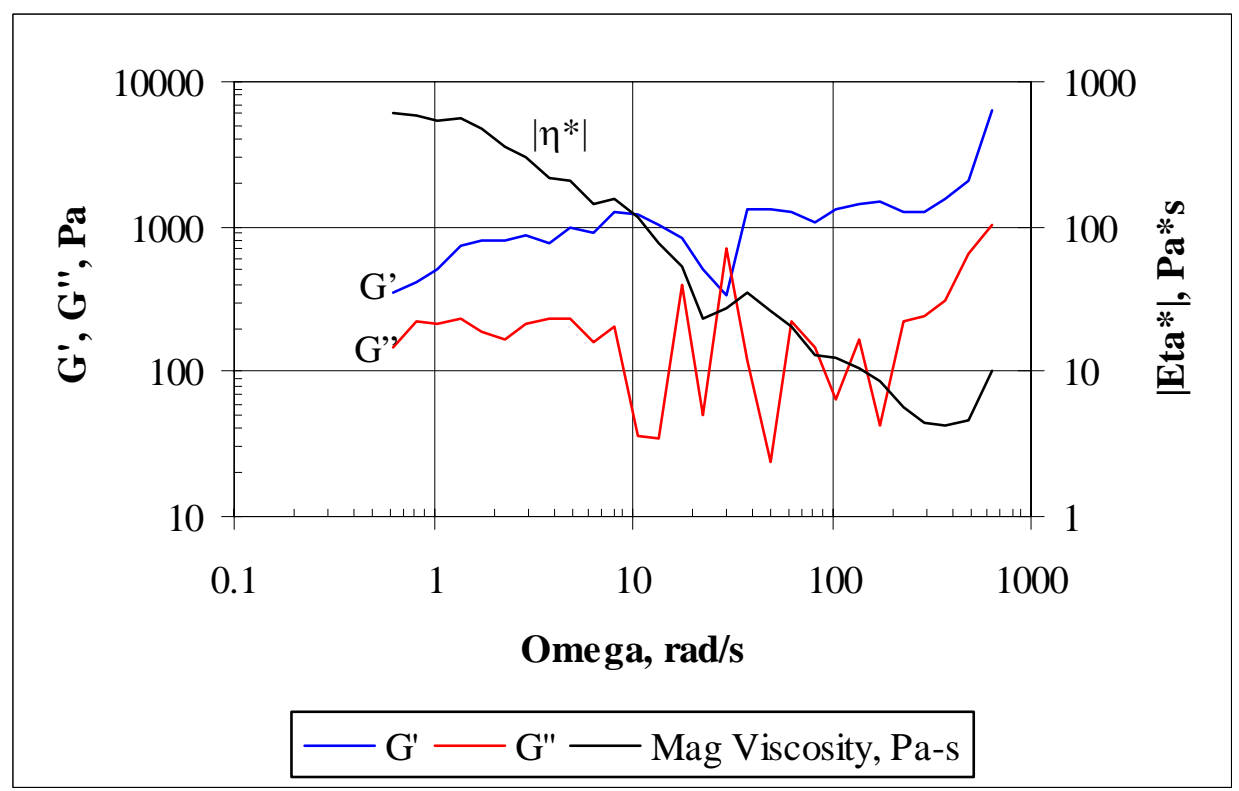

Several measurements were made at $0.5 \mathrm{~Pa}$. The two moduli were comparable in magnitude with G' $>$ G” most of the time in two tests, and with G” > G' most of the time in one test. This was a sign that the true yield stress was very close to the stress setting. The main purpose of the oscillation frequency sweep was to confirm that $1 \mathrm{~Hz}(2 \pi \mathrm{rad} / \mathrm{s})$ was suitable for the oscillation stress sweep.

\subsubsection{Oscillation time sweep}

SB2 CETL sludge (hump) was tested at four oscillatory stresses and $1 \mathrm{~Hz}$. These are given in Figure 19 through Figure 22. Measurements were made with the Z41 bobs. An instrument malfunction aborted the 6 Pa test. The other three tests had 10 minute durations. The true yield stress was about 1 $\mathrm{Pa}$, and the upper (Bingham-like) yield stress was 3.5-10 Pa based on the other tests. 
Figure 19. 0.1 Pa Oscillation Time Sweep of SB2 CETL Sludge at $1 \mathrm{~Hz}$.

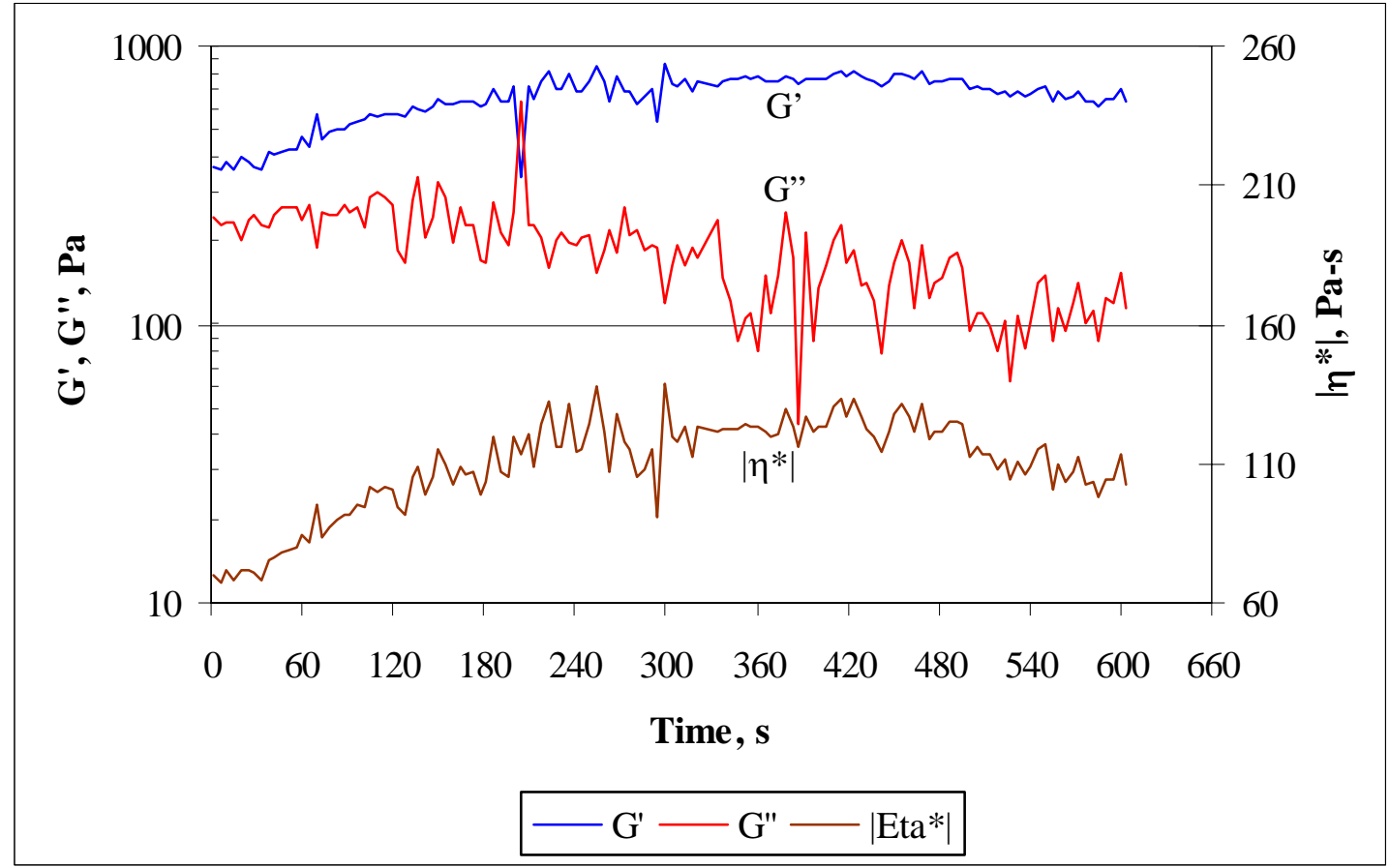

Figure 20. 1.5 Pa Oscillation Time Sweep of SB2 CETL Sludge at $1 \mathrm{~Hz}$.

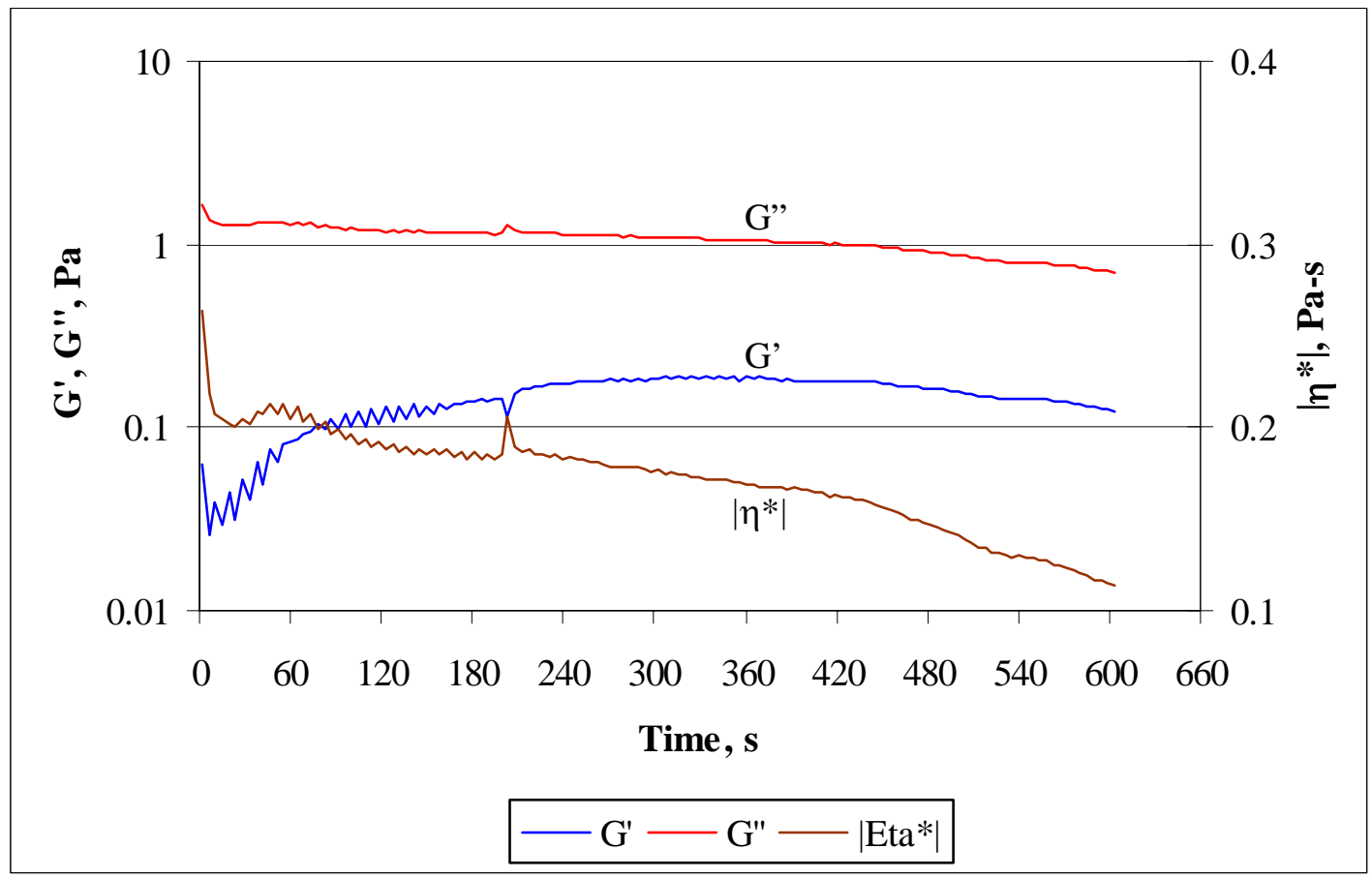


Figure 21. 6 Pa Oscillation Time Sweep of SB2 CETL Sludge at 1 Hz.

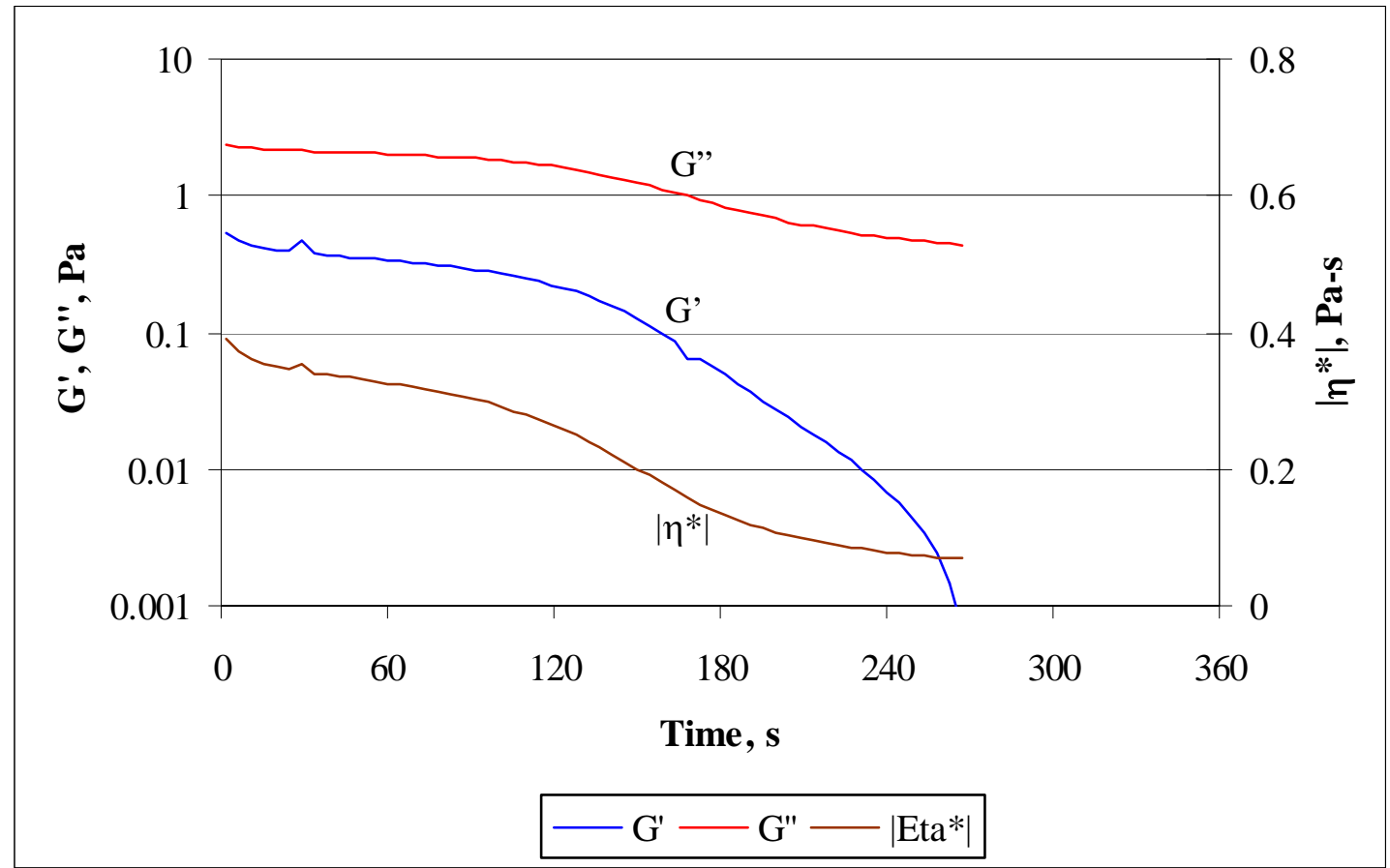

Figure 22. 15 Pa Oscillation Time Sweep of SB2 CETL Sludge at $1 \mathrm{~Hz}$.

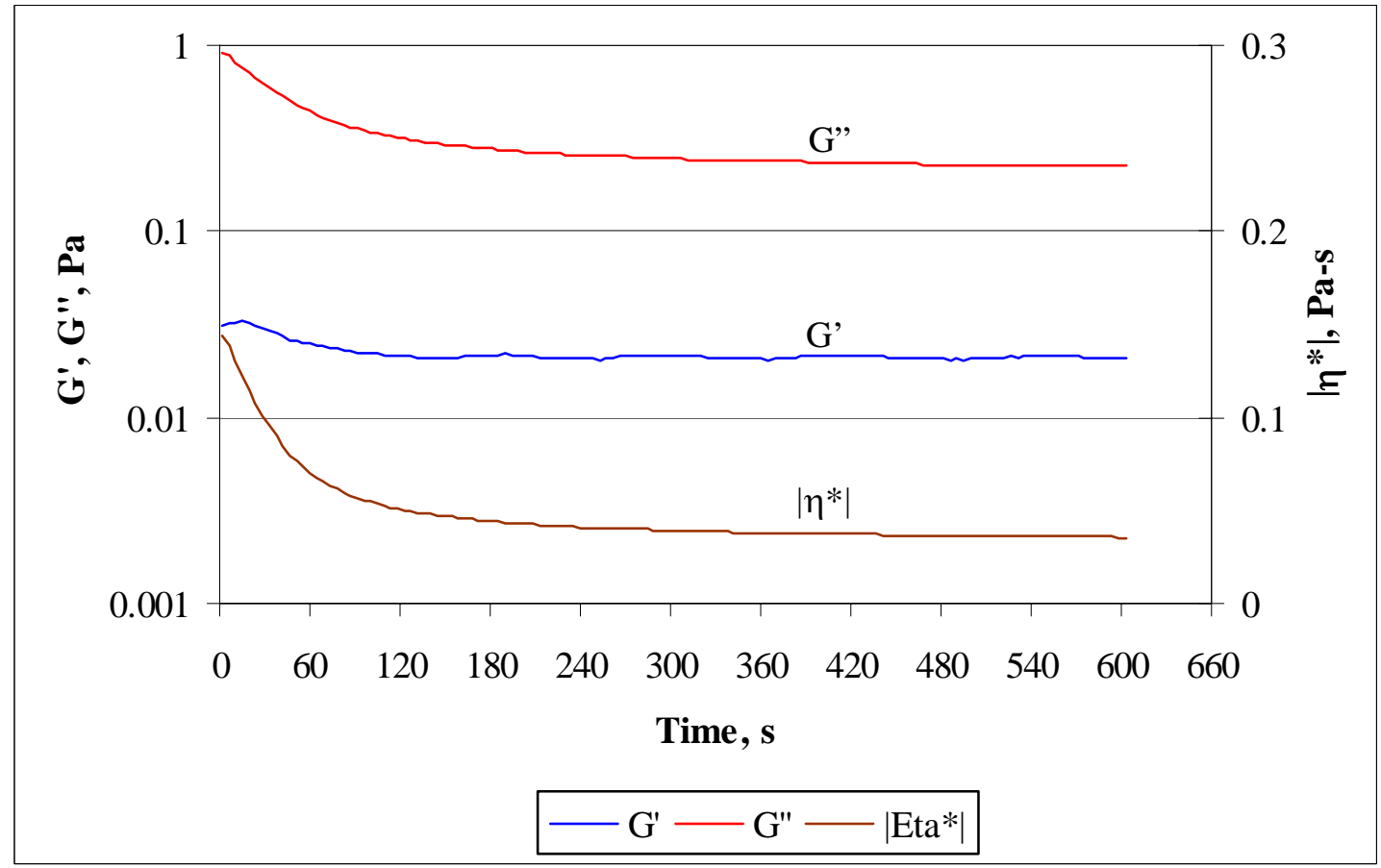

The $0.1 \mathrm{~Pa}$ measurement was expected to be below the true yield stress. Figure 19 indicates that G' > G” for the entire ten minutes. $\delta \approx 10^{\circ}$. These are consistent with the sample being below the true yield stress. $\left|\eta^{*}\right|$ increased for about three minutes, seemed to stabilize, and then appeared to fall 
slightly. The data was the noisiest of the four sets. This was presumably due to the oscillation deformation amplitude being the smallest (most difficult to measure).

The 1.5 Pa measurement was not noisy. G” > G' for the entire test. The sample was confirmed to be above the true yield stress by this measure. $|\eta *|$ fell during most of the test. The sample acted in a thixotropic manner by thinning with time under shear. The aborted $6 \mathrm{~Pa}$ measurement was similar to the 1.5 measurement except that G' was even lower. It is possible that a loss of the G' element caused this test to abort.

The $15 \mathrm{~Pa}$ measurement was above both the true and the Bingham plastic yield stresses by other methods. This was confirmed by the values of G', G”, and $\delta$. The sample thinned rapidly for about three minutes, and then continued thinning very slowly for the last seven minutes. This generally indicates some thixotropy.

The data from these tests and the constant shear rate time curve can be compared in a summary table, Table 5. The measure of thixotropy selected for this table was the ratio of the viscosity at the end of the test relative to the viscosity after two minutes into the test, $\eta_{10} / \eta_{2}$. The magnitude of the complex viscosity was used for the ratios from the oscillation tests. The apparent viscosity, $\eta$, was used for the rotational test. A neutral time dependence denotes a situation between mildly rheopectic and mildly thixotropic. Typical viscosities are provided to give an order of magnitude for the viscosity in each of the test regions. The “state” column is based on G' versus G” data at $1 \mathrm{~Hz}$.

Table 5. Time Dependent Nature of SB2 CETL Sludge

\begin{tabular}{|l|c|c|c|c|}
\hline Test & State & Typical $\left|\eta^{*}\right|, \eta$ & $\eta_{10} / \eta_{2}$ & Time dependence \\
\hline 0.1 Pa Oscillation & Solid-like & $110,000 \mathrm{cP}$ & 1.02 & Neutral \\
\hline $1.5 \mathrm{~Pa}$ Oscillation & Between yield stresses & $164 \mathrm{cP}$ & 0.60 & Thixotropic \\
\hline $15 \mathrm{~Pa}$ Oscillation & Liquid-like & $36 \mathrm{cP}$ & 0.69 & Thixotropic \\
\hline 200/s Rotational & Liquid-like & $34 \mathrm{cP}$ & 0.80 & Thixotropic \\
\hline
\end{tabular}

Rotational and oscillation data in the liquid-like region were consistent in identifying SB2 sludge simulant as significantly thixotropic. The $15 \mathrm{~Pa}$ oscillation sweep indicates even more thixotropy than the constant shear rate time curve, Figure 16. Thixotropy was also indicated in the controlled shear rate flow curve measurement, but it was harder to quantify because of the hump. Such severe time dependence indicates that this sample is not a good candidate for fitting by the Bingham plastic fluid model.

The entire rheological data set indicates that the SB2 CETL sludge has a true yield stress slightly less than $1 \mathrm{~Pa}$. A more complete transition to fluidity exists around 2-3 Pa based on repeated flow curve measurements. This would be the Bingham plastic transition yield stress transition after long times under shear. This is not a particularly meaningful quantity for start-up design calculations, however, since the fluid must already be yielded before obtaining it. It could be used to model steady pipeline flow or other phenomena where the flow field is already established.

The time testing data indicate that the sludge is significantly thixotropic, not rheopectic. This is confirmed by the flow curve measurements with up ramps above down ramps on the flow curve graphs. The extent of the thixotropy is considerable. Thixotropy is a form of time dependent behavior. The hump, as explained best by comparison to the material in Hunter, section 1.3.1, is also a form of time dependent behavior. The bulk of the data indicate that the time dependent behavior is inherent to the sludge sample itself, and is not an artifact of the rheometer measurements. 


\subsection{SB2/3 SME product, Run \#6, 155\% Acid}

This sample was expected to show significant signs of rheopectic-like behavior when given the traditional controlled shear rate flow curve measurement. This expectation was based on flow curves obtained on the various SME products generated during various programs in the prior 6-9 months.

\subsubsection{Controlled Shear Rate Flow Curves}

A sample of SB2/3 SME product from Run \#6 at 155\% acid stoichiometry was tested with the Z38 bob using five minute ramps with a one minute hold. Z38 bobs are typically used with SME products to give a good ratio of annular gap to mean frit size. Fairly large separation was expected between the up and down flow curves based on rheological measurements on similar SME products produced for the melt rate program. The maximum shear rate was 300/s. Figure 23 compares the up and down ramp segments of the flow curve. The 300/s \#2 measurement immediately followed the initial measurement. It was made on the same sample without removing it from the rheometer.

Figure 23. SB2/3 SME Product: Effect of Repeated Ramps

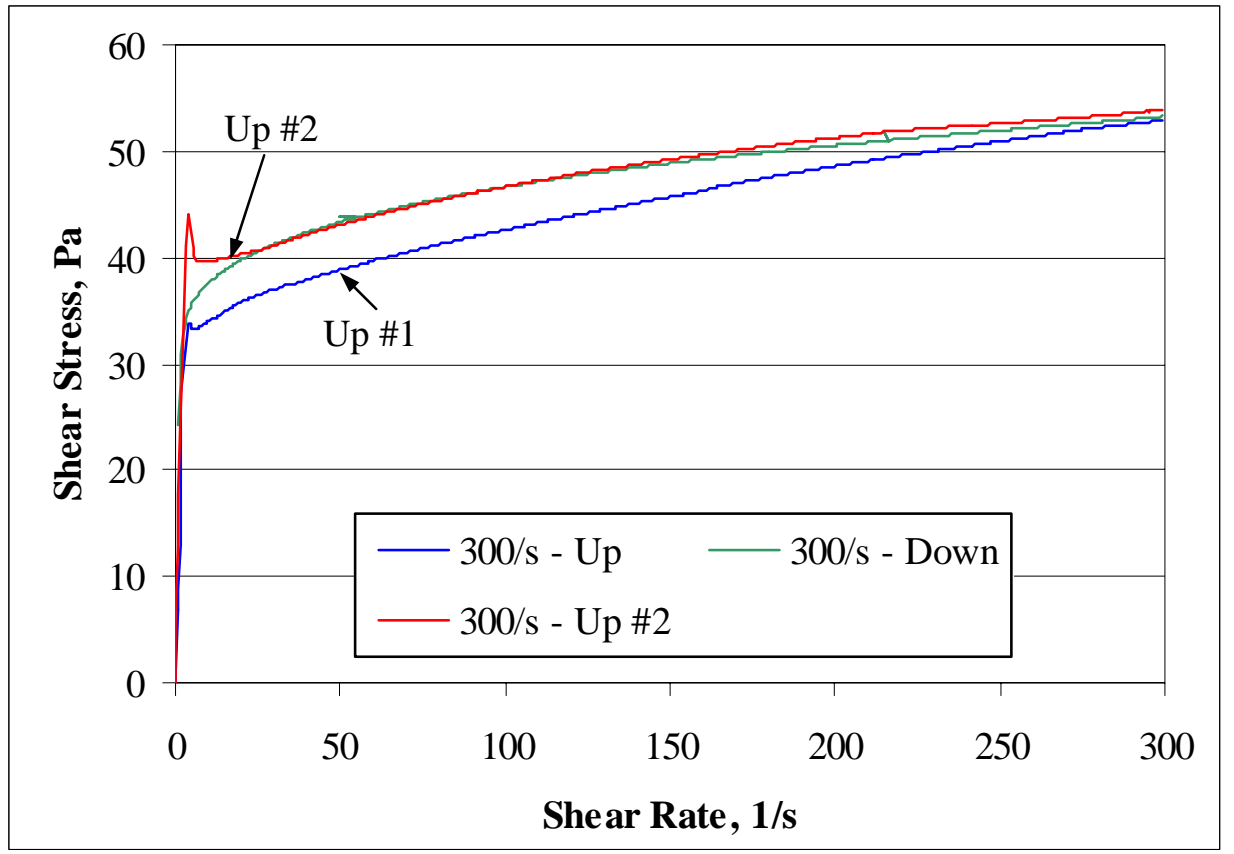

The simplest interpretation of a down ramp segment above an earlier up ramp segment is rheopectic behavior. The first down ramp flow curve was above (thicker than) the earlier up ramp flow curve in Figure 23. The second up ramp segment fell along the down ramp segment from the first flow curve. This suggests that the sample was already approaching its equilibrium flow curve on the initial down ramp.

A more dramatic degree of rheopexy was expected, however. Compare Figure 23 to Figure 24. This suggests that sample aging effects, e.g. slow dissolutions or crystal growth, might be changing the rheological properties on a time scale of days to weeks. The samples used in this program were weeks to months old. These hypothesized changes were removing the rheopectic tendencies. Figure 24 contains historical data for a similar SME product (155\% stoichiometry) made from SB2/3 starting 
simulant. In this measurement, the maximum shear rate was pushed to nearly 1000/s compared to 300/s above. Data were obtained with the Z38 bob using five minute up and down ramps and a one minute hold in both cases.

Figure 24. Historical SB2/3 SME Product Flow Curve Data

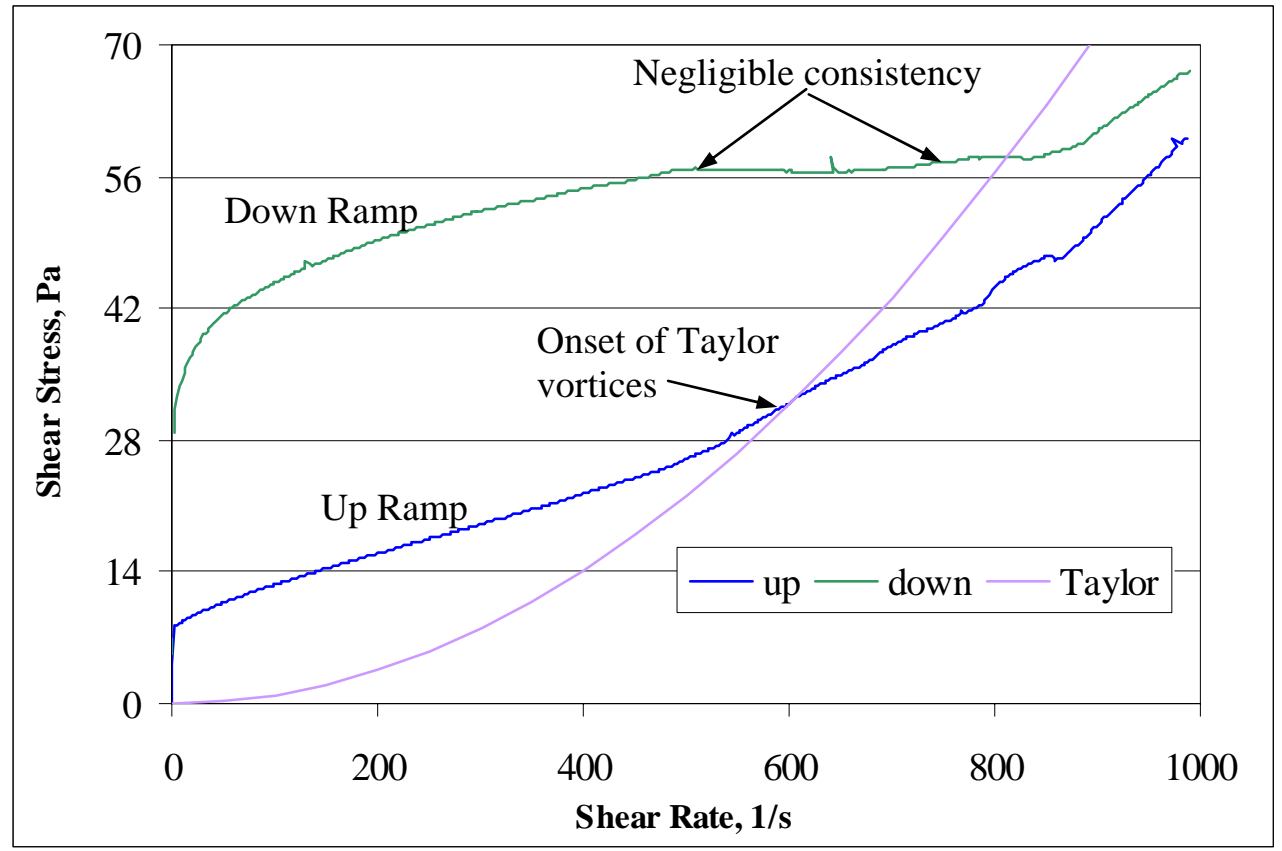

Notice that the historical sample was ramped in shear rate much faster than the sample in Figure 23. The ramp rate was 3.3 times greater because of the maximum shear rate setting of 989/s. This could indicate that the larger the shear rate range, the more the down curve will separate from the up curve.

There is another, and potentially more likely, possibility, however, that may explain the separation seen in Figure 24. The slurry went out of laminar flow and into the region of Taylor vortices during the up ramp (theoretical location of Taylor vortices indicated on graph). It was in this region during the hold. It came out of the region of Taylor vortices with negligible consistency for 700/s to 500/s. This suggests that something was happening, or had happened, to the sample itself. It is possible that the sample was no longer homogenous, e.g. that it had segregated into solid-rich and solid-poor regions, when it came out of the region of Taylor vortices. If that is the case, then the down ramp data is meaningless, and the amount of potential rheopectic behavior was not measured.

The Taylor vortex is a doughnut shaped flow loop inside the annular gap; see lower right-hand-side of Figure 25. The vortex moves material from the inner to the outer wall and back. The vortices are stacked one above the next. The number is a function of the gap width and height. There are regions near the walls, between adjacent vortices, that are relatively undisturbed. 
Figure 25. Secondary Flows (Taylor Vortices)

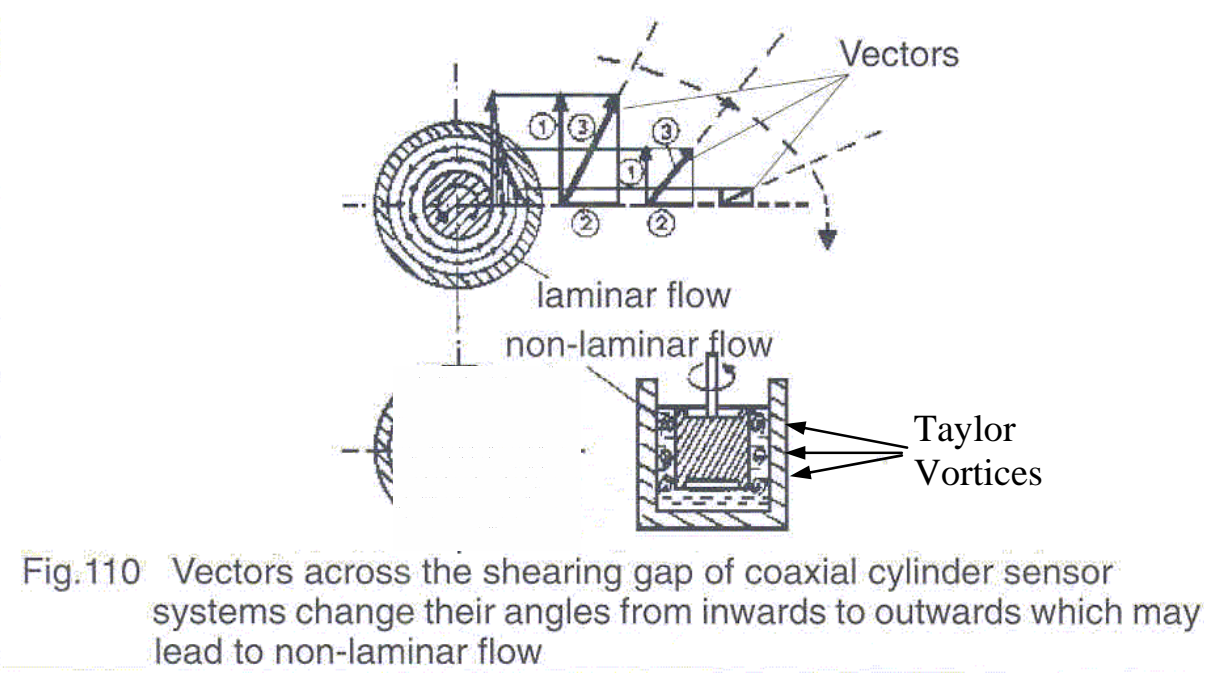

One possibility is that frit might preferentially concentrate into the regions between adjacent vortices. This is more than just a hypothesis. There was an experimental apparatus at the University of Florida in Gainesville, in the Chemical Engineering department. My recollection is that it was a large concentric cylinder system ( 3 ” $\phi$ x 16 ”) made of a clear polymer. It was filled with an oil and fine graphite powder (or some other dark compound) slurry. The particles helped show the flow field. When the Taylor vortices formed, a series of horizontal dark and light bands formed along the full height of the cylinder wall. Where the wall was dark showed the regions between the vortices, and the areas where the wall was light were the vertical centers of the vortices. The wall was dark between vortices because the solid particles clustered into the relatively more stagnant regions there. If frit acts like these particles did, then it, too, could be segregating in the presence of Taylor vortices.

Historical data for SME product rheology indicates that it becomes very sensitive to the wt. \% insoluble solids past some level. If SME product is segregated into solid-rich and solid-lean phases, then the net result is expected to be an increase in apparent viscosity. For example, if $50 \mathrm{wt}$. \% SME product separated into a 50:50 mixture of $48 \mathrm{wt}$. \% and $52 \mathrm{wt}$. \% parts (conservation of total solids), then the increase in the apparent viscosity of the $52 \%$ phase is typically much greater than the decrease of the $48 \%$ phase. The result of two such phases coexisting in the annular gap would appear to a rheometer as an increase in the apparent average viscosity relative to that of the homogeneous sample.

This hypothesis is difficult to test. There was one relevant observation during this testing, however, where the cylindrical bob seemed to have a visual texture to it following certain measurements. (The bob, after removing it from the sample cup, is generally coated with a layer of SME product slurry that is perhaps $0.5 \mathrm{~mm}$ thick.) This instance happened following a measurement that had gone into the region of Taylor vortices. Rubbing the wall of the sensor with a finger gave the impression that the texture was in the form of horizontal bands running around the cylinder. In other cases, observations of texture were not attempted, but it may have been there unseen.

A parametric test was made using SB2/3 SME product from Run 6 at 155\% acid (feed for the melt rate program). In the first test, the sample was pre-sheared at 200/s for one minute, then ramped to $300 / \mathrm{s}$ in five minutes, held for one minute, and ramped back to $0 / \mathrm{s}$ in five minutes. The results are shown in Figure 26. 
Figure 26. Pre-shear Impact on Run 6 SB2/3 SME Product

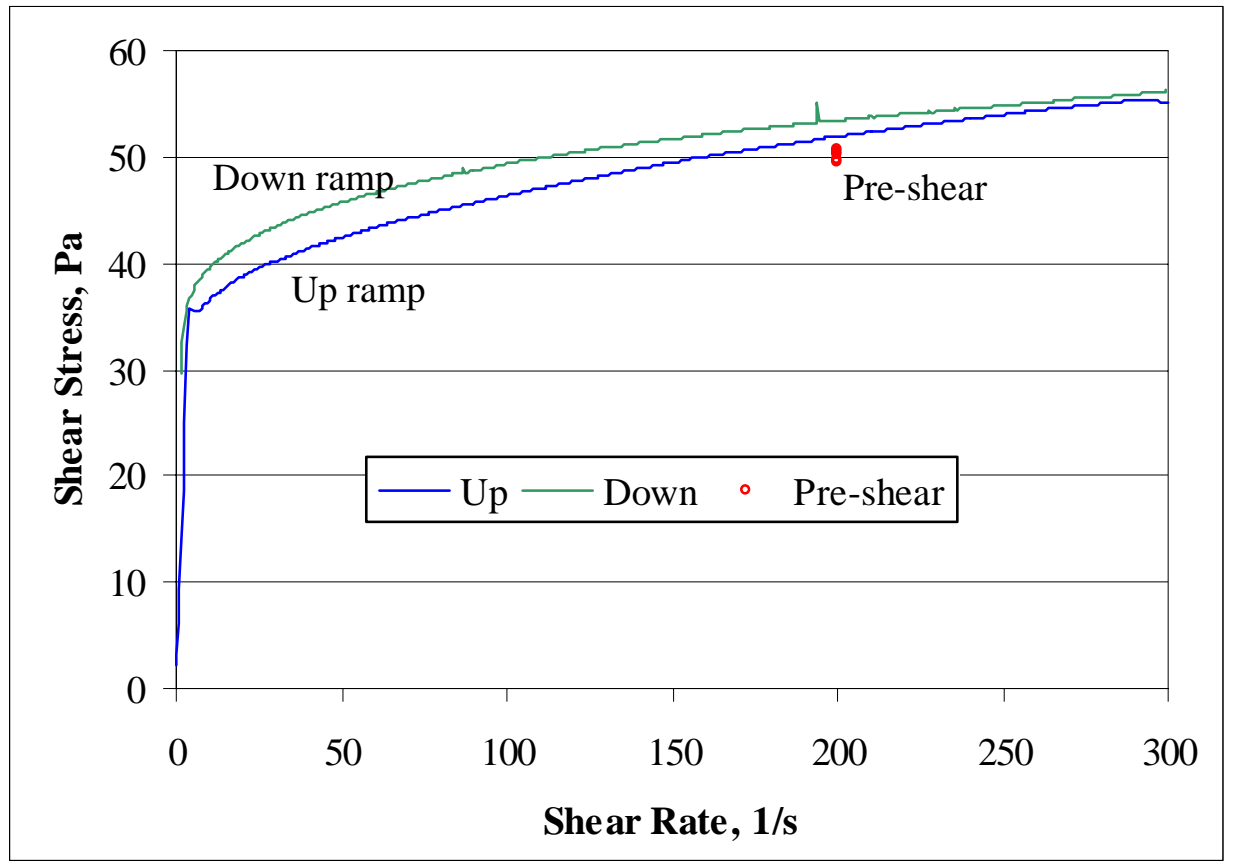

Slightly thickening was observed in the pre-shear. The up and down ramps are somewhat closer together than in Figure 23. The data do not compare in absolute value as well as desired with Figure 23 given the controls in place. Cumulative moisture loss or other sample handling issues tended to slowly shift flow curves to higher shear stresses as testing progressed.

\subsubsection{Controlled Shear Stress Flow Curve}

Figure 27 gives two sets of controlled stress flow curve data. Run 3 was a ramp to $60 \mathrm{~Pa}$, while Run 4 was a ramp to $100 \mathrm{~Pa}$. The two up ramps are essentially identical. The Run 4 down ramp is offset significantly higher relative to the up ramps and Run 3 down ramp. The two most likely causes are that Run 4 entered the region of Taylor vortices (some frit segregation) or that Run 4 went to a higher shear rate region (ramped with more acceleration). 
Figure 27. Controlled Stress Flow Curves for SB2/3 Run 6 SME Product

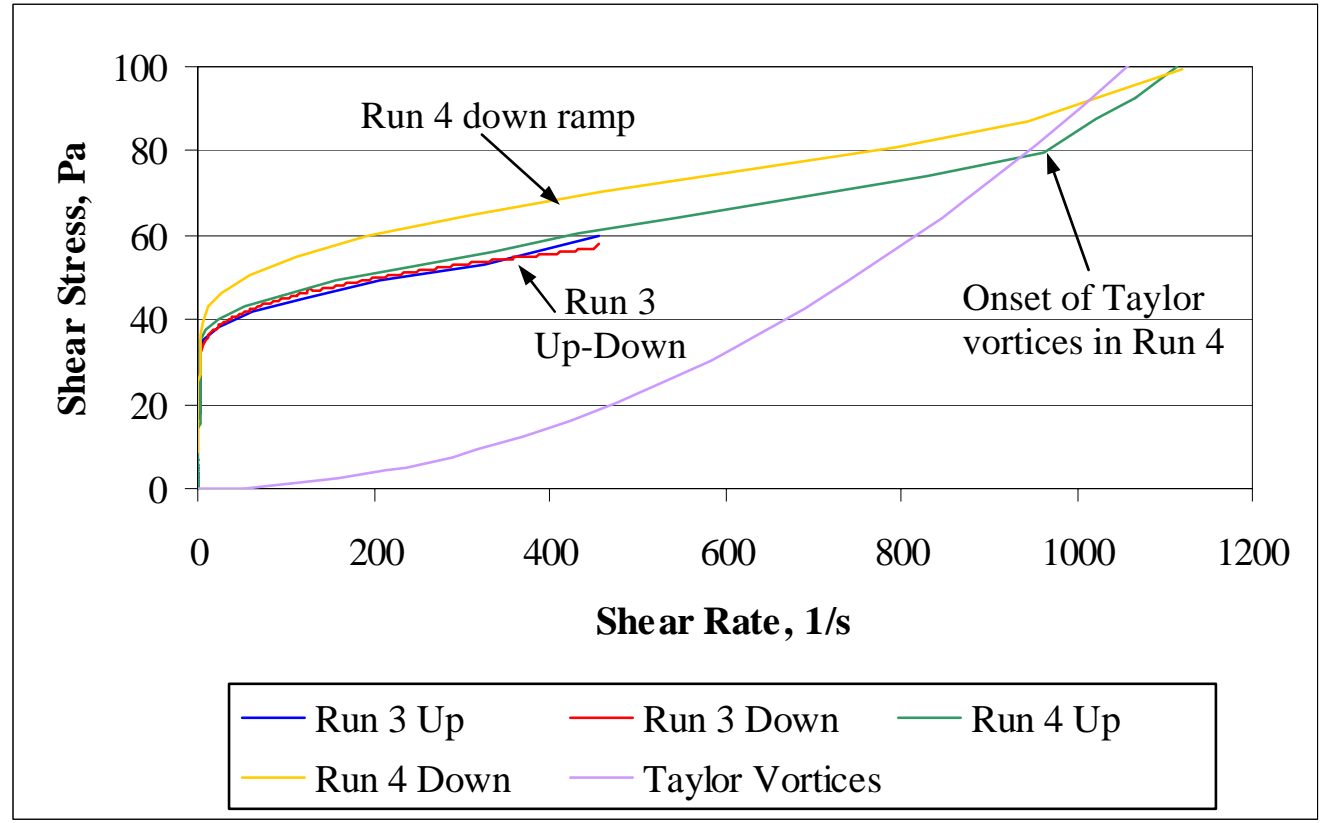

This is another example of why the region of Taylor vortices should be avoided with SME products. The small degree of rheopectic behavior in Run 3 can be attributed to the lack of a hold at the maximum shear stress and the brief duration of the down ramp segment, $100 \mathrm{~s}$. When less time was provided for the detection of time dependence, less time dependence was detected. This was true with all samples tested that exhibited any degree of time dependence.

\subsubsection{Constant Shear Rate Time Curves}

Constant shear rate time curves were generated for five simulant SME products, Figure 28. This included the SB2/3 SME product from Run 6. Relative viscosity was described in section 3.1.3. A steady value of unity indicates no time dependence. The constant shear rate time curve data were all taken using the Z38 bob. Hold times were only long enough to reach thermal equilibrium, since the sample would be fully yielded during the constant shear rate period. All five samples were sheared at a shear rate of 100/s for at least 15 minutes. There were brief up ramps (5 s) and down ramps (30 s) prior to and following the constant shear rate period. The transitional shear rate data (brief ramps) were left off of the plot. A data point was taken each second of the measurement. 
Figure 28. Comparison of the Time Dependence of Five SME Products

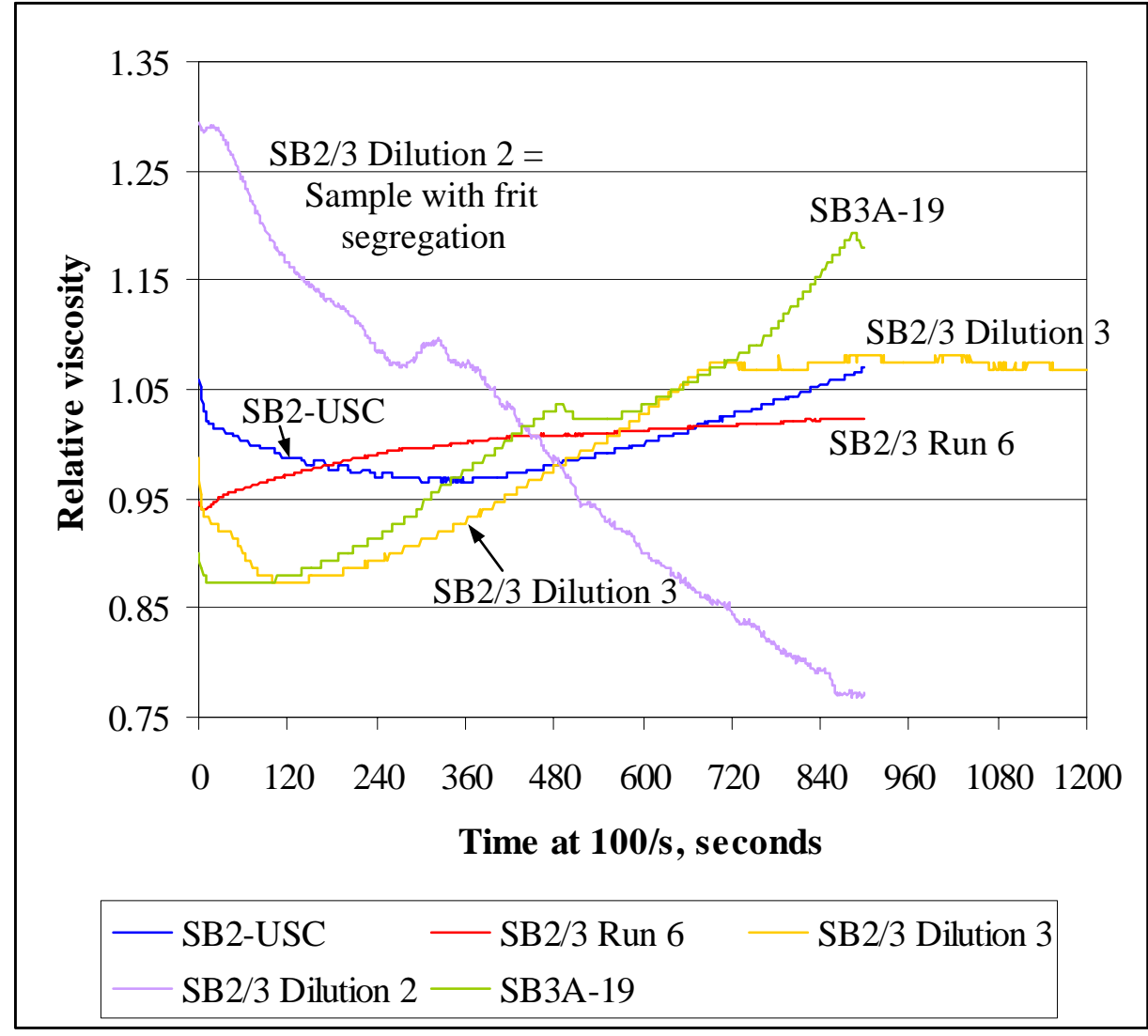

This is clearly a very different graph from the one for the sludge simulants, Figure 16. Many different types of time dependent behavior were seen with SME products. This was not entirely unexpected, since most of the recent unusual rheological data had been coming from SME products. The main exceptions were the hump in the CETL SB2 sludge simulant and occasional cases of flow curve cross-over.

The average apparent viscosities at 100/s shear rate for these five SME products are given in Table 6.

Table 6. Average Apparent Viscosities of SME Products

\begin{tabular}{|l|c|c|c|c|}
\hline Sample & Viscosity & $\begin{array}{c}\text { Wt. \% Total } \\
\text { Solids }\end{array}$ & $\begin{array}{c}\text { Wt. \% Insol. } \\
\text { Solids }\end{array}$ & $\mathrm{pH}$ \\
\hline SB2/3 Run 6 & $460 \mathrm{cP}$ & 54.4 & n.a. & n.a. \\
\hline SB2-USC & $267 \mathrm{cP}$ & 49.3 & 43.3 & 7.98 \\
\hline SB2/3 Dilution 3 & $148 \mathrm{cP}$ & 41.5 & n.a. & n.a. \\
\hline SB2/3 Dilution 2 & $31.9 \mathrm{cP}$ & 29.5 & n.a. & n.a. \\
\hline SB3A-19 & $147 \mathrm{cP}$ & 54 & 37 & 7.67 \\
\hline
\end{tabular}

These five samples were much more viscous than the four sludge simulants described in section 3.1.3 or the three SRAT products described in WSRC-TR-2004-00334. Consequently, inertial effects were expected to be damped out much faster here than in the sludge data. 
The SME product from Run 6 for the SMRF at 155\% acid stoichiometry was the thickest in the set and well above the DWPF design basis window. It exhibited a mildly rheopectic nature that appeared to be leveling off with time. The apparent viscosity changed only 3\% during the last ten minutes of the constant shear rate period. This was the most stable of the five SME products in a relative sense.

The next graph, Figure 29, takes data from the controlled shear rate (CR) and controlled shear stress (CS) flow curves. Values of the shear stress at 100/s are plotted versus the raw constant shear rate time curve data. The times used for the flow curve points are the length of time under shear. They do not attempt to treat different levels of shear rate differently. This plot is just a check on consistency between the three different types of data obtained using the rheometer in the rotational (as opposed to oscillatory) mode.

Figure 29. Comparison of Constant Shear Rate Data and Flow Curve Data

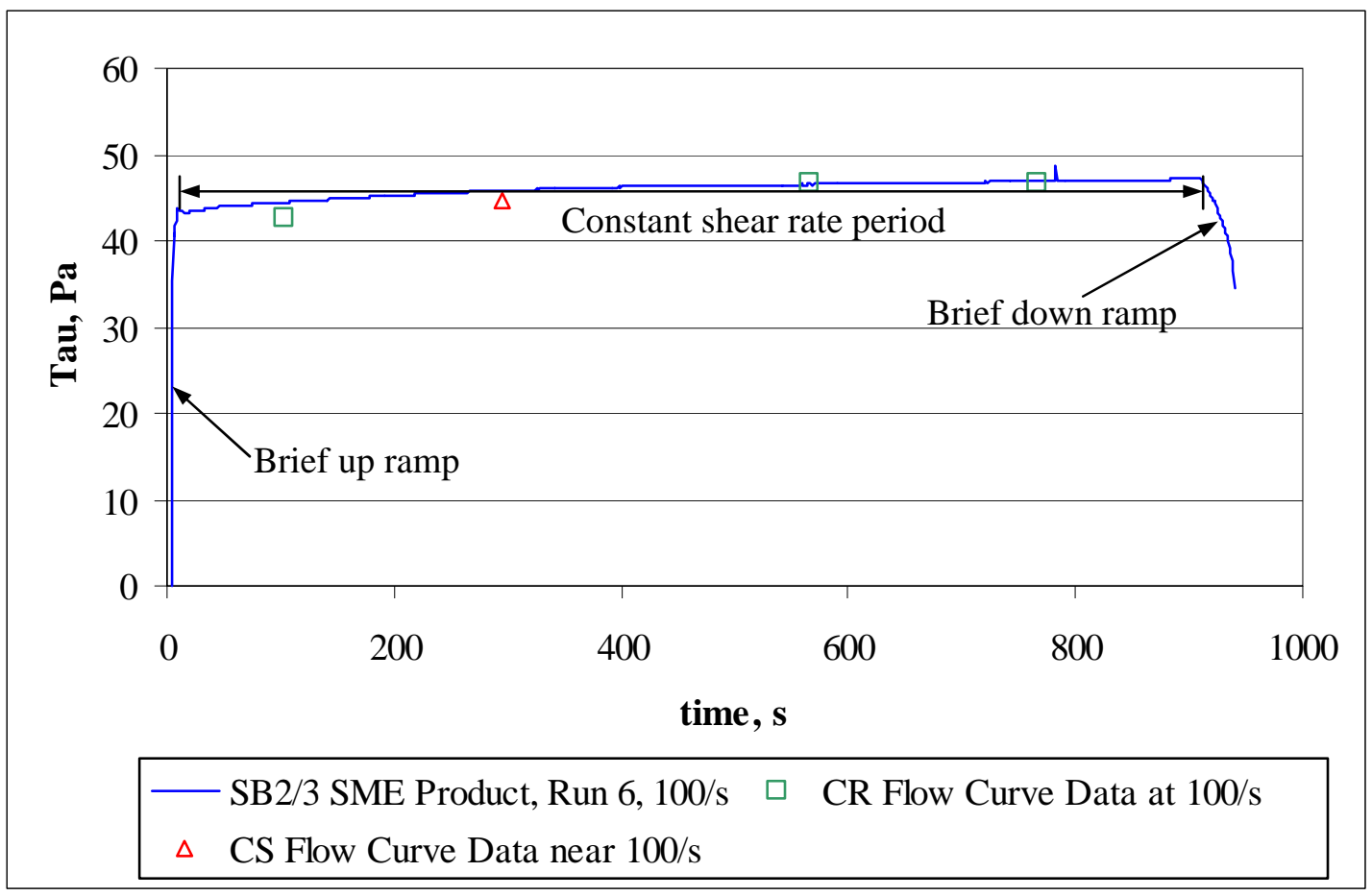

This data indicates that the evolution of the rheological properties with time is not strongly dependent on the shear rate being applied for the typical shear rates of interest (30-300/s). The data at the beginning and end of the constant shear rate trace are the brief up and down ramps, i.e. this is not constant shear rate data. These data were included to show what the actual raw data look like. Agreement between the flow curve and time curve data was not always this good with other, more time dependent samples.

\subsubsection{Oscillation Stress Sweep Data}

Some oscillation stress sweep data was taken at frequencies other than $1 \mathrm{~Hz}$ for comparison. These tests were done with the SB2/3 SME product, Run 6, at 155\% stoichiometry. 
Figure 30. Effect of Frequency of Oscillation Stress Sweep Data

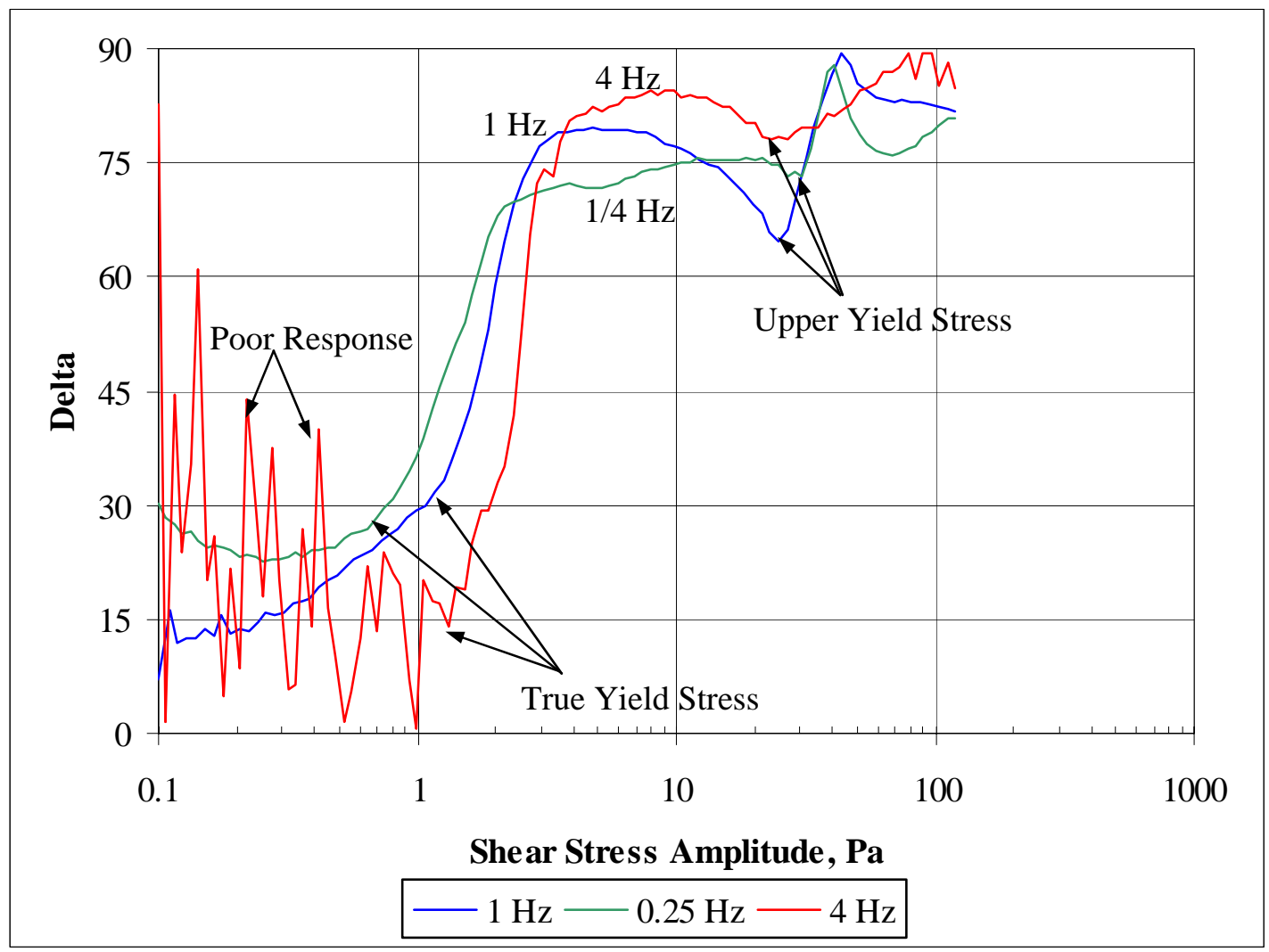

The pre-true yield stress data at $4 \mathrm{~Hz}$ were quite noisy. The RheoWin software tracking the data did not show a deformation response that was wave-shaped until about $1 \mathrm{~Pa}$. These samples were not held for any consistent time prior to initiating the shear wave, which probably impacted the true yield stress values. (The method development work was in its early stages when these data were obtained.) The shift toward higher values for the true yield stresses with increasing frequency was the one that ThermoHaake indicated would happen.

The upper yield stress seemed less sensitive to the frequency choice. These were clustered around 30 $\mathrm{Pa}$, while the Bingham plastic yield stress from the controlled shear rate or shear stress flow curves was in the $35 \mathrm{~Pa}$ range. The relative difference between the true yield stress and the upper yield stress was larger for this slurry than for most samples. No simple rule seemed to be adequate to relate the true yield stress to the upper yield stress.

This data, or an oscillation frequency sweep, are equally adequate in showing that $1 \mathrm{~Hz}$ was a suitable frequency for performing the oscillation tests. Figure 31 shows the elastic and loss moduli in addition to the $1 \mathrm{~Hz}$ data included in Figure 30. 
Figure 31. Oscillation Stress Sweep at $1 \mathrm{~Hz}$

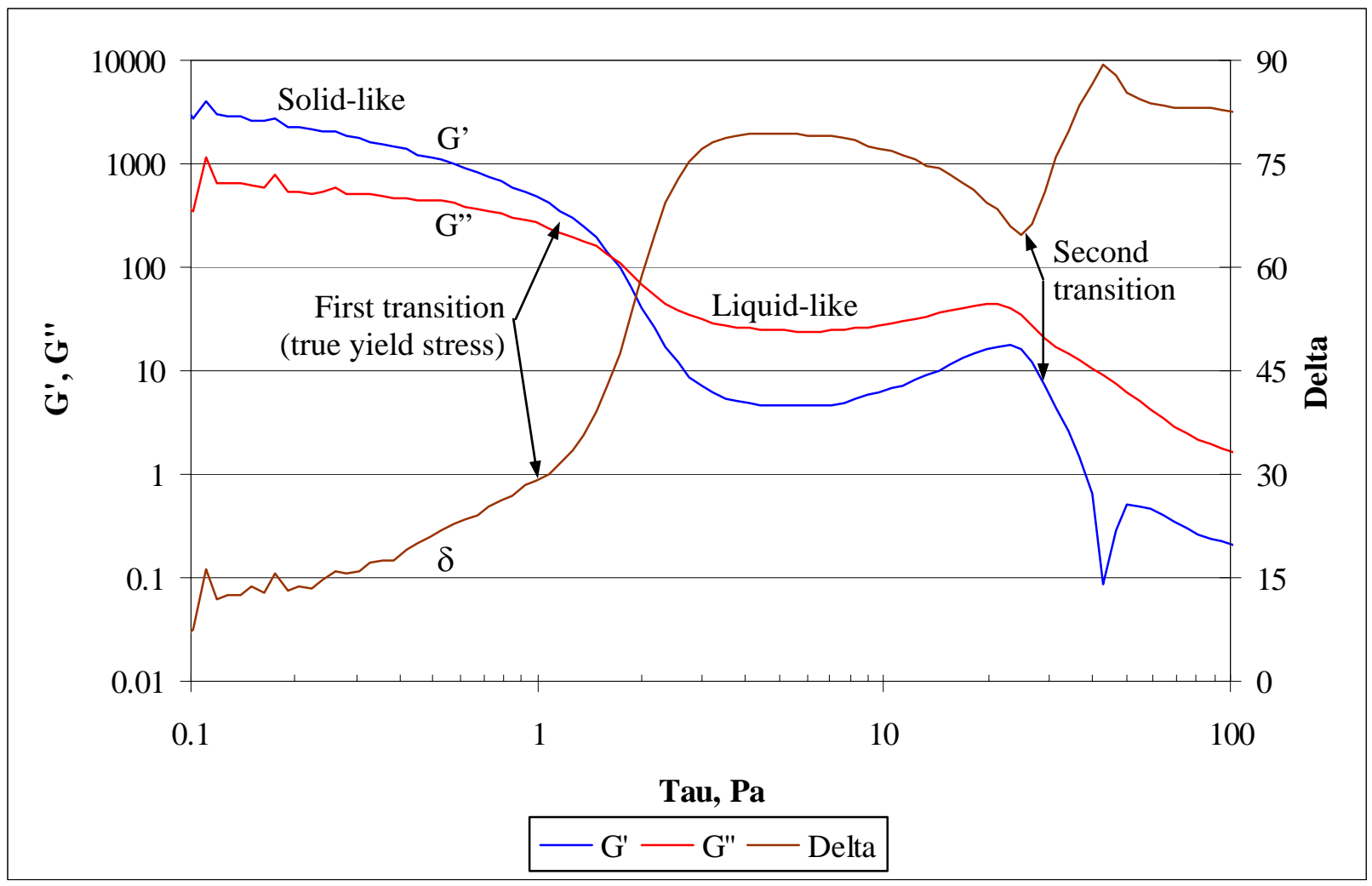

Fluid transitions are associated with rapid increases in $\delta$. These are accompanied in most cases by significant decreases in the two moduli (note the log scale). The magnitudes of the two moduli are directly related to the viscosity, so decreases in moduli correspond to decreases in viscosity.

\subsubsection{Oscillation time sweep analysis}

SB2/3 SME product from Run 6 at 155\% acid was given a set of oscillation time sweeps at four stress levels, Table 7. One other SME product was similarly tested. These two samples were chosen, since they showed rheopectic behavior in the controlled shear rate flow curve measurements. These tests used the Z38 bob. The $0.5 \mathrm{~Pa}$ stress was below the true yield stress. The $45 \mathrm{~Pa}$ test was above the Bingham plastic yield stress. The $3 \mathrm{~Pa}$ stress was chosen in the region between the two yield stresses where the strain amplitude slope is large. The $25 \mathrm{~Pa}$ stress was chosen in the region between the two yield stresses where the strain amplitude slope is small.

Table 7. Time Dependent Nature of SB2/3 SME Product, Run 6

\begin{tabular}{|l|c|c|c|c|}
\hline Test & State & Typical $\left|\eta^{*}\right|, \eta$ & $\eta_{10} / \eta_{2}$ & Time dependence \\
\hline 0.5 Pa Oscillation & Solid-like & $700,000 \mathrm{cP}$ & 1.14 & Rheopectic \\
\hline 3 Pa Oscillation & Above true yield & $7,200 \mathrm{cP}$ & 1.80 & Rheopectic \\
\hline 25 Pa Oscillation & Below Bingham yield & $2,000 \mathrm{cP}$ & 0.79 & Thixotropic \\
\hline 45 Pa Oscillation & Liquid-like & $1,300 \mathrm{cP}$ & 0.95 & Thixotropic \\
\hline 100/s Rotational & Liquid-like & $450 \mathrm{cP}$ & 1.04 & Neutral \\
\hline
\end{tabular}


The rheometer data at $3 \mathrm{~Pa}$ was somewhat unusual, Figure 32. It is, however, clearly above the true yield stress per G” > G' by a significant amount.

Figure 32. SB2/3 SME Product Oscillation Time Sweep at 3 Pa and 1 Hz.

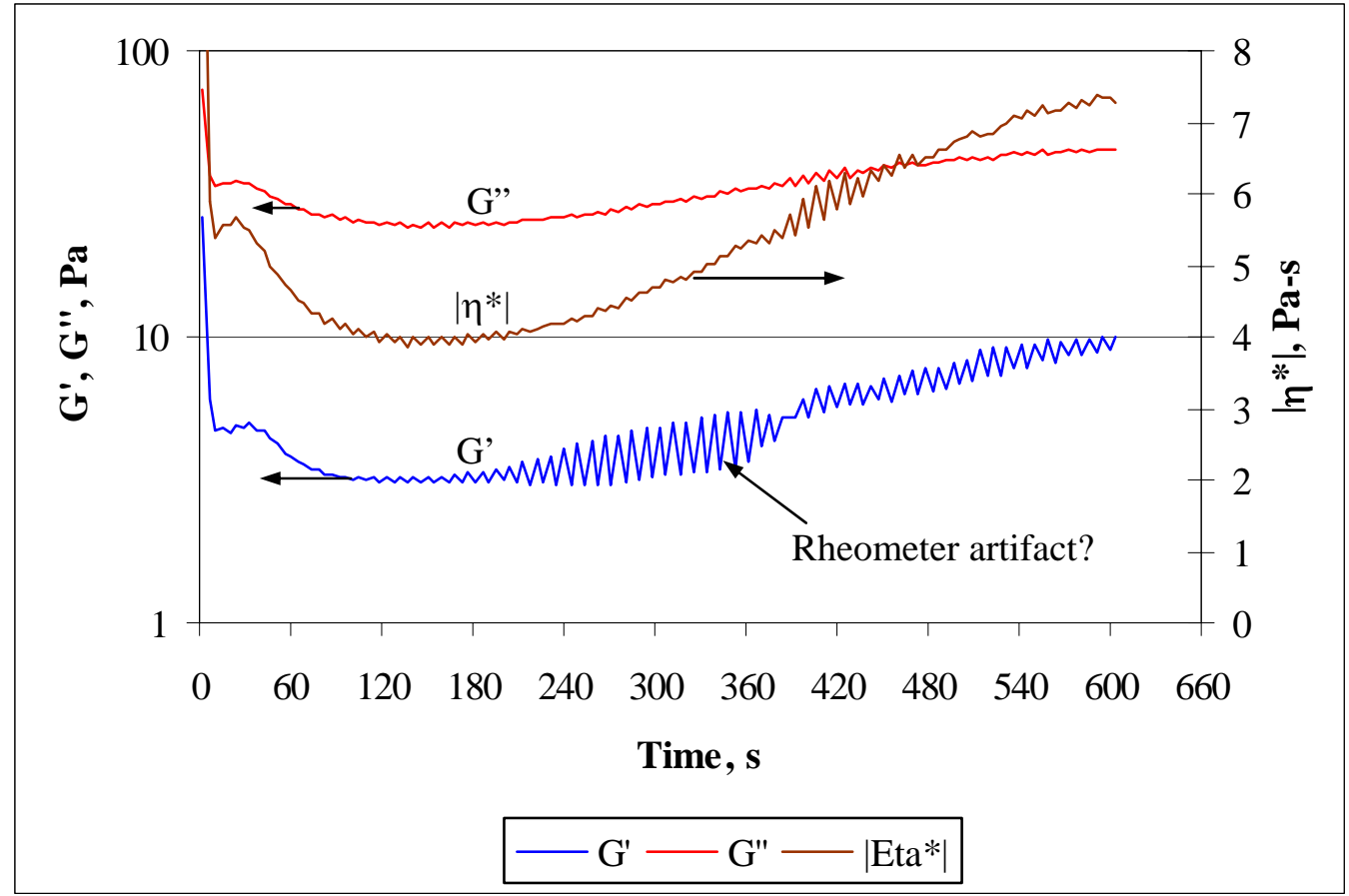

The viscosity fell for three minutes (thixotropy), then rose for seven minutes (rheopexy). It looked like the viscosity was close to leveling out after ten minutes. This slurry was very thick even when yielded as is evident from the typical viscosities in the liquid-like region in Table 7. Inertial effects were expected to be small and rapidly damped by the fluid properties. The cylindrical bob may have gone into some sort of resonance that produced the wavy responses in $G^{\prime}$ and $\left|\eta^{*}\right|$. The bob was touched at about 400 seconds, which muted the phenomenon briefly. Another possibility is that the slurry was trying to reorganize itself into a better configuration for flow, but that the stress wasn't quite high enough to accomplish the transition.

There were no such issues in the data at $45 \mathrm{~Pa}$, Figure 33. 
Figure 33. SB2/3 SME Product Oscillation Time Sweep at $45 \mathrm{~Pa}$ and $1 \mathrm{~Hz}$.

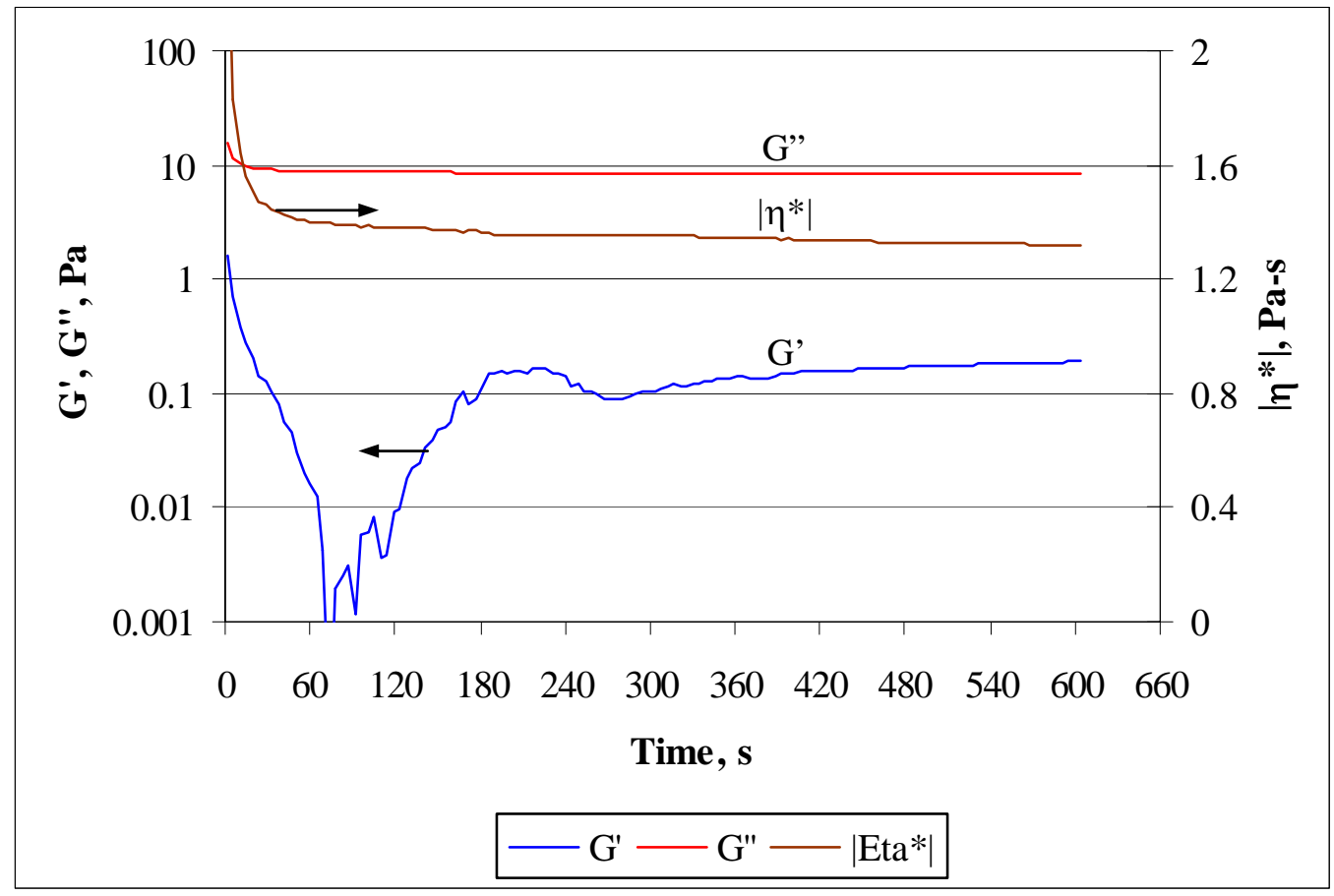

There were some issues with G' early in this measurement as seen in the figure. Some of this was due to the mathematics that partitions the response into the two moduli, G' and G”. G” $\approx 100 * G^{\prime}$, so there is an element of enhanced noise in G' relative to G”. It appeared that most of the change in the viscosity occurred in the first 3-5 minutes, after which the rate of decline was much smaller.

The time series data confirm the results of the flow curve measurements. The SB2/3 Run 6 SME product no longer was exhibiting much time dependent behavior, but what time dependence it had was in the form of mildly rheopectic behavior above the Bingham plastic yield stress.

\subsection{SB2/3 SME Product, Run 5, Heel Study}

\subsubsection{Controlled Shear Rate Flow Curves}

This was another SME product that was expected to be quite rheopectic, but which only showed a small effect when measured during the experimental work. It was from the SB2/3 heel and redox study. Figure 34 shows the up and down ramp flow curve segments for this SME product run using the Z38 bob with an $8 \mathrm{~mm}$ gap versus a $12 \mathrm{~mm}$ gap below the bob. The $8 \mathrm{~mm}$ gap is standard for the Z38. One concern was that solids might be accumulating near the bottom of the bob during the measurement causing increased drag on the rotating bob. This would appear as rheopectic behavior when examining the stress versus shear rate behavior. A similar test was made with SB2 CETL simulant using the Z41 bob, but no such effect was seen. That system, however, did not have frit particles. 
Figure 34. SB2/3 SME Product from Run 5, Heel Study: Effect of Gap

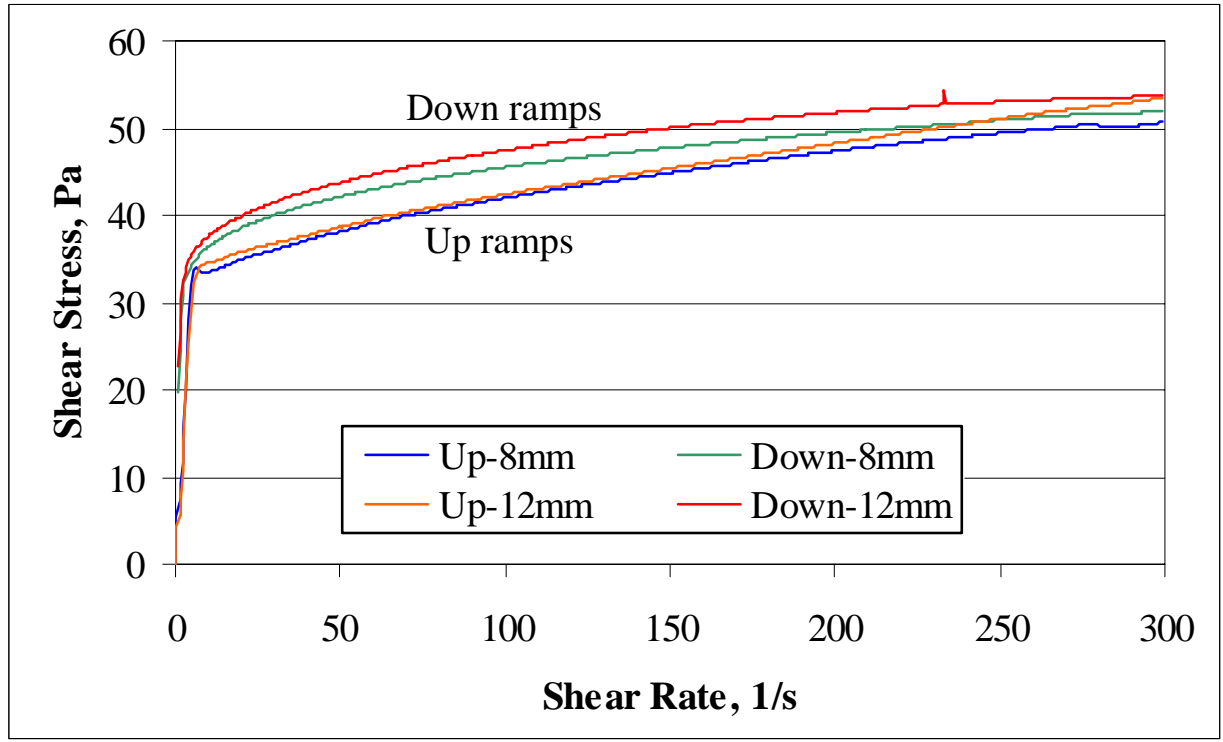

The effect of the bottom gap was fairly minimal on the results obtained. Mild rheopectic behavior was observed in both measurements. The shear rate was ramped to 300/s over five minutes, held there for one minute, and then ramped down to 0/s over five minutes. Sub-samples were held 3-7 minutes in the ready position (bob at the pre-set gap) before initiating the up ramp. This ensured thermal equilibrium. It also allowed some of the structure seen in the other measurements some time to form.

The data was significantly different from that obtained shortly after the SME product was originally prepared. The reasons for this are under investigation. 
Figure 35. Change in Flow Curve with time

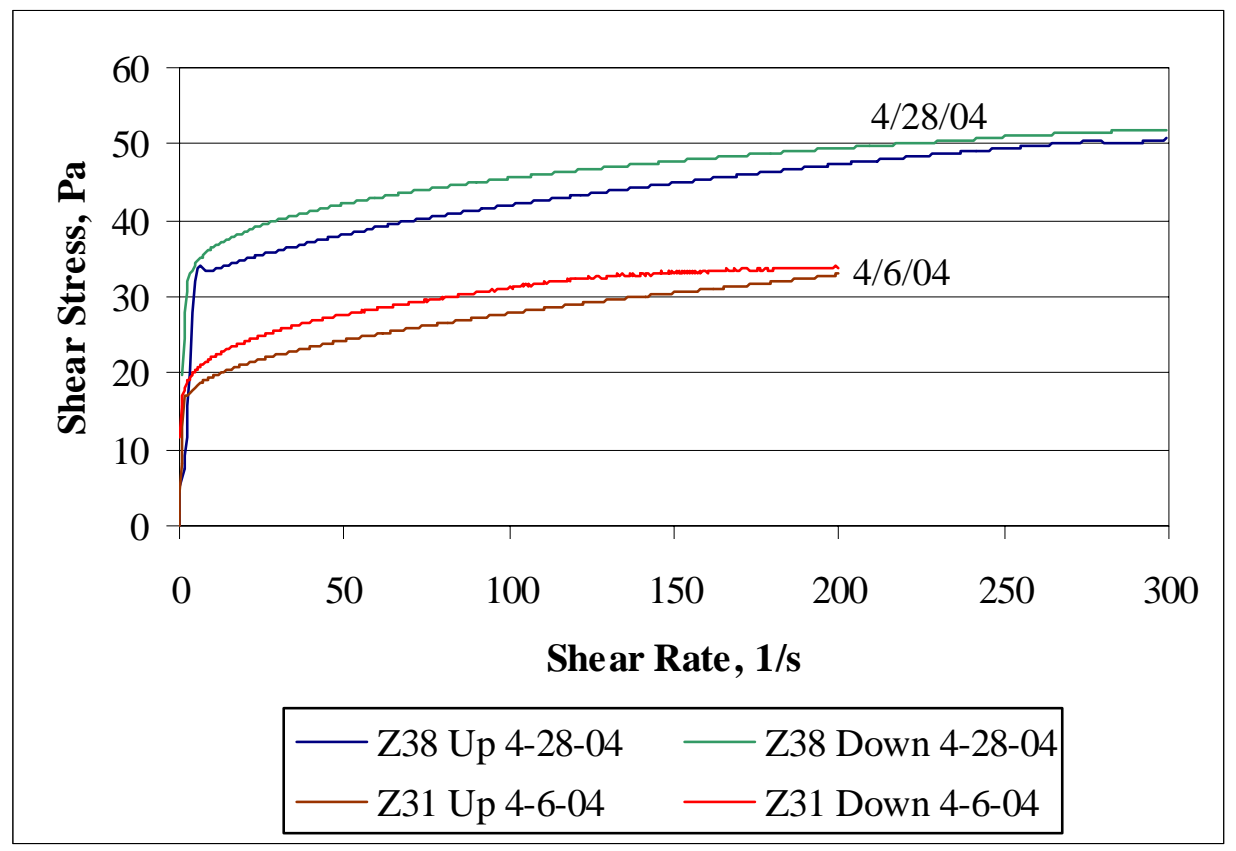

While Z31 and Z38 data do not generally match perfectly, the $50 \%$ increase seen here is much too large to explain as being due to the choice of sensor. It is possible, though not very likely, that the 4/6/04 sample was not taken correctly and was low in insoluble solids. The work on 4/28/04 had the entire remaining SME product available (about two liters), so this material should have been essentially representative of the original SME product made. This issue needs further investigation. If SME product rheology changes on a time scale of 22 days, then it might change significantly on a time scale of just 1-2 days. This would lead to a requirement that SME product rheological measurements must be made within some short period of time following completion of the SME cycle in order to obtain rheological data that can be compared between runs with different conditions.

This SME product was used to obtain a series of dilutions with rheological properties within and near the lower end of the DWPF design basis (yield stress of 2.5 Pa and $10 \mathrm{cP}$ ). This was necessary, since the available SME products were all at or above the DWPF rheological design basis for SME products (15 Pa and $40 \mathrm{cP}$ ). Rheological coverage of the entire design basis region was desired. Data from these dilutions are presented next. They bear on the subject of flow curve cross-over, discussed in section 3.4.

Three dilutions were made. These are described in Table 8.

Table 8. Dilutions of SB2/3 Run 5 SME Product

\begin{tabular}{|l|c|c|}
\hline & Wt. \% de-ionized water & Wt. \% SME product slurry \\
\hline Dilution 1 & 17.71 & 82.29 \\
\hline Dilution 2 & 40.59 & 59.41 \\
\hline Dilution 3 & 24.51 & 75.49 \\
\hline
\end{tabular}

Dilution 3 was prepared after flow curves were generated for Dilutions 1 and 2. Flow curves for the original SME product and the three dilutions are given in Figure 36. 
Figure 36. Impact of Dilution on SB2/3 Run 5 SME Product

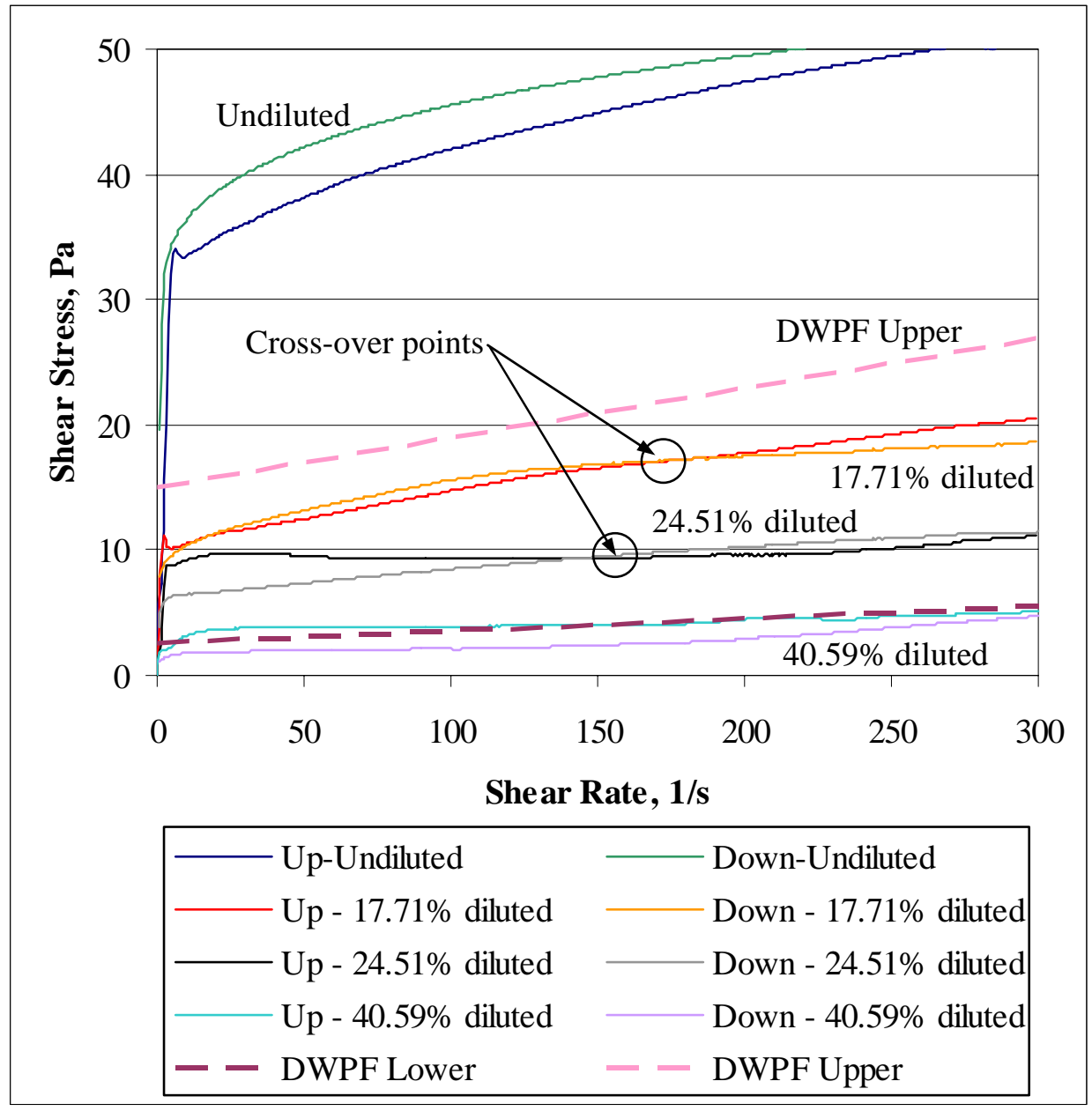

The undiluted sample shows evidence of mildly rheopectic behavior in its flow curve (top). Dilution 2 (40.59\% diluted) shows evidence of mildly thixotropic behavior. The two intermediate dilutions both have a flow curve cross-over point (indicated by the arrows in the figure). These data suggest that the cross-over phenomena is related to thixotropy and rheopexy. Cross-over may be occurring at solids loadings that are in a transition region between thixotropic and rheopectic behavior. This would be consistent with a balance between competing phenomena interpretation as proposed below in section 3.4, and would also link the cross-over phenomenon in with the other time dependent issues with rheology, rather than putting it in a separate category. This is also consistent with Figure 8 from Alderman and Heywood, which indicates that many slurry systems transition from thixotropic to rheopectic as the wt. \% solids increases.

This system also gave some additional insight into the impact of Taylor vortices on the down curve. The relevant data were obtained at the $40.59 \%$ dilution, since this fell near the lower edge of the DWPF design basis. This sample was not particularly effective at suspending frit for periods of time of order ten minutes. Two flow curves were generated. The ramp rates for the two tests were identical. The ramp times of the second test were only half as long, since the maximum shear rate was only half as large. 
Figure 37. Impact of Taylor Vortices on Thin SME Down Curve

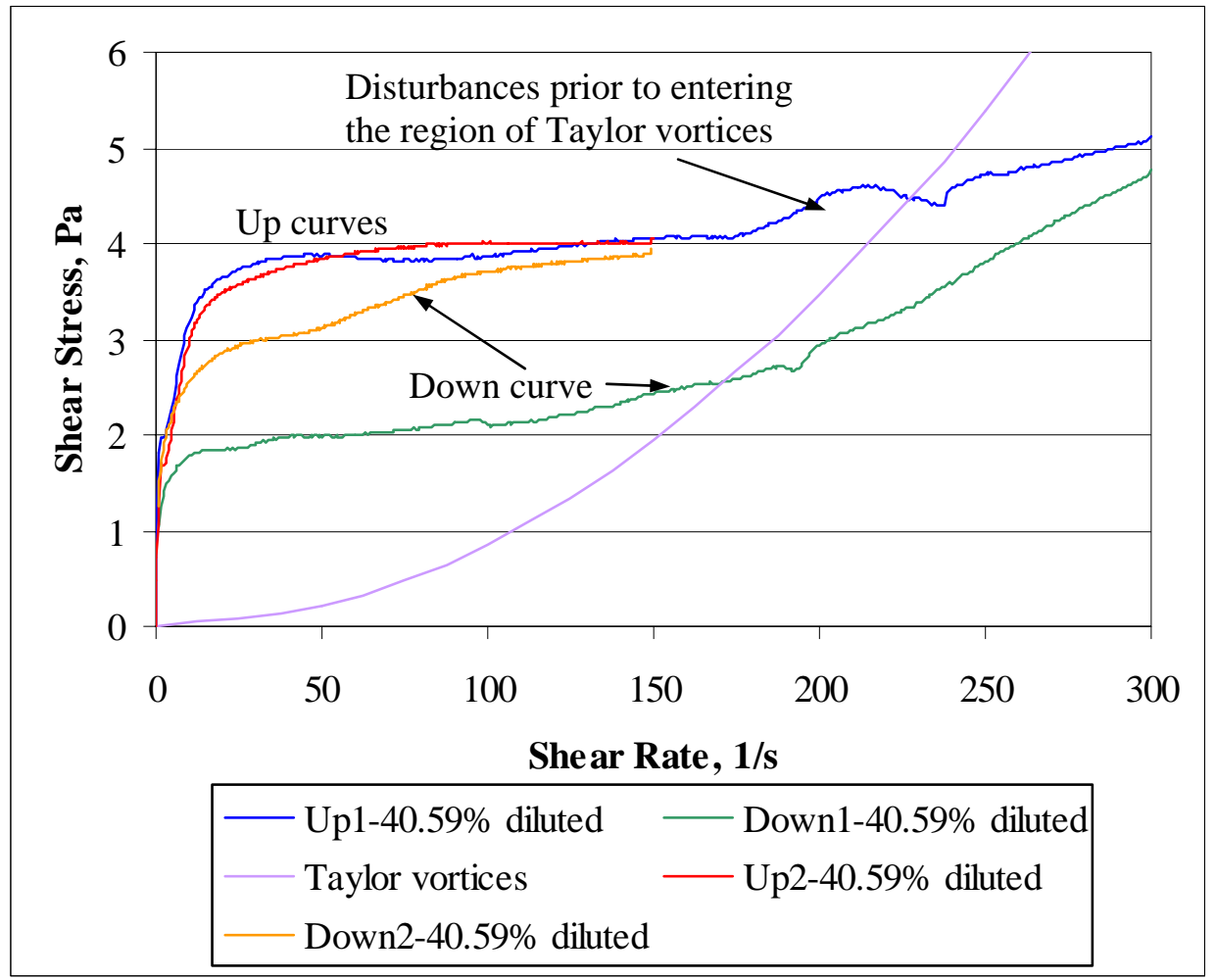

Comparable shear rate up curve data were in a similar region of the plot. The two sets of down curve data were not close. It appears that a significant amount of frit sedimented out of the annular gap during both of these measurements, i.e. the sample in the gap at the beginning of the measurement was not identical to the sample in the gap at the end of the measurement. The sample that was taken into the region of Taylor vortices, however, had a much more significant change between the up and down ramp portions of the flow curve. This is further evidence that the region of Taylor vortices needs to be avoided when analyzing SME product rheology. The up ramp flow curve was not smooth even 50/s before it reached the envelope for Taylor vortices. This further substantiates the recommendation that SME slurries should be kept away from the region of Taylor vortices.

\subsubsection{Controlled Stress Flow Curve}

A controlled stress flow curve was generated on Dilution 2 (40.59\% diluted) SME product from Run 5. Figure 38 gives the strain-stress data. 
Figure 38. Non-typical strain-stress plot of Dilution 2 SME product.

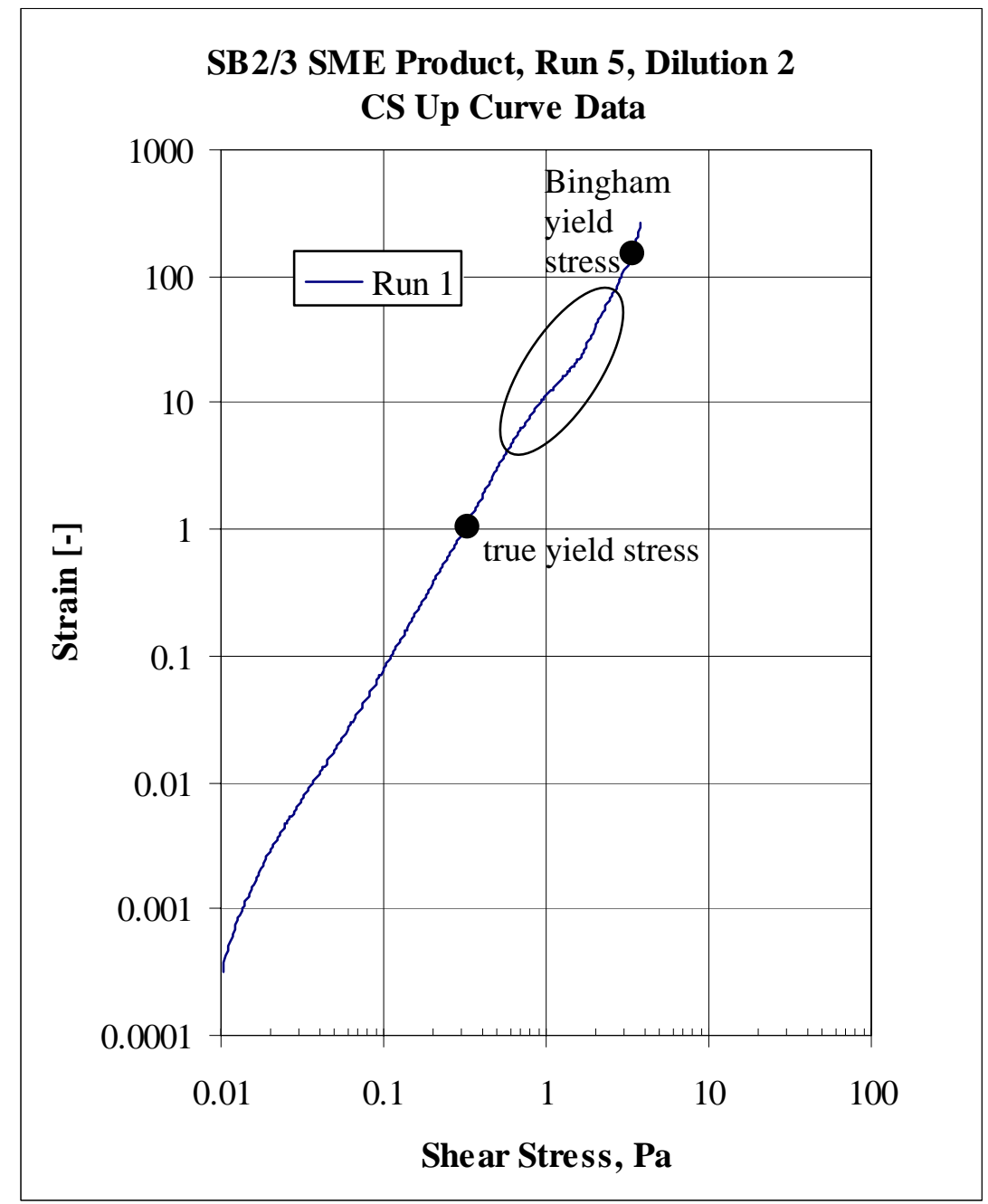

The true yield stress, as given by the oscillation stress sweep technique, lies in the neighborhood of $0.3 \mathrm{~Pa}$. Slopes are approximately two both before and after this point on the controlled stress plot above. The strain at this stress is unusually large for it to be a yield point. This sample was held for ten minutes before applying stress. This was adequate time to form a gel-like structure that produced a yield stress transition for nearly all other samples tested.

This sample may have been thinned to the point where very little structure exists. The Bingham plastic yield stress was approximately 3.5 Pa. This sample is close to the lower limits of the DWPF design basis for SME products. The shape of the data between the two yield stresses (enclosed by oval) is similar to that observed with other slurries, but the slope changes are more muted.

Studies with the N35 viscosity standard indicate that the stress is probably large enough at $0.1 \mathrm{~Pa}$ for the Dilution 2 SB2/3 SME product sample to be exhibiting solid-like or Newtonian fluid-like behavior (slope one), and this is not indicated by the data. This illustrates one of the possible anomalies that can be obtained by this method. The oscillation stress sweep data on this sample was much clearer in delineating the region of the true yield stress. This emphasizes the need for a 
complimentary set of measurement techniques that can remove ambiguity from individual measurements.

\subsubsection{Constant Shear Rate Time Curve Results}

Two dilutions (Dilution 2 and Dilution 3) of Run 5 SME product were given a constant shear rate time curve measurement. These results were given earlier in Figure 28.

The SB2/3 Dilution 2 sample showed considerable thinning with time (thixotropy). This was the thinnest sample. Testing outside the rheometer indicates that this sample does not suspend frit very well on a time scale of ten minutes in a graduated cylinder. Almost certainly this sample changed in wt. \% solids during the measurement of the constant shear rate time curve. This falling wt. \% solids was the primary cause of the rheological change seen. This dilution was also the only one of a set of four, section 3.3.2, that had its down ramp flow curve below its up ramp flow curve. That may also have been due to frit settling out of the annular gap during the controlled shear rate flow curve measurement.

Dilution 3 of the SB2/3 SME product from the heel study was visually thicker than the Dilution 2 sample. This sample appeared to be mildly rheopectic, i.e. thickening with time under shear. The test on the Dilution 3 sample was allowed to continue for an extra five minutes with a surprising result. The apparent end to the rising viscosity at 12 minutes continued past 15 minutes until the end of the test at 20 minutes. This indicated that this sample had stabilized at this shear rate to an essentially constant apparent viscosity. Unfortunately, it took 12 minutes for this to happen. That is roughly the normal length of a controlled shear rate flow curve measurement.

Agreement between the flow curve and constant shear rate time curve data at 100/s shear rate was fairly good for Dilution 3 slurry as seen in Figure 39.

Figure 39. Comparison of Flow Curve to Constant Shear Rate data for Dilution 3

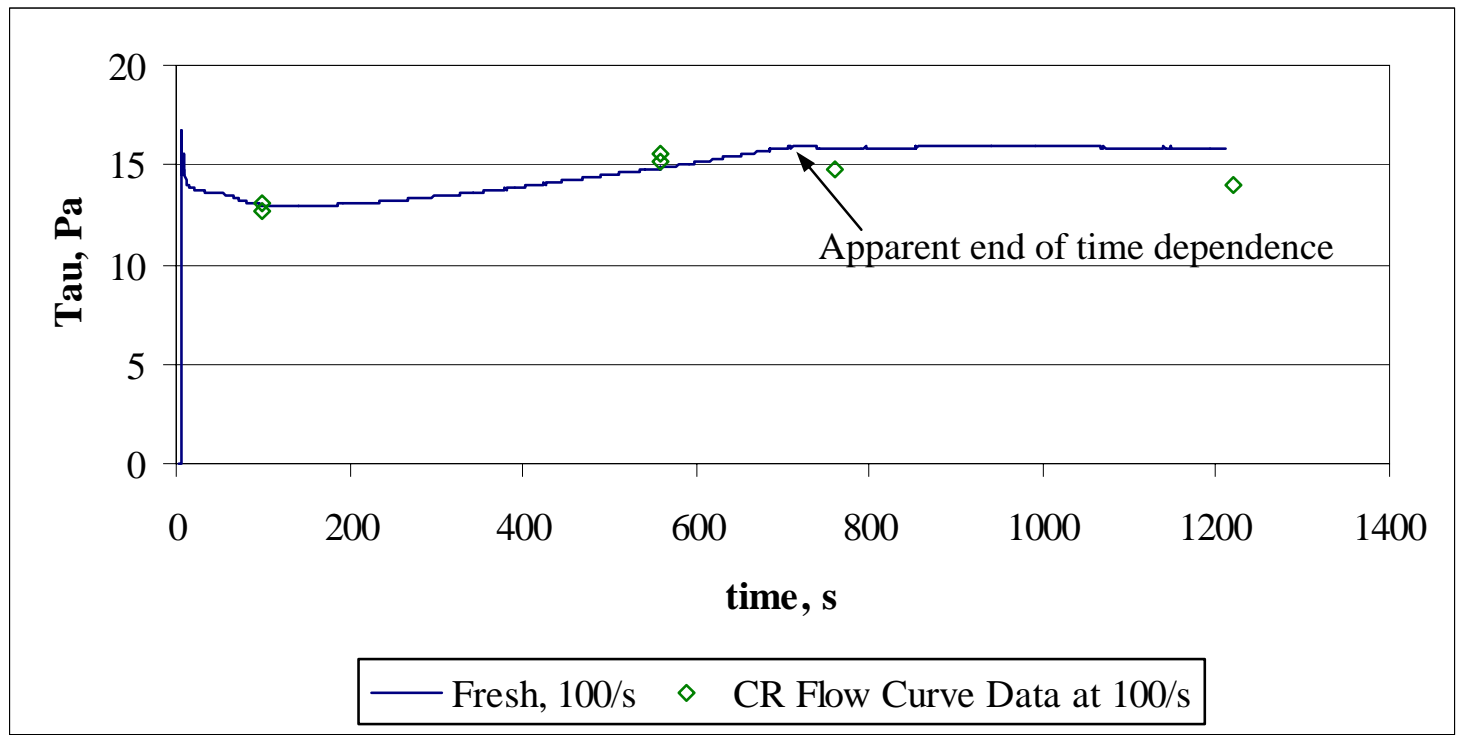

Only the data at long times showed much difference. A similar plot contained little information for Dilution 2. The Taylor vortices that developed in the flow curve so disrupted the data that there was little agreement with the constant shear rate curve beyond the first few points (less than 240 seconds). 


\subsubsection{Oscillation Stress Sweep Results}

Dilution 2 SME product was tested to look for a true yield stress. Data from the controlled stress flow curve, section 3.3.2, did not clearly show a true yield stress.

Figure 40. Oscillation Stress Sweep of Dilution 2 of SME Product from Run 5

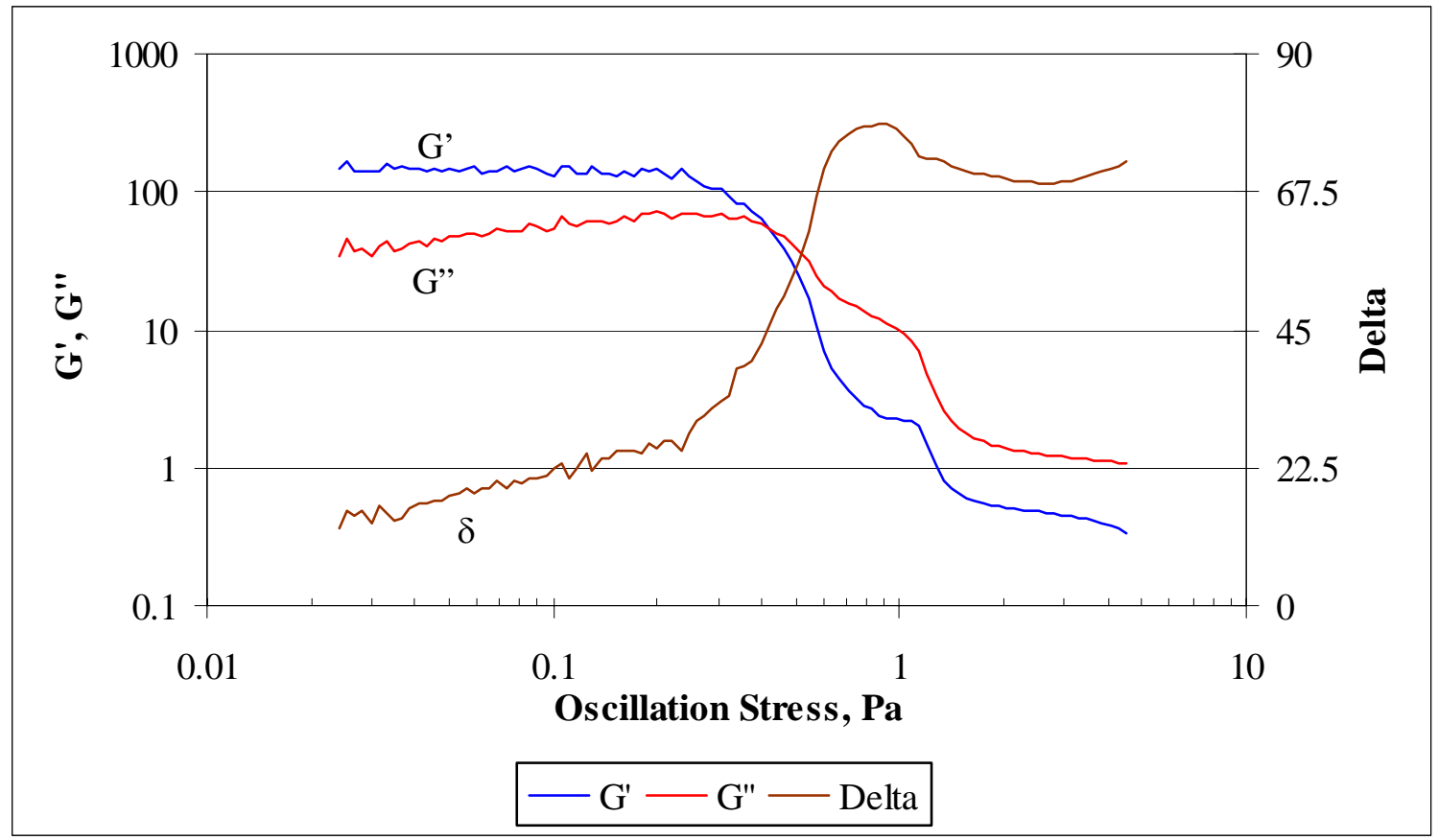

These data indicate that the sample is solid-like below about $0.3 \mathrm{~Pa}$, with the elastic modulus, G', exceeding the loss modulus, G”, and with $\delta$ less than $45^{\circ}$. This yield stress is not very meaningful in a processing context (mixing, pumping). It indicates that this sample will behave in an essentially liquid-like manner under most practical conditions.

\subsection{Cross-over Loop Samples}

\subsubsection{Controlled Shear Rate Flow Curves}

Several systems studied in this program had a down ramp flow curve that intersected the up ramp flow curve at some intermediate value of the shear rate that was well away from $0 / \mathrm{s}$. These flow curves resemble lopsided figure-8's more than loops. Figure 36 shows an example for two SB2/3 SME products prepared by diluting the SME product from Run 5 of the heel and redox study. Figure 41 shows two standard flow curves for SME product based on USC Tank 8 and 40 simulants (SB2). They are for SME product prepared in the $1 / 240^{\text {th }}$ Glass Feed Preparation System. 
Figure 41. SB2 SME Product (USC) with Cross-overs

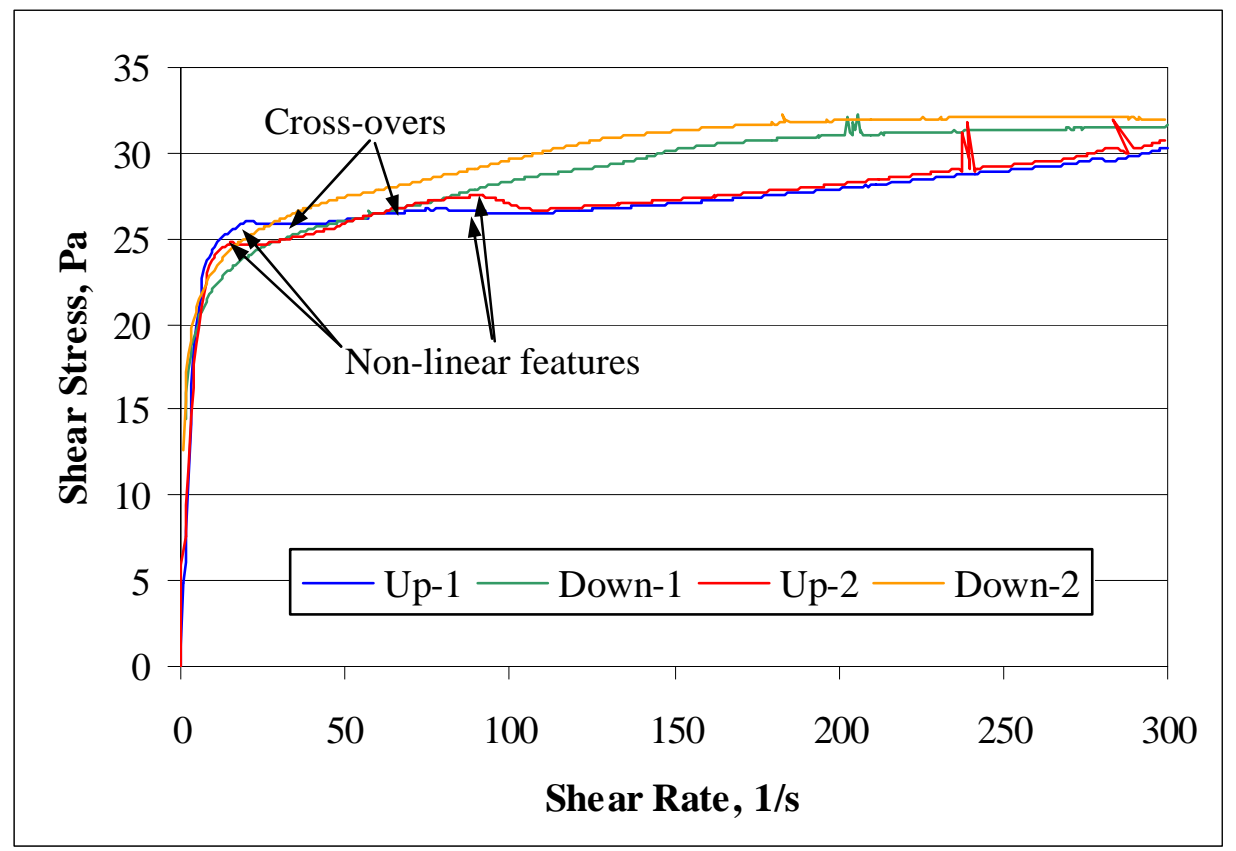

It is interesting that some of the non-linear features in the ramps are reproduced, such as the up ramp region between $15 / \mathrm{s}$ and $120 / \mathrm{s}$, even though they initially appear to be abnormalities, or at least departures from the expected smooth shape of a flow curve. There was a small amount of electronic noise (looks like little stress spikes) that was not cleaned up, but is an instrument issue, not a sample issue.

This sample was also a little unusual in the constant shear rate time curve at 100/s, Figure 28. It thinned slightly over the first six minutes then thickened slightly over the next nine minutes. The flow curve data could be interpreted as thickening at high shear rates and thinning at low shear rates. One interpretation that could be put forward is that there may be two (or more) different phenomena at work in the DWPF slurries. This sample may be an instance where two of the phenomena are of roughly similar significance with respect to the rheological behavior, while the more general case is that only a single phenomenon is dominant.

\subsubsection{Controlled Stress Flow Curve Results}

Another sample that exhibited this phenomenon was the SRAT product made from the CETL SB2 and SB3 simulant blend, Koopman (2004c). This sample was run using the Z38 bob because of the sand and coal added to the sludge prior to processing. Figure 42 compares controlled shear rate (CR) data with controlled shear stress (CS) data for this SRAT product. 
WSRC-TR-2004-00519

Revision 0

Figure 42. SB2/3 SRAT Product: Controlled Stress vs. Controlled Shear

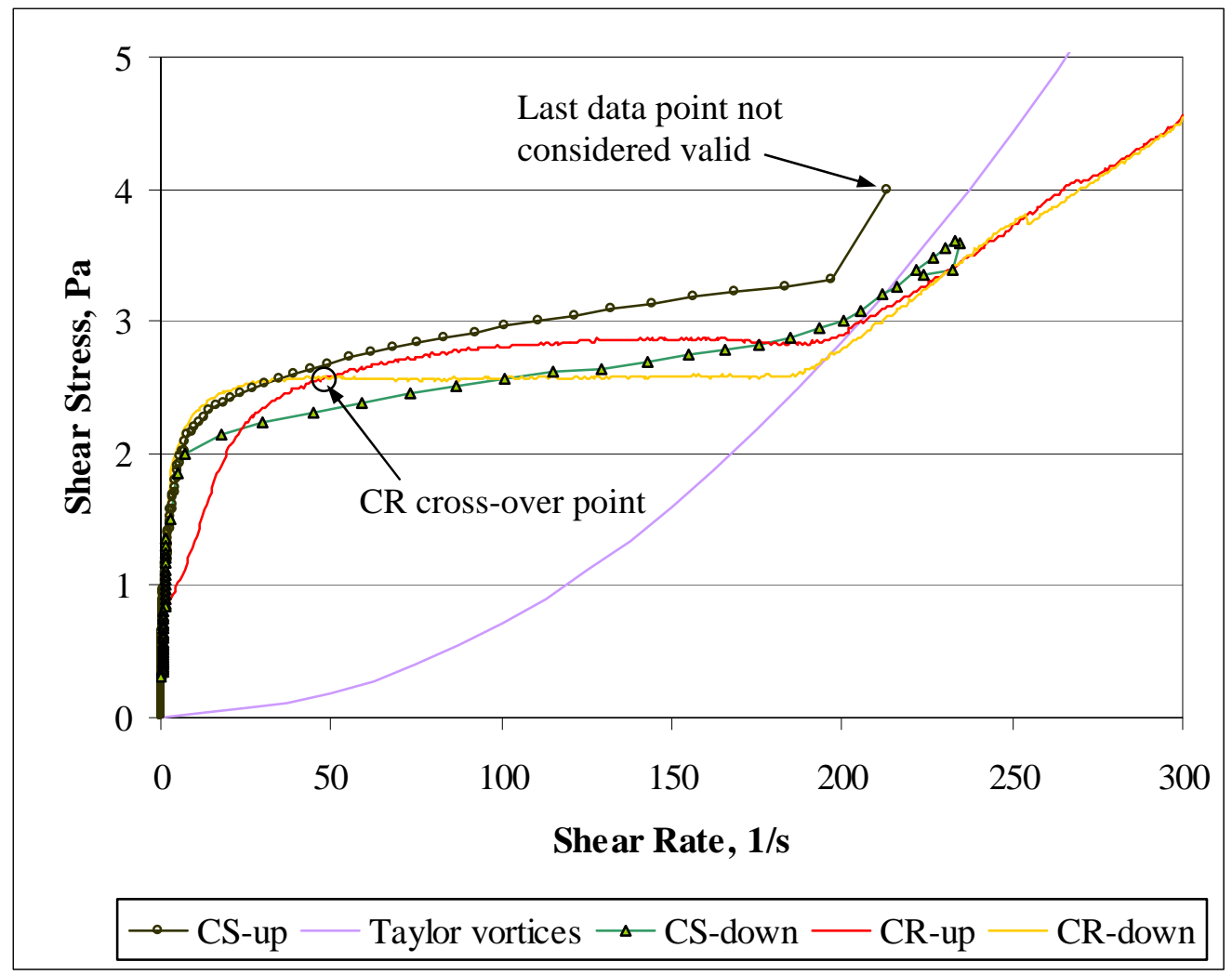

The main point from this figure is that the controlled stress (CS) loop did not have cross-over of the up and down ramps. The controlled stress down ramp was 100 seconds long, so it was not just a quick ramp to a halt. Both controlled stress flow curves also had positive slopes, while the controlled shear rate (CR) down curve had almost a zero slope.

The next data for the USC SB2 SME product are similar. The system is about 15 times thicker, however, than the one above. The CS down ramp was 100 seconds long. 
Figure 43. SB2 USC SME Product.

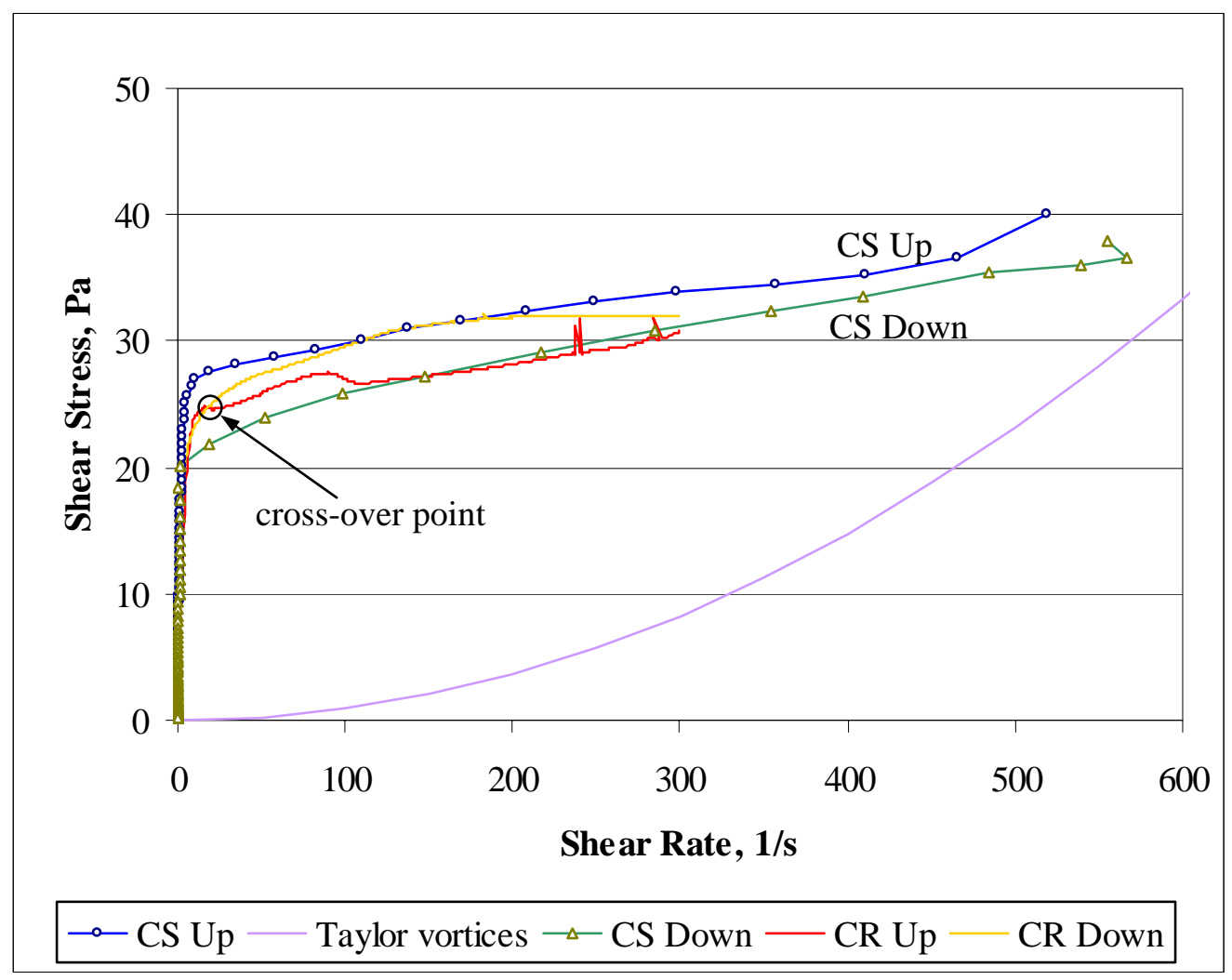

The CS data do not cross-over, while the CR data do cross-over. The irregularity in the CR up flow curve from the cross-over point to about 100/s was seen in duplicate, but did not occur in the CS data. This may not be surprising. The controlled stress data can only ramp in one direction, e.g. up, while the irregularity in the CR data was caused by the stress falling as shear rate was increased. The unexplained stress jump on the last point of the CS up ramp is shown again. The stress jumped to 40 Pa more quickly than expected based on the 8-10 prior data points. The down ramp also was not entirely in the down direction, just like the previous case.

Another interesting aspect of this plot is that the CS up ramp seems more closely aligned with the CR down ramp, and the CS down ramp seems more closely aligned with the CR up ramp. Consequently, the sample appears mildly thixotropic in the CS test, and mildly rheopectic in the CR test. It is unlikely to be both, but the data obtained with these two tests are insufficient to clarify the point.

Cross-over occurred at a wide range of shear stress levels depending on the particular sample. At this point, most of these samples have not been tested at higher and lower wt. \% solids levels. This would be necessary to determine if the transition from thixotropic to cross-over to rheopectic behavior observed for the SB2/3 SME product from Run 5 is a common feature of all of these slurries. 


\subsection{Follow-up SME Product Studies}

The issue of the changing rheology of SME products was investigated further during the preparation of this report. Two systems were checked. The first of these was SB2/3 SME product from Run 1 of the heel-redox study.

Figure 44. Controlled Rate Flow Curve for SB2/3 SME Product, Run 1

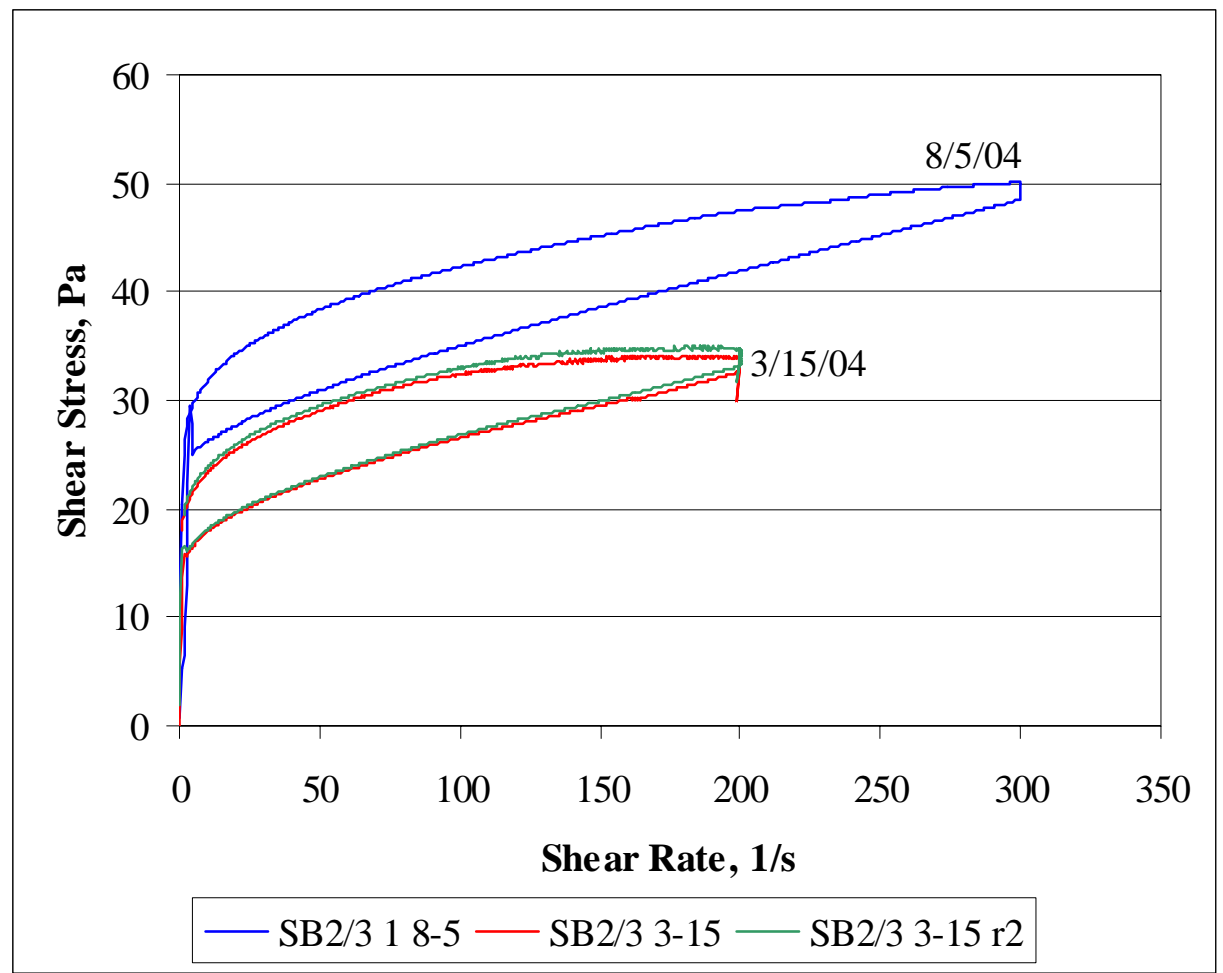

The 3/15/04 data was taken with the Z31 sensor, while the 8/5/04 data was taken with the Z38 sensor. Both sets of results indicate mild rheopectic behavior. Both sets lie above the DWPF design basis for SME product rheology. The shift to increased shear stress is consistent with that seen in the data for the Run 5 SME product, Figure 24.

Analytical data indicated that the sample had changed from $50 \mathrm{wt}$ \% total solids to $51.32 \mathrm{wt}$ \% total solids. A sub-sample was diluted with de-ionized water to $50 \mathrm{wt}$. \% total solids, and this sample was run on the rheometer, Figure 45. This was to ensure that the change in rheological properties was not due to drying of the sample. 
Figure 45. Impact of Dilution on Run 1 SME Product

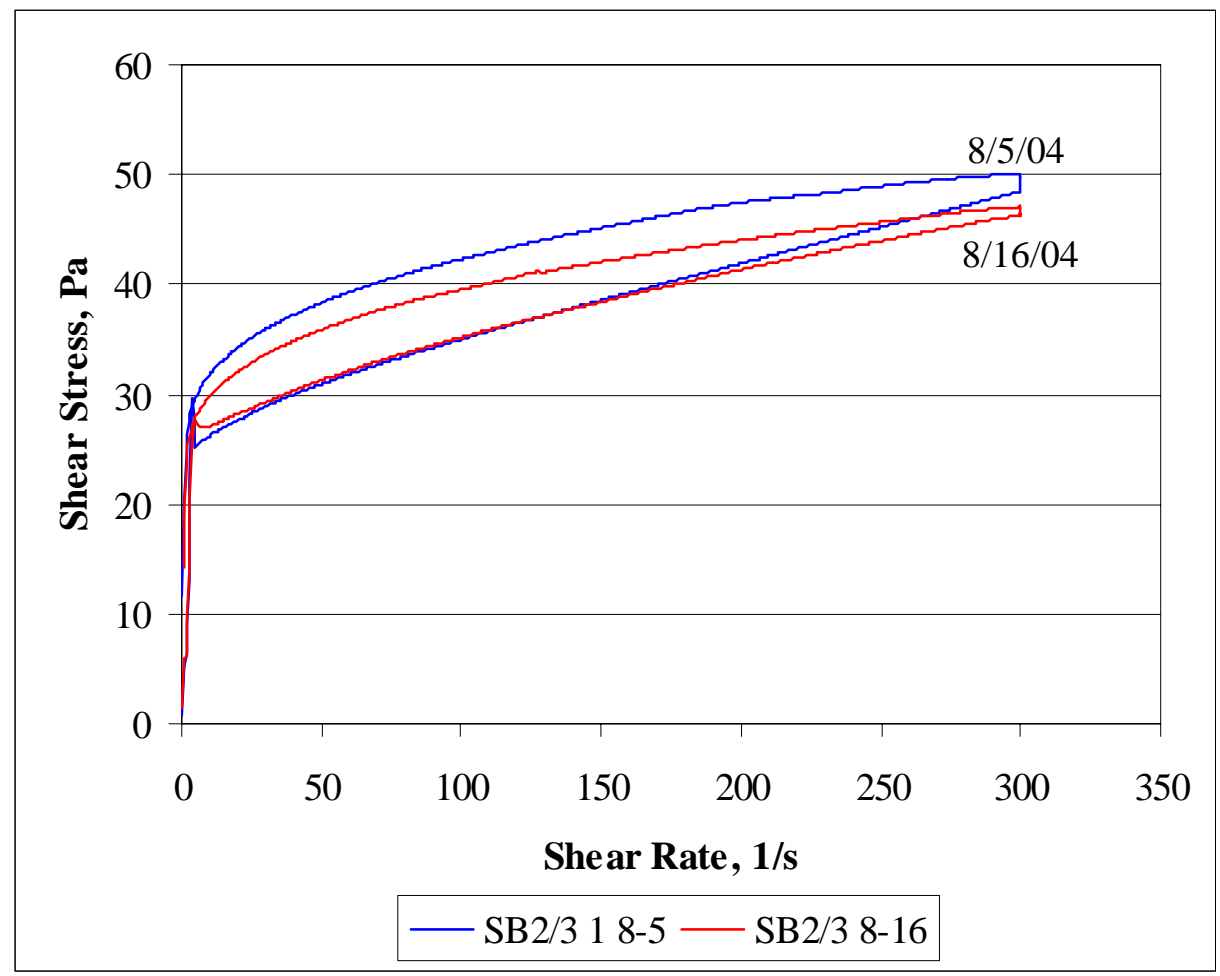

The change in the flow curve was detectable but small. The conclusion was that the observed change from March to August was a real change in rheology that was not due to a change in the water content of the slurry.

Two virtually identical SME products were produced on 8/5/04 using the 22-L equipment at ACTL. These were prepared with frit 320. Rheological data were obtained for both products prior to blending them together for use as feed to the slurry-fed melt rate furnace. A sample of the blended SME product was obtained. It was also run on 8/5/04, but later in the day. All data were taken using the Z38 bob, Figure 46 . The early data used a 0-200/s shear rate range, while the later data used a 0$300 / \mathrm{s}$ shear rate range. 
Figure 46. Rheology Change from Morning to Afternoon

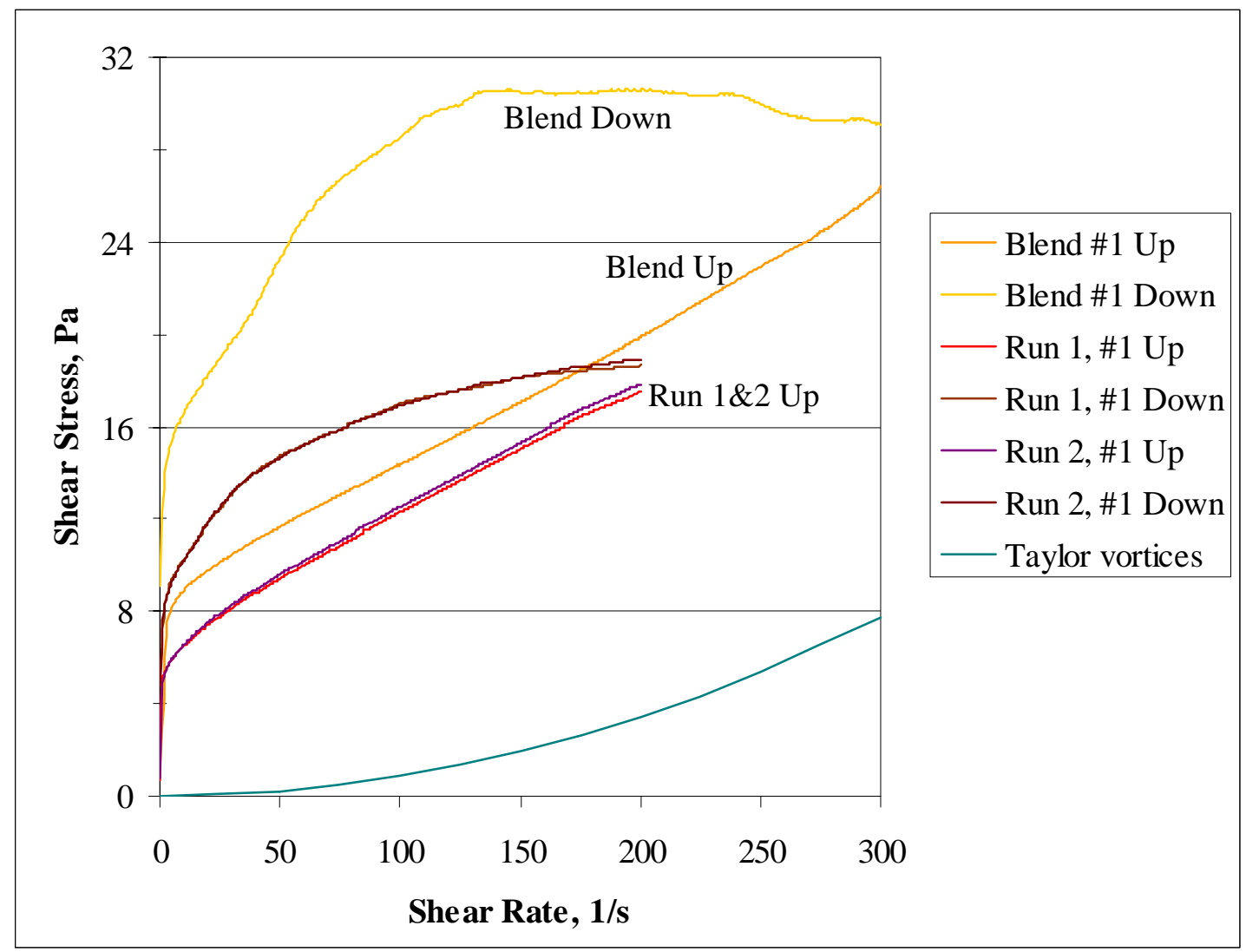

There was a slight upward shift in the up ramp flow curve from the data for the two individual runs (morning) to the data for the blend slurry (afternoon). The properties of the two individual slurries were nearly identical. The down curve for the blend slurry was adversely affected by taking the SME product to higher shear rates (and shear stresses). The region of Taylor vortices was not a factor. The blend showed the unusual rheological behavior that had been unsuccessfully sought for the earlier experimental work.

The blended SME product was rerun once it was discovered that the individual run samples had only been run to 200/s shear rate. This did not occur until 8/9/04. The data are given in Figure 47. 
Figure 47. Follow-up Measurement of SME Rheology

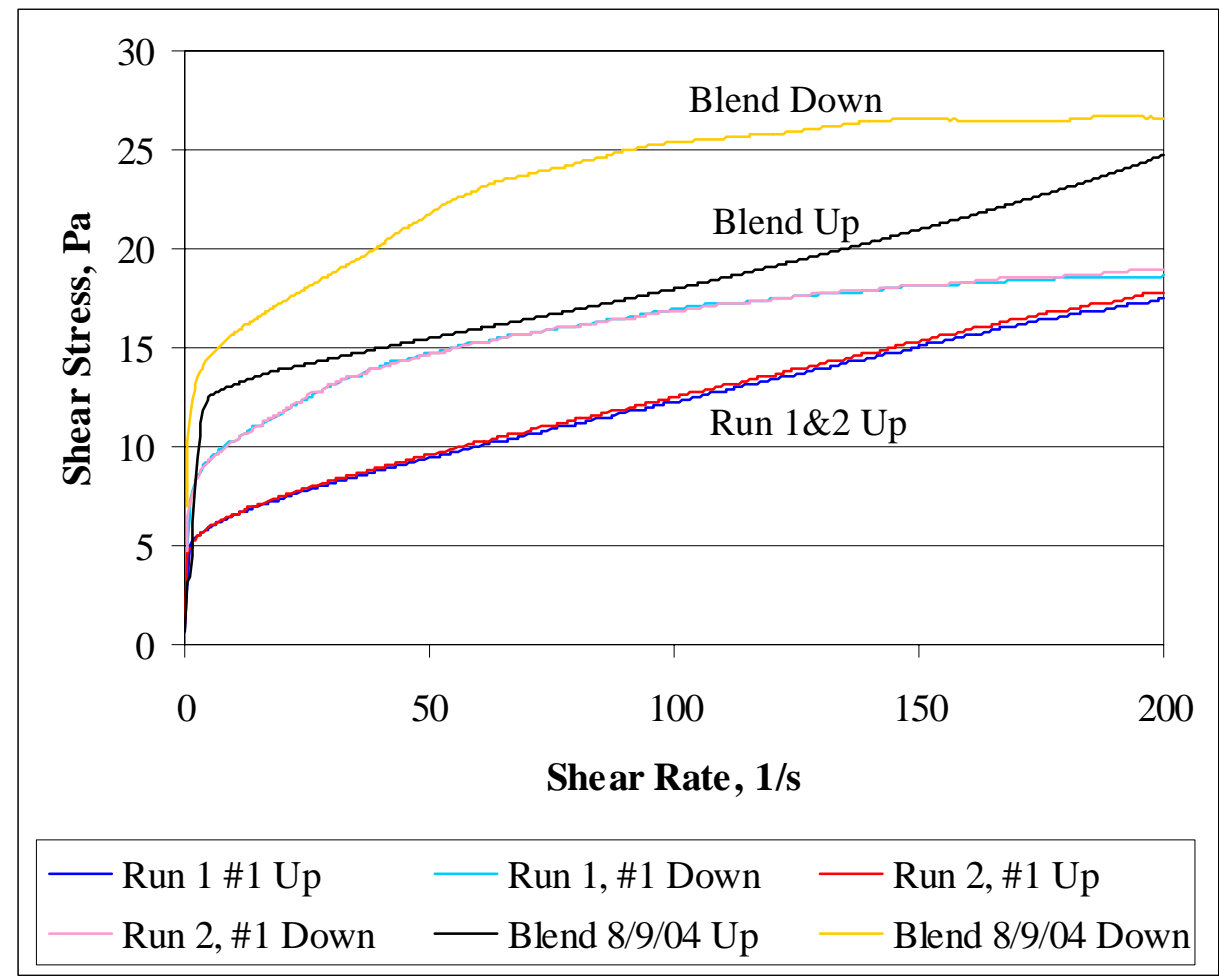

Issues with the location and shape of the blend down curve continued. The down curve issues appeared to have been muted, but not eliminated, by changing the ramp range. The up ramp curve for the blend on 8/9/04 was completely above the entire flow curves for the individual runs from 8/5/04, whereas on $8 / 5$ the blend up ramp had fallen between the up and down ramps for the individual runs. This led to the conclusion that the SME product had continued to thicken from the afternoon of 8/5 through 8/9.

Three examples were given where the rheology of SME products apparently changed with time. It is quite likely that the four SME products from the acid stoichiometry study also got thicker with time. Unfortunately, all four of these samples also changed to higher wt. \% total solids with time. Limited quantities were available for further study. These wt. \% changes, in the absence of this other data on time evolution, would probably have been used to explain the upward shift in the flow curves. The observed changes in the flow curves, however, were probably too large to explain by the change in wt. \% total solids alone. There appears to be a large quantity of data indicating that the SB3 SME products (made from SB3 sludge blended with SB2 sludge) are all showing this slow evolution in properties with time. There is nothing particularly special about the SME product composition to suggest that this phenomenon will be limited to the SB3 SME products. It is recommended that researchers become aware of this phenomenon and plan their work accordingly. 
WSRC-TR-2004-00519

Revision 0

This page intentionally left blank. 


\subsection{CONCLUSIONS}

A set of goals was laid out in the Introduction, section 1.1, of this report. Progress related to these goals is summarized here for the unusual samples and in WSRC-TR-2004-00334 for the development of new rheological methods. Variations in the rheological behavior of simulant DWPF slurry samples have been investigated and documented (first two goals). The findings are summarized below:

- SB2/3 CETL Sludge Hump: based on the data obtained in this study, the most likely explanation for the hump is time dependent inelastic behavior. The literature suggested several possible causes for time dependence. The root cause was not identified. SB2/3 CETL sludge time dependence showed up in many ways under a variety of tests. Shearinduced aggregation did not seem to be indicated, since the hump only occurred during the initial pass through a range of shear rates, and did not occur on subsequent passes. Phase segregation did not seem to be occurring based on tests with the profiled bob and beaker that also showed the hump.

The following mechanism is proposed. There is some limited growth of structure within the sample and that the time for regrowth of the structure is probably some function of time at zero shear rate. This mechanism could produce time dependent inelastic behavior.

- SME products with down flow curves above up flow curves. Based on the data obtained in this study, the most likely explanations for this include a tendency toward a mildly rheopectic slurry in the more viscous SME products, coupled with a tendency to redistribute frit particles when the shear rate is ramped to excessive shear rates. Testing also indicated that one possible reason for the rheopectic behavior was the comparatively high yield stress SME products being produced. Particle configuration effects may be contributing to time dependent behavior, but should be giving lower, rather than higher, down curves. Some data suggest that there may be two or more physical phenomena working in parallel to produce the effects seen. Constant shear rate time curves suggest that these phenomena come close to achieving steady-state in 15-20 minutes.

- None of the SME products initially tested gave the extreme behavior seen in some of the samples in the past year. This appears to be due to changes in the samples with time. Follow-up work indicated that many of the SB2/3 SME products have become both more viscous and less unusual with the passing of time (days to weeks).

- Slurries with flow curves where the up ramp passes through the down ramp (cross-over). This is probably an example of time dependent behavior in the slurry matrix. Cross-over seemed to occur at solids concentrations intermediate to those giving rheopectic behavior (high solids) and those giving thixotropic behavior (low solids) with SB2/3 SME product. Literature data in Figure 8 also indicate that thickening can be seen at higher solids concentration and thinning can be seen at lower solids concentration in general slurry systems. Flow curve regions with negligible consistency by the Bingham plastic model were also seen in these systems. This may be another marker for this behavior.

The single theme that spans all of the unusual rheological behaviors is time dependence. Simulant SME products all showed evidence of some degree of time dependent behavior. In many cases this could be neglected during data analysis. Time dependence in SME products was observed regardless of the nature of the starting sludge (normal or unusual). There is almost no radioactive SME product 
data for comparison and certainly too little to generalize that radioactive SME products lack any time dependence. Neither could it be determined whether some of the time dependence in the simulant SME products was inherited from the starting sludges or was due to the effect of adding frit into the matrix.

The following general observations came out of the experimental data:

- The behavior of SME products and slurries with sand and coal (SB2/3 CETL sludge) were more complex than ordinary sludges and SRAT products. This may be related to the bimodal particle size distribution formed by frit and sludge particles. These complex slurries were more prone to thinning/thickening with time.

- A mildly rheopectic SB2/3 SME product transitioned into a slurry with up curve-down curve cross-over to a slurry that was mildly thixotropic as it was diluted with water. This suggests that a potentially complicated relationship exists between rheology, solids content, and supernate concentration.

- When the up flow curve and the down flow curve are not approximately equal, there is a good chance that the slurry has significant time dependence. In this case, modeling the data with a time independent rheological equation, such as the Bingham plastic equation is not appropriate. The sample needs to be processed until the time dependence is removed (if possible), before fitting the data to the Bingham plastic model. 


\subsection{RECOMMENDATIONS/PATH FORWARD}

The primary recommendations for future tasks relate to the implementation of the new methods developed for rheological characterization. These are discussed in the companion document, WSRCTR-2004-00334.

SME products initially obtained for this study did not perform as unusually as hoped. The degree of rheopectic behavior was consistently less than expected based on historical measurements. As such products become available, it would be worthwhile to apply subset of these rheological tests to ensure that the preliminary conclusions reached here remain valid. Better documenting the change in SME product rheology over a period of days or weeks would be another worthwhile piece of information to have.

Various types of time dependent behavior were observed in simulant SME product slurries. Some thickened with time, some thinned, and some thinned and then thickened. Radioactive SME product rheology has not been studied regularly on Shielded Cells SME products. Consequently, there appears to be a strong need to develop a SME product rheological database that tracks such phenomena. This does not need to be tied directly to the Shielded Cells qualification runs if process samples from DWPF can be obtained in their place. Both flow curves and constant shear rate time curves should be generated.

Given the issues with air entrainment in the SRAT during DWPF processing of SB2, similar arguments could be advanced for starting and maintaining a database of SRAT product slurry rheological data, even though there were no issues in this report specific to SB2 SRAT product rheology. 
WSRC-TR-2004-00519

Revision 0

This page intentionally left blank. 


\subsection{REFERENCES}

Schramm, G. A Practical Approach to Rheology and Rheometry, Haake GmbH, Karlsruhe, Federal Republic of Germany (1994).

Hunter, R. J. Foundations of Colloid Science, vol. II, p. 1027, Clarendon Press, Oxford, (1989)

Baich, M. A., Sludge Batch 2-3 Blend Flowsheet Simulations: Determination of Acid Addition Window. WSRC-TR-2004-00042, Savannah River Site, Aiken, SC 29808 (2004a).

Baich, M. A., Sludge Batch 2-3 Blend Flowsheet Simulations: Process Variability Study. WSRC-TR2004-00225, Savannah River Site, Aiken, SC 29808 (2004b).

Bannochie, C. J., D. C. Koopman, and D. T. Herman, Impact of Uranium Levels on Sludge Batch 2 Simulant Processing. WSRC-TR-2004-00206, Savannah River Site, Aiken, SC 29808 (2004).

Koopman, D. C., Rheology Protocols for DWPF Samples. WSRC-RP-2004-00470, Savannah River Site, Aiken, SC 29808 (2004a).

Koopman, D. C., A Comparison of Rheology Data for Radioactive and Simulant Savannah River Site Waste (U). WSRC-TR-2004-00044, Savannah River Site, Aiken, SC 29808 (2004b).

Koopman, D. C. and E. K. Hansen, A Summary of Rheology Data for SB3 and SB2/3 Simulant Savannah River Site Wastes (U). WSRC-TR-2004-00116, Savannah River Site, Aiken, SC 29808 (2004c).

Koopman, D. C., Development of Alternative Rheological Measurements for DWPF Slurry Samples (U). WSRC-TR-2004-00334, Savannah River Site, Aiken, SC 29808 (2004d).

Alderman, N. J., and N. I. Heywood, "Improving Slurry Viscosity and Flow Curve Measurements", CEP 4, p. 27 (2004).

Alderman, N. J., and N. I. Heywood, “Making Accurate Slurry Flow Curve Measurements”, Chemical Engineering Progress 5, p. 35 (2004).

Chang, J. C., F. F. Lange, and D. S. Pearson, "Viscosity and Yield Stress of Alumina Slurries Containing Large Concentrations of Electrolyte", Journal of the American Ceramic Society 77[1], p. 19 (1994).

Gustafsson, Jan, E. Nordenswan, and J. B. Rosenholm, "Shear-Induced Aggregation of Anatase Dispersions Investigated by Oscillation and Low Shear Rate Viscometry”, Journal of Colloid and Interface Science 242, p. 82 (2001).

Kawaguchi, M., A. Mizutani, Y. Matsushita, and T. Kato, "Influence of Nonadsorbed Polymer Chains on Rheology of Silica Suspensions”, Langmuir 13, p. 6339 (1997).

Nyström, Roger, M. Lindén, J. B. Rosenholm, “The Influence of $\mathrm{Na}+$, Ca2+, and La3+, on the $\zeta$ Potential and Yield Stress of Calcite Dispersions”, Journal of Colloid and Interface Science 242, p. 259 (2001). 


\section{Distribution:}

E. W. Holtzscheiter, SRNL

D. A. Crowley, 999-W

S. L. Marra, 999-W

T. B. Calloway, 999-W

N. E. Bibler, SRNL

C.M. Jantzen, SRNL

J. R. Harbour, 773-42A

G. C. Wicks, SRNL

R. E. Eibling, 999-W

P. R. Burket, 773-42A

M. E. Stone, 999-W

T. L. Fellinger, SRNL

E. K. Hansen, 999-W

T. M. Jones, 999-W

M. S. Miller, 704-S

J. E. Occhipinti, 704-S

R. M. Hoeppel, 704-27S

H. H. Elder, 703-H

J. F. Iaukea, 704-30S

J. W. Ray, 704-S

A. B. Sanders, 704-27S

W. B. Van-Pelt, 704-S 